\title{
4 Fallstudien II: Romane in der Zeit der literarischen Moderne
}

In der zweiten Gruppe von Fallstudien wurde die Rezeption von Gabriele Reuters Aus guter Familie. Leidensgeschichte eines Mädchens (1895), Thomas Manns Buddenbrooks. Verfall einer Familie (1901) und Erich Maria Remarques Im Westen nichts Neues (1928/1929) analysiert. Romane aus der Zeit der Moderne (1880 bis 1930) zu wählen, bot sich an, weil die Epoche relativ genau in der Mitte liegt zwischen dem letzten Drittel des 18. Jahrhunderts (Kap. 3) und der Gegenwart (Kap. 5). Vor allem aber war die literaturgeschichtliche Bedeutsamkeit der Epoche von Belang. Sie bezeichnet eine wichtige Etappe in dem Entwicklungsprozess, in welchem Literatur im heutigen Sinne entsteht. Bei allen drei Romanen erweist sich die Quellenlage als ausgesprochen gut, insbesondere bei Remarques Roman. Reuters Roman rief ebenfalls ein breites, lange anhaltendes publizistisches Echo hervor. Da Mann sich kontinuierlich zu seinem Roman geäußert hat, gibt es eine Fülle an Selbstzeugnissen, welche auf intendierte Applikationen hin ausgewertet werden konnten. Selbstaussagen lassen sich ferner bei Reuter und Remarque ausmachen. Sie können, ebenso wie die feststellbaren Applikationen, mit der Beschaffenheit der Texte und ihrem Applikationspotenzial in Beziehung gesetzt werden. Alle drei nehmen, wie sich zeigen wird, in signifikanter Weise Bezug auf die Wahrnehmung zeitgenössischer Gegebenheiten, auf Erfahrungen und Mentalitäten.

\subsection{Gabriele Reuter: Aus guter Familie (1895)}

Gabriele Reuter sei, so die zum radikaleren Teil der bürgerlichen Frauenbewegung gehörende Helene Stöcker in einem Zeitschriften-Beitrag anlässlich des siebzigsten Geburtstags der Autorin, „seit einem Menschenalter eine der bekanntesten und gelesensten deutschen Schriftstellerinnen“. ${ }^{1}$ Der 1895 erschienene Roman Aus guter Familie. Leidensgeschichte eines Mädchens habe sie „mit einem Schlage berühmt“ gemacht und „eine leidenschaftliche Diskussion in ganz Deutschland“ hervorgerufen. ${ }^{2}$ Über mehr als dreißig Jahre wurde der Ro-

1 Helene Stöcker: Eine Dichterin und Kämpferin. Gabriele Reuter 70 Jahre alt. In: Die neue Generation. Jg. 25, H. 2 (1929), Rubrik „Ehe- und Sexualreform“, S. 75-77. Zitiert nach Mellmann: Dokumente, S. 554-557, hier S. 554.

2 Stöcker: Eine Dichterin und Kämpferin, S. 556. 
man nachgefragt, bis 1931 erschienen 28 Auflagen mit zusammengenommen mindestens 28.000 Exemplaren. ${ }^{3}$ Die „Leidensgeschichte“ der Protagonistin Agathe Heidling, die daran scheitert, den für eine ,höhere Tochter` aus dem Bürgertum vorgesehenen Lebensweg zu gehen, wurde in zahlreichen zeitgenössischen Stellungnahmen auf die geschlechtergeschichtlichen Gegebenheiten bezogen und es wurde gefragt, ob und welche Konsequenzen aus dem im Roman Dargestellten zu ziehen seien. ${ }^{4}$

In einem ersten Schritt (Kap. 4.1.1) wird ein Blick auf die Forschung geworfen und der in einem Forschungsbeitrag zur Erstrezeption des Romans ermittelte Bezug auf die historischen Gegebenheiten, die sogenannte ,Mädchenfrage‘, dargestellt. Er ist im Zusammenhang zu sehen mit den geschlechtergeschichtlichen Verhältnissen der Zeit. Außerdem werden einige besonders deutliche Beispiele für Applikationen angeführt. In einem zweiten Schritt (Kap. 4.1.2) wird dann zu zeigen versucht, dass die Mehrzahl der Applikationen, die sich in den Quellen identifizieren lassen oder die von ihnen zumindest nahegelegt werden, auf die ,Mädchenfrage“ bezogen sind. In einem dritten Schritt (Kap. 4.1.3) werden alternative Applikationen behandelt. Abschließend wird danach gefragt, in welchem Verhältnis die zeitgenössischen Applikationen zur Beschaffenheit des Textes stehen (Kap. 4.1.4).

\subsubsection{Die,Mädchenfrage“}

Die Forschung hat den Roman hauptsächlich als kritische Darstellung geschlechtergeschichtlicher Verhältnisse interpretiert, vor allem der Rolle bürger-

3 Vgl. Donald Ray Richards: The German Bestseller in the 20th Century. A Complete Bibliography and Analysis, 1915-1940. Berne 1968, S.199, und die Angaben in Katja Mellmann: Einleitung. In: Gabriele Reuter: Aus guter Familie. Leidensgeschichte eines Mädchens. Bd. II: Dokumente. Hg. von K.M. Marburg 2006, S.311-324, hier S.316; Renate von Heydebrand/Simone Winko: Geschlechterdifferenz und literarischer Kanon. Historische Beobachtungen und systematische Überlegungen. In: Internationales Archiv für Sozialgeschichte der deutschen Literatur 19 (1994), S. 96-172, hier S. 98.

4 Die Quellen sind in einer neueren Edition zugänglich, vgl. Gabriele Reuter: Aus guter Familie. Leidensgeschichte eines Mädchens. Bd. II: Dokumente. Hg. von Katja Mellmann. Marburg 2006. Der Band enthält insgesamt 68 Rezeptionszeugnisse, unter anderem aus dem Nachlass der Autorin im Goethe- und Schiller-Archiv. Darunter befinden sich 18 Rezensionen und 41 publizistische Beiträge und Äußerungen in zeitgenössischen literaturgeschichtlichen Darstellungen. Sie stammen aus den Jahren 1895 bis 1942. Im Folgenden werden die Quellen nach dieser Quellensammlung zitiert. Bei etwa der Hälfte der Quellen war es mit vertretbarem Aufwand möglich, eine Autopsie vorzunehmen. 
licher Frauen und der damit verbundenen sozialen Normen. ${ }^{5}$ Durch Einblick in die Psyche der Protagonistin zeige der Roman, ,welche Schwierigkeiten einer Herauslösung aus der naiven Identifikation mit der anerzogenen Geschlechterrolle entgegenstanden“. ${ }^{6}$ Es sei die Absicht der Autorin gewesen, „das herkömmliche Rollenstereotyp als destruktiv für die weibliche Existenz darzustellen und so die Gültigkeit traditioneller weiblicher Geschlechtsdefinitionen zu unterminieren“.7 Der Roman mache deutlich, dass die zeitgenössischen Auffassungen von Weiblichkeit und die damit verbundenen Erwartungen an bürgerliche Frauen als Gattin und Mutter nicht vermeintlich ,natürlich' seien, sondern soziale Konstrukte; Ort der Konstruktion sei die bürgerliche Familie. ${ }^{8}$ Charakteristisch für Reuters Romane sei, dass sie „das Leiden der bürgerlichen Frau am normierten Weiblichkeitsideal und ihre fehlenden Entscheidungsmöglichkeiten, ihr Leben selbst nach ihren Bedürfnissen zu gestalten“, verdeutlichten. ${ }^{9}$ Aus guter Familie sei ein „Verbildungsroman“ und biete eine „accurate description of the patriarchal institutions that combine to crush a young bourgeois

5 Vgl. neben den im Anschluss genannten Gabriele Rahaman: Gabriele Reuter's Aus guter Familie in the Light of Klaus Theweleit's Concept of ,Entlebendigung'. In: German Life and Letters 44 (1991), S. 459-468; Gaby Pailer: Der Staatsdiener, der Staatsfeind und die gute Tochter. Gender und Nation in Gabriele Reuters Aus guter Familie (1895). In: Gudrun LosterSchneider (Hg.): Geschlecht - Literatur - Geschichte. Bd. 2: Nation und Geschlecht. St. Ingbert 2003, S. 101-119; Melanie Cordes: Weibliche Adoleszenz? Die Entwicklungswege von Protagonistinnen in Romanen um 1900 - Aus guter Familie von Gabriele Reuter und Ellen Olestjerne von Franziska Gräfin zu Reventlow. In: Carsten Gansel/Paweł Zimniak (Hg.): Zwischenzeit, Grenzüberschreitung, Aufstörung. Bilder von Adoleszenz in der deutschsprachigen Literatur. Heidelberg 2011, S. 311-327.

6 Gisela Brinker-Gabler: Perspektiven des Übergangs. Weibliches Bewußtsein und frühe Moderne. In: G. B.-K. (Hg.): Deutsche Literatur von Frauen. Bd. 2: 19. und 20. Jahrhundert. München 1988, S. 169-205, zu Reuters Roman S. 170-175, das Zitat S. 175. Vgl. dazu Gisela BrinkerGabler: Weiblichkeit und Moderne. In: York-Gothart Mix (Hg.): Hansers Sozialgeschichte der deutschen Literatur vom 16. Jahrhundert bis zur Gegenwart. Bd. 7: Naturalismus, Fin de siècle, Expressionismus, 1890-1918. München/Wien 2000, S. 243-256, hier S. 247.

7 Ludmila Kaloyanova-Slavova: Übergangsgeschöpfe. Gabriele Reuter, Hedwig Dohm, Helene Böhlau und Franziska von Reventlow. New York u. a. 1998, zu Reuters Roman S. 45-61, das Zitat S. 58.

8 Vgl. Susanne Balmer: Töchter aus guter Familie. Weibliche Individualität und bürgerliche Familie um 1900. In: Thomas Martinec/Claudia Nitschke (Hg.): Familie und Identität in der deutschen Literatur. Frankfurt a. M. u. a. 2009, S. 177-195, hier S. 184-188, besonders S. 188.

9 Karin Tebben: Psychologie und Gesellschaftskritik. Gabriele Reuter. In: K. T. (Hg.): Deutschsprachige Schriftstellerinnen des Fin de siècle. Darmstadt 1999, S. 266-289, zu Reuters Roman S. 268-272, das Zitat S. 268. 
woman“. ${ }^{10}$ Bisweilen wird der Roman in einer diachronen Perspektive betrachtet, bei der dann insbesondere auffällt, was er ,immer noch“ an überkommenen Vorstellungen enthalte und wo er ,noch nicht' emanzipatorischen Einsichten Rechnung trage. Anders als Helene Böhlau in Halbtier, so wird in einem Forschungsbeitrag festgestellt, bleibe die in Reuters Roman geäußerte Kritik eingeschränkt: „Reuters Sozialkritik bleibt immer noch im Muster der Entsagung, die von der sympathischen Heldin verlangt wird. Die Autorin bietet keine Alternative zu diesem Leiden an; es ist unnötig, tragisch, aber anscheinend ewig." ${ }^{11}$

Nicht alle Interpretationen des Romans nehmen für sich in Anspruch, die zeitgenössische Wahrnehmung zu berücksichtigen oder mit ihr kompatibel zu sein. ${ }^{12}$ Sie sind dann zum Beispiel symptomatische Interpretationen, die den Roman als Anzeichen für gesellschaftliche Verhältnisse untersuchen, die den Zeitgenossen bewusst sein konnten, aber nicht mussten. Ein Forschungsbeitrag, der die zeitgenössische Rezeption ausführlich untersucht und darin herausragt, hat gezeigt, dass Reuters Roman vor allem als Beitrag zur von den Akteur/innen so genannten ,Frauenfrage‘, oder genauer: ,Mädchenfrage‘ rezipiert wurde. Dabei handelte es sich um das in der Wahrnehmung der Zeitgenossen bestehende Problem, dass vermehrt junge Frauen aus dem Bürgertum unverheiratet blieben. Es rief Diskussionen hervor, in denen nach den Gründen für das

10 Richard L. Johnson: Men's Power over Women in Gabriele Reuter's Aus guter Familie. In: Marianne Burkhard (Hg.): Gestaltet und gestaltend. Frauen in der deutschen Literatur. Amsterdam 1980, S. 235-253, hier S. 246 und 252. Vgl. dazu Richard L. Johnson: Gabriele Reuter. Romantic and Realist. In: Susan Cocalis/Kay Goodman (Hg.): Beyond the Eternal Feminine. Critical Essays on Women and German Literature. Stuttgart 1982, S. 225-244, und Linda Kraus Worley: Girls from Good Families. Tony Buddenbrook and Agathe Heidling. In: The German Quarterly 76 (2003), S. 195-211.

11 Jeannine Blackwell: Die nervöse Kunst des Frauenromans im 19. Jahrhundert - oder Der geistige Tod durch kränkende Handlung. In: Renate Berger (Hg.): Frauen, Weiblichkeit, Schrift. Berlin 1985, S. 145-158, hier S. 153. Zur berechtigten Kritik an solchen häufig anachronistischen Interpretationen vgl. Katja Mellmann: Die Mädchenfrage. Zum historischen Bezugsproblem von Gabriele Reuters Aus guter Familie. In: Internationales Archiv für Sozialgeschichte der deutschen Literatur 33 (2008), S. 1-25, hier S. 14-16.

12 Auf die zeitgenössische Rezeption eingegangen wird v. a. in Mellmann: Die Mädchenfrage, daneben in: Jeannine Blackwell: Bildungsroman mit Dame. The Heroine in the German Bildungsroman from 1770 to 1900. Diss. Bloomington, IN 1982, S. 373-408, hier S. 373-376; Faranak Alimadad-Mensch: Gabriele Reuter. Porträt einer Schriftstellerin. Bern u. a. 1984, S. 17, S. 114-121 und S. 196-200; Georgia A. Schneider: Portraits of Women in Selected Works of Gabriele Reuter. Bern u. a. 1988, S. 15-21; Linda Kraus Worley: Gabriele Reuter. Reading Women in the „Kaiserreich“. In: Gerhard P. Knapp (Hg.): Autoren damals und heute. Literaturgeschichtliche Beispiele veränderter Wirkungshorizonte. Amsterdam u. a. 1991, S. 419-439, hier S. 420-426. 
Problem gefragt und über Maßnahmen nachgedacht wurde, zu denen die Forderung gehörte, die Erziehung von Mädchen so zu ändern, dass sie auf den Fall vorbereitet sind, nicht heiraten zu können und stattdessen erwerbstätig zu sein. Ein Blick in Ratgeberliteratur für junge Frauen und in essayistische und soziologische Arbeiten zeigt, dass und wie die Zeitgenossen die ,Mädchenfrage‘ als dringliches Problem ansahen. ${ }^{13}$ Eine Untersuchung der Beschaffenheit des Textes macht deutlich, dass es in erster Linie die ,Mädchenfrage und die mit ihr verbundenen Sachverhalte sind, die im Roman zur Darstellung kommen. ${ }^{14}$ In den Rezeptionszeugnissen lässt sich nachweisen, dass der Roman als Beitrag zur ,Mädchenfrage، aufgefasst wurde. ${ }^{15}$ Die Ergebnisse dieser Studie leuchten sehr ein, gerade da, wo die Aussagen auf eine Untersuchung von Quellen gestützt sind. Umso mehr muss es überraschen, dass Applikationen weder dem Begriff noch der Sache nach in den Blick kommen. Es lässt sich zeigen, dass die Rezeptionszeugnisse eine Fülle an Belegen liefern für das Vorkommen und die Relevanz der Applikation.

Die sogenannte ,Frauen-“ oder ,Mädchenfrage“ ist vor dem Hintergrund der geschlechtergeschichtlich beschreibbaren Gegebenheiten des Kaiserreiches zu sehen. ${ }^{16}$ Sie steht insbesondere im Zusammenhang mit der bürgerlichen Frauenbewegung. Im Kern geht es um ein tatsächliches soziales Problem, nämlich die schwierige wirtschaftliche Situation mancher bürgerlichen Frauen, die, oft gegen ihren Willen, unverheiratet blieben. Mindestens zwei sozialgeschichtliche Faktoren sind als Ursachen zu nennen. ${ }^{17}$ Zum einen stieg das Heiratsalter bürgerlicher Frauen im 19. Jahrhundert auf 25 bis 26 Jahre. Dadurch ergab sich eine distinkte, rund zehn Jahre währende biographische Phase zwischen Kind-

13 Vgl. Mellmann: Die Mädchenfrage, S. 4-11.

14 Vgl. Mellmann: Die Mädchenfrage, S. 17-24.

15 Vgl. Mellmann: Die Mädchenfrage, S. 2-4, S. 9-11 und S. 16 f.

16 Vgl. zum Folgenden Ute Frevert: Frauen-Geschichte. Zwischen Bürgerlicher Verbesserung und Neuer Weiblichkeit. Frankfurt a. M. 1986, S. 63-145; Angelika Schaser: Frauenbewegung in Deutschland 1848-1933. Darmstadt 2006, S. 23-37; Thomas Nipperdey: Deutsche Geschichte. Bd. 1: Arbeitswelt und Bürgergeist. München 1990, S. 43-124. Die ersten beiden Publikationen sind spezifische geschlechtergeschichtliche Darstellungen, die letzte ist allgemeingeschichtlicher Art. Sie bieten kodifiziertes und bewährtes Wissen über den in Rede stehenden Sachverhalt. Quellen sind leicht zugänglich in Elke Frederiksen (Hg.): Die Frauenfrage in Deutschland 1865-1915. Stuttgart 1981. Eine zeitgenössische Darstellung der Geschichte der deutschen Frauenbewegung bietet Gertrud Bäumer: Die Geschichte der Frauenbewegung in Deutschland. In: Helene Lange/G. B. (Hg.): Handbuch der Frauenbewegung. Bd.1: Die Geschichte der Frauenbewegung in den Kulturländern. Berlin 1901, S. 1-166.

17 Vgl. dazu Frevert: Frauen-Geschichte, S. 116-119, und Nipperdey: Deutsche Geschichte, S. $75 \mathrm{f}$. 
heit und Ehe. Zum anderen verlor die Familie im Zuge der Industrialisierung einige ihrer ökonomischen Funktionen. Zahlreiche Verbrauchsgüter konnten nun gekauft werden, statt sie in Heimarbeit herzustellen; eine Tätigkeit, die bis dato unverheiratete Frauen übernahmen. In der Wahrnehmung der Zeitgenossen waren zwei Ursachen dafür verantwortlich, dass vermehrt Frauen aus dem Bürgertum ledig blieben: sinkende Heiratsbereitschaft und ein statistischer Überschuss an Frauen.

Es sind diese Gegebenheiten und die Deutung durch die Akteur/-innen, welche Forderungen nach verbesserter weiblicher Bildung und nach Erwerbstätigkeit aufkommen ließen. Große Teile der bürgerlichen Frauenbewegung und maßgebliche Akteurinnen sahen „die ,Frauenfrage“ primär als Bildungs- und Berufsproblem“. ${ }^{18}$ Die Frauenbewegung im Kaiserreich war in erster Linie eine „Frauenbildungsbewegung“, die sich für „verbesserte Mädchenbildung und die Erschließung von Erwerbsmöglichkeiten für Frauen“ einsetzte. ${ }^{19}$ Zudem war sie „zuerst eine Bewegung unverheirateter Frauen“, die für die verheirateten bürgerlichen Frauen sprechen und, etwa durch karitatives Engagement, die Situation der Frauen aus der Arbeiterschaft verbessern wollten. Die aus heutiger Sicht moderat erscheinenden Forderungen wurden von manchen Zeitgenossen begrüßt, von anderen aber vehement abgelehnt. Unter den Frauen blieb die Frauenbewegung eine Minderheit mit starker Gegenposition und indifferenter Mehrheit. ${ }^{20}$ Dafür dürfte unter anderem verantwortlich sein, dass gerade Wandel in einer lebensweltlich so zentralen Hinsicht wie dem Verhältnis der Geschlechter mit Widerstand verbunden sein kann. Daneben ist zu bedenken, dass Nicht-Erwerbstätigkeit bürgerlicher Frauen als Statussymbol galt. ${ }^{21}$ Ferner genoss die nach wie vor in Teilen, zumal rechtlichen Belangen, patriarchalisch strukturierte Familie großes Ansehen, sodass gar von einer „Familienreligion“ gesprochen werden kann, und galt das Verheiratetsein als erstrebenswerter Normalfall des Erwachsenseins. ${ }^{22}$ Weitgehend unbestritten blieb, nicht zuletzt bei vielen Akteurinnen der Frauenbewegung, dass „die eigentlich wichtigste Rolle der Frau die der Hausfrau und Mutter sei““. ${ }^{23}$ Die Forderung nach Emanzipation im Sinne behutsamer beruflicher und rechtlicher Gleichberechtigung hieß noch nicht, vermeintlich ,natürliche“ Unterschiede zwischen den Ge-

18 Frevert: Frauen-Geschichte, S. 123.

19 Schaser: Frauenbewegung in Deutschland, S. 23 und 24.

20 Nipperdey: Deutsche Geschichte, S. 76 und 87 f.

21 Vgl. Frevert: Frauen-Geschichte, S. 117.

22 Vgl. Nipperdey: Deutsche Geschichte, S. 43 f., das Zitat S. 43.

23 Nipperdey: Deutsche Geschichte, S. 75. 
schlechtern abzulehnen. Zum Frauenbild der Frauenbewegung gehörte die Vorstellung, dass Frauen durch das, was als spezifisch weiblich angesehen wurde, die polare Ergänzung zum Männlichen bilden. ${ }^{24}$

Veränderungen in der Erziehung und Ausbildung der Mädchen, für die insbesondere manche der zahlreichen Frauenvereine eintraten, sollten also dazu dienen, Berufstätigkeit und damit finanzielle Unabhängigkeit und Entlastung der Herkunftsfamilie für den Fall zu ermöglichen, dass Frauen ledig blieben. Das ist die weniger weitreichende Position, die innerhalb der Frauenbewegung die Mehrheit darstellte. Die weitergehende Forderung, verheirateten bürgerlichen Frauen die Berufstätigkeit zu ermöglichen, wurde nur von einem kleinen Teil vertreten. Hier zeigt sich eine Binnendifferenzierung zwischen einer moderaten, an praktischen Verbesserungen der sozialen und rechtlichen Stellung der Frauen interessierter Mehrheit und einer radikaleren Minderheit, die weiterreichende Forderungen stellte, zumal mit Blick auf das Frauenstimmrecht und eine Reform des bürgerlichen Rechtes, hinsichtlich des Umgangs mit außerehelichen Gemeinschaften und Sexualität, Scheidung und unehelichen Kindern. ${ }^{25}$

Es sind nicht zuletzt diese Gegebenheiten, die zu berücksichtigen sind, wenn im Folgenden die Quellen ausgewertet werden, in denen auf die ,Frauenfrage', die Frauenbewegung und Frauenemanzipation Bezug genommen wird. Sie trugen dazu bei, dass der Roman als Stellungnahme zu diesen Fragen wahrgenommen und die Autorin als Frauenrechtlerin angesehen werden konnte. Solche Zuschreibungen und die tatsächliche oder vermeintliche Vereinnahmung der Autorin für die Frauenbewegung spielten, wie sich zeigen wird, in vielen Quellen eine Rolle. Man habe Reuter, so Hedwig Dohm, gegen ihren Willen als „Bannerträgerin der großen Frauenbewegung“ angesehen. ${ }^{26}$ Der Roman polarisierte und gab Anlass zu konträren Zuschreibungen: „Als ihr Buch Aus guter Familie erschien, belegten die Vertreterinnen der Frauenbewegung sie mit Beschlag und riefen sie zu ihrer Führerin aus. Und von gegnerischer Seite wurde sie mit Ehrentiteln wie ,Ehebekämpferin', ,Männerfeindin', ,Vertreterin wilder Zügellosigkeit‘ u. a. beglückt. “27 In manchen zeitgenössischen literaturgeschichtlichen Darstellungen wurde die Resonanz des als literarisch wertlos

24 Vgl. Nipperdey: Deutsche Geschichte, S. 75 und 86; Schaser: Frauenbewegung in Deutschland, S. 8-14.

25 Vgl. dazu Frevert: Frauen-Geschichte, S. 128-134; Schaser: Frauenbewegung in Deutschland, S. 69-76; Nipperdey: Deutsche Geschichte, S. 83-85.

26 Hedwig Dohm: Gabriele Reuter: Das Tränenhaus. In: Der Tag. 23. Dezember 1908. Zitiert nach Mellmann: Dokumente, S. 509-511, hier S. 510.

27 August Friedrich Krause: Gabriele Reuter. In: Nord und Süd. Eine deutsche Monatsschrift. Bd. 102, Nr. 306, September 1902, S. 319-334, hier S. 320. 
abqualifizierten Romans auf „die Frauenbewegung“ zurückgeführt, „die in das Buch hineinspielt“. ${ }^{28}$

$\mathrm{Zu}$ den Autorinnen der Rezeptionsdokumente gehören Vertreterinnen der Frauenbewegung. Mitunter ist das Publikationsorgan besonders einschlägig. Die Quellen sind überwiegend Besprechungen und weitere publizistische Texte, etwa Zeitungs- und Zeitschriftenbeiträge anlässlich von Jubiläen. Daneben sind populäre literaturgeschichtliche Darstellungen aus der Zeit um 1900 zu nennen, die an der (Negativ-)Kanonisierung des Romans mitwirkten. Sie stammten von professionellen Rezipient/-innen. Darüber, wie der Roman von Mädchen und jungen Frauen gelesen wurde, lässt sich auf dieser Grundlage nichts sagen. ${ }^{29}$ Bisweilen ist in Rechnung zu stellen, dass männliche Akteure den Roman aufgrund der Tatsache, dass er von einer Frau geschrieben wurde, und aufgrund des ,weiblichen' Themas nicht angemessen rezipierten. ${ }^{30}$ Neben den geschlechtergeschichtlichen Faktoren sind politische und weltanschauliche Annahmen sowie Auffassungen davon zu beachten, was Kunst und Literatur ausmacht. Die Mehrzahl der Quellen stellte einen Bezug zu geschlechtergeschichtlichen Gegebenheiten her. Neben positiven Einschätzungen gab es, wenig überraschend, negative, die wohl zum Teil als Reaktion auf die positiven anzusehen sind oder sie antizipierten und sich gegen sie wandten.

Die zeitgenössischen Rezeptionsdokumente lassen zahlreiche Rückschlüsse auf Applikationen zu. Dass unterschiedliche Applikationen möglich waren, macht eine Besprechung in der Nation besonders deutlich. Der Rezensent lobte den Roman als „eines der bedeutendsten Bücher [...], die wir seit langem in

28 Anselm Salzer: Illustrierte Geschichte der Deutschen Literatur von den ältesten Zeiten bis zur Gegenwart. 2., neu bearb. Aufl. Regensburg 1931, Bd.4.1, Kap. „Der Frauenroman“, S. 1810 f., hier S. 1810.

29 Vgl. dazu Mellmann: Die Mädchenfrage, S. 24 f.

30 Vgl. dazu am Beispiel von Reuters Frauenseelen Livia Z. Wittmann: ,Übergangsgeschöpfe‘. Eine erneute kritische Reflexion über Gabriele Reuters Novellenband Frauenseelen. In: Albrecht Schöne (Hg.): Kontroversen, alte und neue. Akten des VII. Internationalen GermanistenKongresses. Tübingen 1986. Bd. 6, S. 73-77. Als Beispiel aus den untersuchten Quellen, explizit mit Bezug auf Reuters Roman, vgl. Frieda Freiin von Bülow: Männerurtheil über Frauendichtung. In: Die Zukunft. Jg. 7, Bd. 26, H. 15, 7. Januar 1899, S. 26-29, hier S. 27, und die darauf reagierende Gegenposition von Lou Andreas-Salomé: Ketzereien gegen die moderne Frau. In: Die Zukunft. Jg. 7, Bd. 26, H. 20, 11. Februar 1899, S. 237-240, hier S. 237 f. Vgl. zur Frage der geschlechtsspezifischen Unterschiede bei der Wertung und Kanonisierung von Reuters Roman im Vergleich mit Fontanes Effi Briest Heydebrand/Winko: Geschlechterdifferenz und literarischer Kanon, S. 97-112. 
Deutschland erlebt haben“. ${ }^{31}$ Einer konservativen, klassischen und als geistesgeschichtlich zu bezeichnenden Literaturkonzeption verpflichtet, sah er in dem Roman den individuellen Ausdruck des Leidens der Autorin und verglich ihn mit Goethes Werther. Die vermeintliche Tragik der Protagonistin offenbare sich in ihrer Schuld, anders zu sein als andere Menschen. ${ }^{32}$ Zwei Applikationen, die in seiner Wahrnehmung vorkamen, wehrte er als verfehlt ab. Wer den Roman „den Müttern und Töchtern zur moralischen Nutzanwendung“ empfehle und darin „eine sozialreformatorische That“ sehe, wer, wie manche Frauen, den Roman „als eine Propagationsschrift für ihre Sache verstehen und ausrufen“ wolle, der habe zum einen eine unangemessene Auffassung von Literatur und zum anderen eine falsche Auffassung des Verhältnisses von Individuum und Gesellschaft. ${ }^{33}$ Literatur in den Dienst derartiger Aufgaben zu stellen, sei „philisterhaft“, für Agathe Heidlings Schicksal sei nicht „die Organisation der Gesellschaft“ verantwortlich zu machen, „sondern die Artung des Menschenmaterials [!]“.34 ,Nutzanwendungen“, also Applikationen, die das im Roman Dargestellte als zutreffende Schilderung sozialer Missstände begreifen und daraus Konsequenzen ableiten für eine Reform der gesellschaftlichen Stellung der Frau, erteilte er mithin eine Absage. Gleiches gilt für die auf die einzelne Person bezogene Applikation. Leserinnen, welche die Situation der Protagonistin auf sich anwenden, rezipierten den Roman ebenfalls auf unangemessene Weise: „Wenn Hunderte sich in dieser Agathe wiedererkennen, so gleichen sie ihr deswegen noch lange nicht, oder sie gleichen ihr wie jene schwärmerischen Jünglinge des 18. Jahrhunderts dem göttlichen Wolfgang." ${ }^{35}$ Nun ist es aber keinesfalls so, dass der Rezensent Applikationen prinzipiell abgelehnt hätte. Ein in seiner Wahrnehmung angemessenes Verständnis des Romans erhelle, dass er, wie jedes gute Buch, eine „Moral“ habe im Sinne einer „Ausstrahlung allgemeiner Wahrheiten“, und damit eine Applikation ermögliche:

Was dann also das Buch der Gabriele Reuter lehrt, ist am allerwenigsten Wasser auf die Mühle irgend einer Bewegung. Es lehrt mit erschütternder Eindringlichkeit, was des Weibes Glück ausmacht, nämlich nicht die Unabhängigkeit, sondern die Zugehörigkeit zum Manne, nicht Wettbewerb mit dem Manne, sondern vom Manne begehrt, vom Manne ge-

31 Benno Rüttenauer: Agathe. In: Die Nation. Wochenschrift für Politik, Volkswirtschaft und Litteratur. Jg. 13, Nr. 52 (1895/1896), S. 784-786. Zitiert nach Mellmann: Dokumente, S. 339344, hier S. 344.

32 Vgl. Rüttenauer: Agathe, S. 341-343 und S. 340 f.

33 Rüttenauer: Agathe, S. 340 und 344.

34 Rüttenauer: Agathe, S. 340 und 341.

35 Rüttenauer: Agathe, S. 342. 
liebt und genommen zu werden: Der Mann und das Kind, Liebesglück und Mutterglück, wogegen alles andere nichts als ein Kleid ist, ein reiches oder armes, um einen schönheitsherrlichen oder um einen häßlichen und verkrüppelten Leib. ${ }^{36}$

Im Scheitern der Protagonistin zeige sich also, dass weibliches Glück nicht durch die Ziele der Frauenbewegung zu erreichen sei, sondern durch eine auf Liebe basierende Ehe und daraus hervorgehende Mutterschaft. Das ist ebenfalls eine Applikation: Der Roman war in der Wahrnehmung des Rezensenten geeignet, auf einen Sachverhalt der Lebenswelt bezogen zu werden und damit verbundene Überzeugungen zu bilden oder zu verstärken. Das, was angeblich in der Welt des Textes der Fall ist, soll als lebensweltlich zutreffend und richtig akzeptiert werden.

Nicht immer sind, um es noch einmal zu betonen, Applikationen oder die Rede über Applikationen so deutlich wie in dem eben herangezogenen Beispiel. Dennoch gibt es in den Quellen weitere explizite Hinweise, die auf Applikationen schließen lassen. Die Schriftstellerin und Literaturkritikerin Laura Marholm (d.i. Laura Mohr, verh. Hansson) meinte, die stärkste Wirkung des Romans gehe von dem Umstand aus, „daß man sich erinnert“. Sie verstand darunter, dass Leserinnen des Buches in der im Roman geschilderten psychischen Disposition der Protagonistin eigene „Leiden“ wiedererkennen könnten, „die die Scheidewand zwischen dem Mann und dem Weibe bilden, - das dumpfe Hindämmern, die unbewußte Sprödigkeit, die innere Abwehr, vor Allem die Gleichgiltigkeit der noch ungeweckten Sinne““ ${ }^{37}$ Der Roman war Marholm zufolge also geeignet, auf die eigene Erfahrung bezogen zu werden. Sie beschrieb die Möglichkeit, sich mit dem Gelesenen zu identifizieren und es somit zu applizieren. Man kann sie so verstehen, dass sie zum einen eine Aussage über ihren eigenen Umgang mit dem Roman machte, zum anderen aber auch meinte, dass andere in gleicher

36 Rüttenauer: Agathe, S. 344.

37 Laura Marholm: Die Leidensgeschichte eines jungen Mädchens. In: Die Zukunft. Jg. 4, Bd. 14, H. 18, 1. Februar 1896, S. 222-225, hier S. 223. An derselben Stelle wird außerdem gesagt, dass männliche Leser der Problematik mit Desinteresse begegneten und dass die Protagonistin für einen „Typus“ von „Mädchen“ stehe, „die darin aufgehen würden, Mütter zu sein; der Mann ist dabei Nebensache“. Von der Möglichkeit, „daß der Leser sich selbst darin [in den Figuren] findet und sich vertieft darin wiedererkennt“, spricht eine andere Quelle, die den Roman allerdings etwas anders wahrnimmt und von der allgemeinen „Aufforderung“ des Textes spricht, „sich selbst klar zu werden und an seiner inneren Befreiung zu arbeiten“ [Josef August] Beringer: Aus guter Familie. In: Badische Schulzeitung. Vereinsblatt des Badischen Lehrervereins, des Witwen- und Waisen-Stifts und des Pestalozzi-Vereins. Nr. 48, 28. November 1896, S. 582 f., und Nr. 49, S. 597. Zitiert nach Mellmann: Dokumente, S. 309407, hier S. 407. 
Weise den Text applizieren können. Sie empfahl den Leserinnen einen solchen Umgang mit dem Gelesenen. Dem Format nach ähnlich argumentierte Stöcker, wenn sie schrieb: „Wir kennen sie alle, diese ,Leidensgeschichte““. Sie sah in dem Roman das Problem der ,Mädchenfrage‘ dargestellt, das die mit dem ,wir gemeinten Leserinnen aus eigener Erfahrung und lebensweltlicher Anschauung kennen. ${ }^{38}$ Da das Gelesene auf Erfahrenes und Erlebtes bezogen wurde, handelt es sich ebenfalls um einen Fall von Applikation. Dieser Bezug auf die Lebenswelt wurde ferner in einem im Druck erschienenen Vortrag hergestellt. Der Verfasser erklärte, bei der Lektüre des Romans habe er „sich der vielen gleichen oder ähnlichen Mädchenschicksale erinnert, die ihm aus eigener Erfahrung und Beobachtung bekannt sind“. ${ }^{39}$ Es gab in seiner Wahrnehmung tatsächlich Menschen, denen es wie der Protagonistin ergeht. Um zu der Überzeugung zu gelangen, hat er das im Roman Geschilderte auf die reale Welt bezogen, eine Übereinstimmung festgestellt und als relevant für den Roman angesehen, also eine Applikation vorgenommen.

\subsubsection{Auf die ,Mädchenfrage‘ bezogene Applikationen}

Zahlreiche Stellungnahmen sahen, wie im Folgenden gezeigt werden soll, in dem Roman den bereits erwähnten Beitrag zur ,Mädchenfrage“ und fassten ihn als Kritik an der Erziehung und an damit verbundenen Sachverhalten auf oder sie hoben insbesondere den Einblick in die Psyche eines solchen ,Mädchens“ hervor. Daraus wurden verschiedene Konsequenzen gezogen.

Vielfach wurde die sogenannte ,Mädchenfrage‘ explizit als relevanter Bezugsrahmen für den Roman identifiziert. ${ }^{40}$ Das galt schon für einige der ersten Rezensionen. Der Roman zeige die „Tragödie des modernen“ beziehungsweise des „einsamen verspäteten Mädchens“, ${ }^{41}$ er schildere „nicht nur die gesell-

38 Helene Stöcker: Gabriele Reuters Aus guter Familie. In: Frauenbewegung. Jg. 2, Nr. 4, 15. Februar 1896, S. 37-39. Zitiert nach Mellmann: Dokumente, S. 355-365, hier insbesondere S. 355 f. und S. 357, das Zitat S. 355.

39 Paul Bergemann: Die werdende Frau in der neuen Dichtung. [Vortrag gehalten am 7. Januar 1898 im Jenaer und am 24. Februar 1989 im Berliner Verein „Frauenwohl“]. Leipzig 1898, S. 79, das Zitat S. 8.

40 Vgl. dazu bereits die Auswertung von Quellen in Mellmann: Die Mädchenfrage, z. B. S. 2 und 3.

41 [Anon.]: Ein neues Buch. In: Breslauer Morgenzeitung. Nr. 569, 5. Dezember 1895, Zweite Beilage, S. 1. Zitiert nach Mellmann: Dokumente, S. 327-332, hier S. 331; Felix Poppenberg: Frauenbekenntnisse. In: Die Gegenwart. Bd. 49, Nr. 11, 14. März 1896, S. 165-167. Zitiert nach 
schaftlichen und psychologischen, sondern auch die innig damit zusammenhängenden physiologischen Ursachen des traurigen Unterganges eines solchen Mädchens der höheren Stände““.42 Bereits hier lässt sich von einer Applikation sprechen, insofern davon ausgegangen wird, dass das im Roman Dargestellte ein in der Wahrnehmung mancher Akteur/-innen tatsächlich vorhandenes zeitgenössisches Problem deutlich macht. Es ist verbunden mit der Annahme, dass damit etwas Wesentliches und Relevantes über den Text ausgesagt wird, nicht etwas, das nur von nebensächlicher Bedeutung wäre. Die ,Mädchenfrage‘ ist in dieser Sicht bestimmend für den Gesamttext.

Für die folgenden Jahre lassen sich bisweilen Stimmen nachweisen, die weiterreichende Applikationen vornahmen. Das Problem unverheiratet bleibender bürgerlicher Frauen wurde als weitverbreitet aufgefasst und im Zusammenhang gesehen mit einer vermeintlichen Krise der Ehe. In einer Quelle wurde Ehelosigkeit als „,sociale Massenerscheinung“ angesehen und von der „Zersetzung des Instituts der Ehe“ gesprochen. Der Verfasser zog daraus die Konsequenz, dass die Gesellschaft bürgerlichen Frauen eine Erziehung schulde, die es ihnen für den Fall, dass sie nicht heiraten können, ermöglicht, erwerbstätig zu sein. ${ }^{43}$ In die gleiche Richtung ging einige Jahre später der Vorschlag in einer Abhandlung, deren Verfasser Reuters Roman zum Anlass nahm, das zu verdeutlichen, was in seiner Wahrnehmung für die ,Frauenfrage“ entscheidend sei: Frauen wollten ,naturgemäß` eine Liebesehe eingehen und Mutter werden. Bleibe ihnen Mutterschaft versagt, fänden sie immer noch in der Liebesehe Erfüllung. Sei eine Liebesehe nicht möglich, so müsse ,kultureller' Ersatz geschaffen werden. Das setze aber voraus, dass Frauen die Freiheit haben, aktiv Ehe und Mutterschaft anzustreben und im Falle des Scheiterns eine berufliche Tätigkeit auszuüben. ${ }^{44}$ Es zeigt sich, dass das im Roman Geschilderte in einem

Mellmann: Dokumente, S. 369-371, hier S.371. Vgl. dazu die ähnlich lautende Aussage in Franz Servaes: Leidensbekenntnisse eines Mädchens. In: Neue Freie Presse (Wien). Nr. 11423, 12. Juni 1896, S. 1-3, hier S. 1.

42 Ernst von Wolzogen: Münchner Neueste Nachrichten. Der Münchner Kunstbriefe siebentes Stück. In: Das Magazin für Literatur. Jg. 64, Nr. 51, 21. Dezember 1895, Sp. 1673-1682, hier Sp. 1680-1682. Zitiert nach Mellmann: Dokumente, S. 332-334, hier S. 333 f.

43 Vgl. Eugen Ehrlich: Aus guter Familie. In: [Unbekannte Quelle; Sonderdruck an Gabriele Reuter, Poststempel vom 14. März 1898]. Zitiert nach Mellmann: Dokumente, S. 413-420, hier S. 419 f., die beiden vorangehenden Zitate S. 414.

44 Otto Hartwich: Der springende Punkt der Frauenfrage. Gabriele Reuter: Aus guter Familie. In: O. H.: Kulturwerte aus der modernen Literatur. 3 Bde. Bremen 1911/1912. Bd. 1, S. 133-161. Zitiert nach Mellmann: Dokumente, S. 517-540, hier S. 534 f. 
umfassenden Sinne auf die gesellschaftlichen Verhältnisse bezogen und mithin appliziert werden konnte.

Ein weiterer Gesichtspunkt ist die häufig anzutreffende Einschätzung, der Roman sei als Kritik an der verfehlten Erziehung junger Frauen aus dem Bürgertum aufzufassen. Sie kommt gleichfalls in verschiedenen Rezensionen vor. Es wurde angenommen, dass das Scheitern der Protagonistin mit den „Fehlgriffen einer Erziehung“ zu erklären sei, die einseitig darauf ausgerichtet ist, junge Frauen zu Gattinnen zu machen: „[E]s soll an einem instructiven Fall gezeigt werden, wohin die unfruchtbare Erziehungsmethode und die systematische Niederhaltung der Frau bisweilen führen kann“. ${ }^{45}$ Die Schriftstellerin und Publizistin Ella Mensch, die Redakteurin der Frauenrundschau war, nahm an, dass Reuters Roman, ebenso wie Frieda von Bülows Einsame Frauen, Figuren schildere, ,welche aus jener einseitigen Erziehung, die nicht die Entfaltung allgemein menschlicher Fähigkeiten, sondern den Drill auf die Ehe im Auge hat, als müde, gebrochene und depravirte Geschöpfe hervorgehen“. ${ }^{46}$ In einer Publikation, in der eine ablehnende Haltung gegenüber der Frauenbewegung überwog, wurde Reuter, die dort als eine ihrer Exponentinnen galt, zu Gute gehalten, dass sie sich in dem Roman "gegen die falsche Erziehung“ gewandt habe und „die Vervollkommnung und Veredlung des Weibes“ anstrebe. ${ }^{47}$ Solche Annahmen fanden Eingang in populäre literaturgeschichtliche Darstellungen der Zeit. ${ }^{48}$

45 Josef Ettlinger: [Rezension von Reuter: Aus guter Familie]. In: [Unbekannte Quelle. o. D., Rubrik „Mittheilungen und Nachrichten“, S.6]. Zitiert nach Mellmann: Dokumente, S. 346349, hier S. 347 und 348.

46 Ella Mensch: Die Frau in der modernen Literatur. Ein Beitrag zur Geschichte der Gefühle. Berlin 1898, S. 14-17, hier S. $15 \mathrm{f}$.

47 Franz Christel: Gabriele Reuter. In: Lechners Mitteilungen aus dem Gebiete der Literatur, Kunst, Kartographie und Photographie (Wien). Nr. 1, 1. Mai 1903, S. 1-4. Zitiert nach Mellmann: Dokumente, S. 461-463, hier S. 463.

48 So hieß es z. B., die Protagonistin gehe an „der Erziehungslüge zu Grunde“ - Emil Thomas: Die letzten zwanzig Jahre deutscher Litteraturgeschichte 1880-1900. Leipzig 1900, Kap. „Amazonen des Geistes“, S. 97-99, hier S. 98. In einer anderen Darstellung wurde mit unverhohlener Ablehnung festgestellt, der Roman sei Kritik an „der verkehrten Mädchenerziehung in der heutigen Zeit“ - Hermann Hölzke: Zwanzig Jahre deutscher Literatur. Ästhetische und kritische Würdigung der schönen Literatur der Jahre 1885-1905. Braunschweig 1905, S. 170. Vgl. dazu die nahezu wortgleichen Aussagen in Hermann Hölzke: Die Deutsche Literatur von den Anfängen der Moderne bis zur Gegenwart. 3., völlig umgearb. und stark erw. Aufl. von „Zwanzig Jahre deutscher Literatur“. Leipzig 1913, S. 542, und bereits in Hermann Hölzke: Das Häßliche in der modernen Litteratur. Braunschweig/Leipzig 1902. Zitiert nach Mellmann: Dokumente, S. 448. 
Es geht, so kann man die Quellen verstehen, nicht allein darum, eine Aussage darüber zu machen, was im Text den Gang der Handlung motiviert, nämlich die fehlgeleitete Erziehung der Protagonistin. Vielmehr wird zum einen davon ausgegangen, dass Fälle einer solchen Erziehung realweltlich vorkommen. Darin zeigt sich eine erste Applikation des Gelesenen. Zum anderen wird davon ausgegangen, dass es sich um Missstände in der Erziehung handelt, die kritikwürdig sind. Darin zeigt sich eine darauf aufbauende Applikation. Es wird nämlich nicht allein angenommen, dass die im Roman auf das Geschehen entwickelte Perspektive eine kritische ist, sondern es soll gesagt werden, dass der Roman geeignet ist, lebensweltliche Sachverhalte in einem kritischen Licht erscheinen $\mathrm{zu}$ lassen, also bei den Rezipient/-innen eine kritische Sicht zu entwickeln oder zu verstärken, etwas als problematisch erkennbar zu machen und gegebenenfalls verfehlte Ansichten über den in Rede stehenden Sachverhalt zu korrigieren.

Die Kritik an der Erziehung stand häufig im Zusammenhang mit einem weiteren spezifischen Gesichtspunkt. Der Roman wurde als Kritik an den Konventionen und Normen aufgefasst, die bestimmen, wie in bürgerlichen Kreisen mit den Töchtern umgegangen wird. Sie wurden der Gesellschaft oder aber den Akteur/-innen, vor allem den Eltern, zugeschrieben. Die Protagonistin scheitere, so die Annahme in einer Besprechung, an der ,konventionelle[n] Heuchelei“, den „leeren Gesellschaftsformen“ und den „zahllosen Vorurteilen“, denen sie als „Mädchen aus guter Familie“ ausgesetzt sei. ${ }^{49}$ Der Roman sei, so die Aussage in einer weiteren Besprechung, „eine bittere Anklage gegen die Gesellschaft und die in falschen engen Anschauungen befangenen Eltern, die dem Popanz der Standes- und Classenvorurtheile oft blindlings Existenz und Lebensglück ihrer Kinder ausliefern, während sie nur deren Bestes zu wollen des Glaubens sind“. ${ }^{50}$ Neben charakterlichen Faktoren seien es, so eine dritte Einschätzung, ,doch ebenso sehr die gesellschaftlichen Verhältnisse und Vorurtheile, die sie [die Protagonistin] hindern, durch freie Entfaltung und Bethätigung ihrer Anlagen ein selbstgeschaffenes Glück zu genießen“. ${ }^{11}$ Solche Aussagen fanden ebenfalls Eingang in Quellen der folgenden Jahre, darunter populäre literaturgeschichtliche Darstellungen. Reuter schildere in ihren Romanen, darunter Aus guter Familie, „Frauencharaktere, die im Kampf mit den

49 Wolzogen: Münchner Neueste Nachrichten, S. 336.

50 Ettlinger: [Rezension von Reuter: Aus guter Familie], S. 349.

51 M[argarete] Lisco: [Rezension von Reuter: Aus guter Familie]. In: Nationalzeitung. 1. November 1896, Rubrik „Die Frau in eigener Sache“. Zitiert nach Mellmann: Dokumente, S. 394-399, hier S. 396. 
Vorurteilen der Gesellschaft und in der Familie ihre eigene, ursprüngliche Persönlichkeit zu wahren suchen“.52 Die Protagonistin sei „[e]in Opfer der Gesellschaft, der ,guten Familie““; sie sei als „ein trauriges Opfer konventioneller Anschauungen“ anzusehen. ${ }^{53}$ Insofern anhand dessen, was der fiktionale Text zeigt, die Verhältnisse in der realen Welt als kritikwürdig aufgefasst werden sollen, kann von einer Applikation gesprochen werden. Das im Text Dargestellte lässt die lebensweltlichen Gegebenheiten in einem kritischen Licht erscheinen.

Besonders betont wurde des Weiteren der Einblick, welchen der Roman in die Psyche einer solchen Frau ermögliche, und die Innenansicht der ,Mädchenfrage', die er auf diese Weise biete. In einem Zeitschriften-Beitrag wurde Reuter gar zur „Dichterin der modernen Frauenpsyche“ erklärt. ${ }^{54}$ Als positiv wurde der Umstand gewertet, dass Bücher wie Reuters Roman einen „Einblick [geben] in das Seelenleben der Frau, wie Frauen selbst es auffassen“. ${ }^{55}$ Aufgrund ihres Geschlechtes erschien die Autorin als epistemisch privilegiert, derartige Einsichten zu vermitteln. Helene Lange, eine der prominentesten Akteurinnen der gemäßigten Frauenbewegung und neben ihrer Tätigkeit in führender Funktion im Bund deutscher Frauenvereine und im Allgemeinen Deutschen Frauenverein Gründerin des Allgemeinen Deutschen Lehrerinnenvereins, schrieb in einer Rezension, dass der Roman die „ganze innerlich verkommene Existenz eines Mädchens der ,guten Gesellschaft““ in zutreffender Weise (,wahr“) schildere. ${ }^{56}$ Marholm sah „das Verdienstliche“ des Romans darin, das „innere Leben“ eines solchen Menschen „anschaulich zu machen“. ${ }^{57}$ Andere lobten, dass „mit realistischer Schärfe die inneren Phasen des weiblichen Seelenlebens in wahrhaft überzeugender und dabei fesselnder Art“ beschrieben würden, oder sie spra-

52 Erich Mühsam: Gabriele Reuter. In: Hanns Heinz Ewers (Hg.): Führer durch die moderne Literatur. Dreihundert Würdigungen der hervorragendsten Schriftsteller unserer Zeit. Vollständig neu bearb. Aufl. Berlin 1910, S. 137.

53 Victor Klemperer: Gabriele Reuter. In: Westermanns Monatshefte. Illustrierte deutsche Zeitschrift für das geistige Leben der Gegenwart. Jg. 52, Bd. 104:2, September 1908, S. 866-874, hier S. 871, vgl. dazu S. 870 f.; Albert Soergel: Dichtung und Dichter der Zeit. Eine Schilderung der deutschen Literatur der letzten Jahrzehnte. Zweiter unveränderter Abdruck. Leipzig 1912, S. 305-309, hier S. 316.

54 Krause: Gabriele Reuter, S. 334.

55 Ernst Heilbronn: Frauenantworten auf Frauenfragen. In: Die Frau. Monatsschrift für das gesamte Frauenleben unserer Zeit. Jg. 3, H. 7, April 1896, S. 385-390, hier S. 390.

56 [Helene Lange]: Bücherschau. Aus guter Familie. In: Die Frau. Monatsschrift für das gesamte Frauenleben unserer Zeit. Jg. 3, H. 5, Februar 1896, S. 317.

57 Marholm: Die Leidensgeschichte eines jungen Mädchens, S. 224. 
chen von der „feinen psychischen Analyse“.58 Insofern mit solchen Aussagen gemeint ist, dass der Roman zeige, wie die psychische Disposition realer Menschen beschaffen sein kann, lässt sich von einer Applikation sprechen. Sie betrifft nicht ein peripheres Detail des Textes, sondern etwas, das als zentral und besonders relevant angesehen wird.

Verschiedentlich wurde explizit auf potenzielle Konsequenzen hingewiesen, die sich aus der Lektüre des Romans ergeben sollen. Sie sind ein deutliches Indiz für Applikationen. Der Roman werde zwar, so hieß es gleich in der ersten vorliegenden Rezension, von den „Stützen der Gesellschaft“ als „unmoralisch und empörend“ abgelehnt werden, er könne aber vielleicht „den Erfolg haben, daß Einer oder der Andere an der Vollkommenheit der Normen zu zweifeln beginnt, welche ,Convention und Sitte' der Entwicklung der menschlichen und speciell der weiblichen Individualität gesetzt hat“. Obwohl der Roman keine „ausgesprochene Tendenz“ habe, werde doch jemand, der ihn angemessen rezipiere, „seine Consequenzen selbst zu ziehen wissen“. ${ }^{59}$ Das Buch solle, so Ina Foerster, nicht primär von Töchtern gelesen werden, sondern von deren Eltern und anderen, die Einfluss haben, damit sie es zum Anlass nehmen, ,gegen alle Heuchelei in Erziehung und Lebensführung“ vorzugehen. ${ }^{60}$ Sie sah in dem Buch „eine gute That, die langsam, aber sicher weckend, warnend und erziehend das ihrige zur Befreiung der Menschheit aus unwürdigen Fesseln beitragen will“. Bisweilen wurden mögliche Konsequenzen konkret benannt: Das „Motto“ des Romans sei „Entwicklung“, aufgrund der Lektüre könne man zu der Überzeugung kommen (oder darin bestärkt werden), dass für junge Frauen aus dem Bürgertum „Pflichten, Verantwortung, geistige und körperlicher Arbeit, Fortentwicklung, ein lebenswertes Leben statt des leeren Tändelns“ geboten seien. ${ }^{61}$

Die Möglichkeit einer tatsächlichen Wirkung des Buches wurde einige Jahre später in einer Quelle eher vorsichtig eingeschätzt: „Wieweit es tatsächlich pädagogische Wirkung getan hat, das wird wohl erst in viel späteren Jahren zu

58 [Anon.]: Literarische Notizen, S. 419; Lisco: [Rezension von Reuter: Aus guter Familie], S. 395.

59 [Anon.]: Ein neues Buch, S. 332.

60 Vgl. Ina Foerster: Bücherbesprechung. [Unbekannte Quelle. o. D.]. Zitiert nach Mellmann: Dokumente, S. 344-346, hier S. 344 f., das Zitat S. 345, das folgende Zitat S. 346. Vgl. dazu die Einschätzung, wonach der Roman geeignet sei, in den „Glauben eine Bresche zu legen“, dem zufolge Töchter nur zu Ehefrauen zu erziehen sind - Ettlinger: [Rezension von Reuter: Aus guter Familie], S. 349. Ähnlich Heilbronn: Frauenantworten auf Frauenfragen, S. 387: Der Roman „mahnt andere Wege einzuschlagen“.

61 [Lange]: Bücherschau, S. 317. 
ergründen sein.“62 Anlässlich des siebzigsten Geburtstags der Autorin schrieb jedenfalls Stöcker, vierunddreißig Jahre nach Erscheinen des Romans:

Die junge Generation ahnt nicht, wie groß der Unterschied zwischen damals und heute ist, versteht jene - unbewußte - Grausamkeit gegen Millionen weiblicher Menschen überhaupt nicht mehr. Das ist der beste Beweis, wie sehr die Zeit sich gewandelt hat, wie groß die Wirkung jener gewesen ist, die diese Umwälzung vorbereiten halfen. Unter den Bahnbrecherinnen für eine neue Epoche der Frau, der Liebe, der Mütterlichkeit wird Gabriele Reuter nie vergessen werden. ${ }^{63}$

Bei Unterschieden im Detail scheint solche Aussagen in den Quellen doch die Vorstellung zu einen, dass die Lektüre des Romans Folgen haben kann und soll und tatsächlich hatte, die sich auf die Überzeugungen und das konkrete Handeln der Rezipient/-innen bezogen, Folgen mithin, denen eine Applikation des Gelesenen zugrunde liegen musste.

Die vorangehend dargestellten Aussagen aus Rezeptionsdokumenten geben einen Einblick in die ,materielle‘ Seite eines wesentlichen Teils der zeitgenössisch möglichen Applikationen, indem sie deutlich machen, welche Ausprägungen sie konkret annahmen. Mit den Applikationen gehen verschiedene ,formale‘ Gesichtspunkte einher: Hervorgehoben wurde die Bedeutsamkeit und ,Wahrheit‘ des Dargestellten, seine nicht auf den Einzelfall zu beschränkende Exemplarizität, die Frage nach der ,Tendenz' des Romans und seine Wahrnehmung als ,Anklage'. Sie stehen im Zusammenhang mit den Applikationen, insofern sie Voraussetzungen dafür benennen, dass und wie der Roman appliziert werden konnte. Als rein formale Gesichtspunkte sind sie unabhängig davon, welche konkrete Form die Applikation annimmt: So kann man aus der Annahme, das Schicksal der Protagonistin sei typisch, unterschiedliche Schlüsse ziehen, etwa dass im Sinne der ,Mädchenfrage‘ eine Reform der Erziehung erforderlich ist oder dass die gesellschaftliche Stellung der Frau grundsätzlich verändert werden muss.

Eine zwar nicht notwendige, aber doch Applikationen potenziell förderliche Voraussetzung ist die Annahme, der Text thematisiere etwas, das zeitgenössisch oder allgemein als besonders bedeutsam einzuschätzen sei. In einer Rezension findet sich die Aussage, der Roman behandle „eine der wichtigsten

62 Klemperer: Gabriele Reuter, S. 871.

63 Helene Stöcker: Gabriele Reuter. Zu ihrem siebzigsten Geburtstag. In: Neue Rundschau. Jg. 40, Bd. 1 (1929), S. 268-272, hier S. 272. 
Entwicklungsfragen der Menschheit“. ${ }^{64}$ An anderer Stelle heißt es, er leiste „einen so merkwürdigen und werthvollen Beitrag zur Kulturgeschichte der Gegenwart“. ${ }^{65}$ Solche Stellungnahmen legen nahe, dass das Thema des Romans als besonders wichtig angesehen wurde. Darüber hinaus wurde ihm Aktualität bescheinigt. Der Erfolg des Romans erkläre sich aus der „Aktualität seines Stoffes, der verkehrten Mädchenerziehung in der heutigen Zeit“. ${ }^{66}$

Zahlreiche Rezeptionszeugnisse betonten, dass das im Roman Erzählte ,wahr“ sei. Immer wieder war von der „Wahrheit des Dargestellten“ die Rede; es sei „wahr, wahr, schauerlich wahr“ oder „stark und wahr“. ${ }^{67}$ Damit war in der Regel nicht gemeint, dass das Geschilderte in einem einfachen Sinne referenzialisierbar sei. Es wurde nicht angenommen, dass zum Beispiel Agathe Heidling existiere. ${ }^{68}$ Gemeint war vielmehr, dass der Roman „das Leben, wie es ist“ zeige beziehungsweise „die Verhältnisse, wie sie sind“. ${ }^{69}$ Es wurde also angenommen, dass das im Roman Dargestellte eine zutreffende Schilderung der realweltlichen Verhältnisse ist. Im Zusammenhang mit den oben identifizierten Applikationen erweist sich das als eine wichtige, Applikationsmöglichkeiten verstärkende Voraussetzung. Der Roman kann relativ direkt und unmittelbar als Beitrag zur ,Mädchenfrage‘ aufgefasst und appliziert werden, wenn man annimmt, dass es sich in der realen Welt genauso verhält. Damit ist nicht ausgeschlossen, dass ein ,wahrer' historischer oder phantastischer Roman oder einer, der zum Beispiel die Erziehung indischer Mädchen Ende des 19. Jahrhunderts schildert, vom zeitgenössischen Publikum des Romans von Reuter als Beitrag zur ,Mädchenfrage‘ aufgefasst und appliziert werden könnte. Eine solche Applikation wäre jedoch indirekt und würde etwas anders, zum Beispiel über die Feststellung von Analogien oder Unterschieden zur Lebenswelt, funktionieren. Varianten der Rede von ,Wahrheit' verweisen auf die Wahrhaftigkeit und Ehr-

64 [Anon.]: Ein edles Buch. In: Der Bund. Eidgenössisches Centralblatt. Jg. 46, Nr. 358, 25. Dezember 1895, S. 1. Zitiert nach Mellmann: Dokumente, S. 334-338, hier S. 338.

65 Marholm: Die Leidensgeschichte eines jungen Mädchens, S. 225. Vgl. dazu die Einschätzung, wonach der Roman „ein meisterliches Stück Kulturgeschichte“ sei (Klemperer: Gabriele Reuter, S. 871).

66 Hölzke: Zwanzig Jahre deutscher Literatur, S. 170.

67 Beringer: Aus guter Familie, S. 400; [Lange]: Bücherschau, S. 317; Hans Pauli: FrauenLitteratur. In: Neue Deutsche Rundschau (Freie Bühne). Jg. 7, Bd. 1, Nr. 3, März 1896, S. 276281. Zitiert nach Mellmann: Dokumente, S. 365-369, hier S. 368.

68 In seltenen Fällen wurde allerdings angenommen, die Autorin schildere eigenes Erleben. Neben dem bereits oben erwähnten Rüttenauer, Agathe, gilt das z. B. für Marholm: Die Leidensgeschichte eines jungen Mädchens, S. 222. Gelobt wurde dann die Aufrichtigkeit und Authentizität.

69 Heilbronn: Frauenantworten auf Frauenfragen, S. 385 und 390. 
lichkeit der Autorin oder heben hervor, dass es eine besondere Leistung gewesen sei, Missstände konkret zu benennen: Der Roman trage den „Stempel der Wahrhaftigkeit“, er sei „[e]hrlich durch und durch“, Reuter habe „Mut“ besessen, „auszusprechen, was war“. ${ }^{70}$

Immer wieder wurde darauf hingewiesen, dass das Geschilderte exemplarisch sei. Erzählt werde „nichts als die trostlose Geschichte von Hunderten von Existenzen“. ${ }^{71}$ „Tausende von Töchtern“ seien wie die Protagonistin mit Vorurteilen und anderen Einschränkungen konfrontiert. ${ }^{72}$ Die besondere Leistung des Romans sei darin zu sehen, dass an einem Einzelfall ein allgemeines Problem deutlich gemacht werde: „Es ist das Geschick unzähliger Tausende von verfehlten Existenzen, die sonst stumm, unverstanden und unbeachtet duldeten und nun auf einmal Bewußtsein und Stimme bekommen haben.“73 In einem Rückblick dreiunddreißig Jahre nach Erscheinen des Romans hieß es sogar: „Hier war kein Einzelfall geschildert, sondern das Schicksal aller Frauen verraten. “74 Eine häufig anzutreffende Redeweise hebt auf ,Typisches` im Dargestellten ab: Die Protagonistin sei „typisch für eine ganze Klasse von jungen Mädchen“; „[d]as Schicksal, das sie schildert, ist typisch“; für die große Resonanz des Romans sei der Umstand verantwortlich, dass das Geschilderte „ganz typisch ist“ und „die uns wohlvertraute Alltagswelt“ zeige. ${ }^{75}$ Die Auffassung, der Roman sei in dem, was er zeigt, im Ganzen oder in Teilen exemplarisch oder typisch, ist Applikationen insofern förderlich, als sie deren Anwendungsbereich erheblich vergrößert. Geschildert wird nicht ein besonderer, untypischer Fall, der eventuell nur mittelbar durch Kontrast zum vermeintlichen Normalfall eine Applikation ermöglicht, sondern ein Fall, der unmittelbar auf ein weitverbreitetes Phänomen verweist. ${ }^{76}$

70 Lisco: [Rezension von Reuter: Aus guter Familie], S. 395; Marholm: Die Leidensgeschichte eines jungen Mädchens, S. 222; Eugenie Schwarzwald: Dreiunddreißig Jahre. In: Neue freie Presse (Wien). Nr. 23019, 14. Oktober 1928, S. 12.

71 Stöcker: Gabriele Reuters Aus guter Familie, S. 356.

72 Lisco: [Rezension von Reuter: Aus guter Familie], S. 396.

73 H[einrich] M[eyer]-B[enfey]: Gabriele Reuter. In: Göttinger Zeitung. 12. Februar 1904, S. [2].

74 Schwarzwald: Dreiunddreißig Jahre, S. 12.

75 Stöcker: Gabriele Reuters Aus guter Familie, S. 356; Pauli: Frauen-Litteratur, S. 368; M[eyer]-B[enfey]: Gabriele Reuter, S. [2].

76 Einer in diesem Zusammenhang bemerkenswerten Gegenstimme zufolge ist der Roman in darstellungstechnischer Hinsicht misslungen, da er gerade daran scheitere, das Schicksal der Protagonistin als exemplarisch zu erweisen: „[A]ls Beitrag zur Frauenbewegung ist das Buch verfehlt, denn der Beweis, den die Verfasserin gibt, ist mißlungen. Gabriele Reuter stellt nämlich die Behauptung auf, daß man, wenn man ,aus guter Familie‘ stammt, nur die allersimpelsten Forderungen ans Leben stellen darf, weil man sonst unglücklich wird, aber sie beweist das 
Verschiedene Auffassungen wurden vertreten in der Frage, ob der Roman eine ,Tendenz' habe - bei weitverbreiteter Einigkeit, dass eine Tendenz bei literarischen Texten abzulehnen sei. Als prinzipiell positiv besetzte Gegenbegriffe fungierten ,Kunstwerk، oder ,Dichtung،. Ein besonders gutes Beispiel bietet eine Quelle, in welcher gesagt wird, dass der Roman weder „reine Dichtung“ sei noch ein „Tendenzbuch“:

Gabriele Reuter erklärt selbst: Aus guter Familie ist weder ein Erziehungs- noch ein Tendenzbuch. Nun braucht man Dichtern solche Aussagen nicht immer aufs Wort zu glauben, aber in diesem Fall hat sie doch buchstäblich recht. Ein Tendenzbuch im eigentlichen Sinne ist ihr Roman nicht, insofern Tendenz das Hinstreben auf ein Ziel ausdrückt. Er enthält kein Ideal und keine sittlichen Forderungen; es steht kein Programm und keine Weltanschauung dahinter; er stellt nur dar, was ist, ohne anzudeuten, was sein sollte oder sein könnte. ${ }^{77}$

Dem widersprach eine Einschätzung wie die folgende, wonach der Roman seinen Erfolg einer „krassen Tendenz“ verdanke, die in der Darstellung der „verkehrte[n] Mädchenerziehung in heutiger Zeit“ bestehe; einer Darstellung, die als künstlerisch misslungen beurteilt wurde: „Agathe ist kein Wesen von Fleisch und Blut, sondern eine für die tendenziöse Absicht der Verfasserin extra konstruierte Figur, der alles schief geht, damit sie nur ja recht bedauerlich erscheint, die auf Draht gezogene Erbärmlichkeit; aber man merkt die Absicht und man wird verstimmt. “78 Eine mittlere Position wurde von solchen Stimmen eingenommen, die zwar in dem Roman eine gewisse Tendenz verwirklicht sahen, sie aber als moderat oder unproblematisch betrachteten. Das gilt für eine Aussage, wonach es sich um einen Frauenroman mit Bezug auf die Frauenbewegung handele, allerdings „ohne bei aller Tendenz die Grenzen zur Unterhaltungskunst und der guten Sitte zu überschreiten“. ${ }^{79}$ Diese Auseinandersetzung

nicht durch eherne Notwendigkeiten, sondern durch eine Reihe von Zufällen, die innerlich mit der aufgestellten Hypothese gar nichts zu tun haben. Die arme Agathe wird nicht unglücklich, weil sie aus guter Familie ist und mehr will als das Alltägliche, sondern weil sie zufällig gewissenlose Eltern, gewissenlose Freundinnen, gewissenlose Lehrer etc. hat.“ - Hölzke: Zwanzig Jahre deutscher Literatur, S. 171.

77 Heinrich Meyer-Benfey: Gabriele Reuter, Zeitung für Literatur, Kunst und Wissenschaft. Beilage des Hamburgischen Correspondenten, 28. Mai 1905. Zitiert nach Mellmann: Dokumente, S. 484-491, hier S. 487.

78 Hölzke: Das Häßliche in der modernen Litteratur, S. 448 und 449. Vgl. dazu Hölzkes Einschätzung, wonach der Roman in „eine ganze Reihe vielgelesener Tendenzroman“ gehöre Hölzke: Zwanzig Jahre deutscher Literatur, S. 32.

79 Adolf Bartels: Die Deutsche Dichtung der Gegenwart. Die Alten und die Jungen. 3., verbesserte Aufl. Leipzig 1900, S. 237 f. 
muss hier nicht im Detail oder mit Blick auf die zeitgenössischen Auffassungen von Kunst und Literatur, etwa ihre vermeintliche Zweckfreiheit, nachgezeichnet werden. Aufschlussreich ist die Wahrnehmung des Modus, in welchem die Kritik des Romans artikuliert wird. Es konnte sowohl, wie gesehen, angenommen werden, dass der Roman nur darstelle, was ist, als auch, dass er einseitig geschrieben sei und dem Publikum die damit verfolgte Absicht aufgedrängt werde. Im ersten Fall erbringt das Publikum selbst die Applikationsleistung, in dem anderen Fall wird sie explizit vermittelt.

In diesen Zusammenhang gehört die wiederholt in den Quellen anzutreffende Meinung, der Roman sei als ,Anklage‘ zu verstehen, dem Text also ein bestimmter Sprechakt zuzuweisen. Der Roman sei eine „vernichtende Anklage“, er weise einen „Anklagezug“ auf, „den man nicht wegleugnen sollte“, er sei „eine einzige empörende und niederschmetternde Anklage““. ${ }^{80}$ Es liegt auf der Hand, dass die Annahme, der Roman bringe einen solchen Sprechakt zum Ausdruck, Applikationen begünstigt, bei denen das im Roman Dargestellte als Bezugnahme auf und Kritik an realweltlichen Missständen angesehen wird. Während die meisten Rezipient/-innen, die den Roman als ,Anklage“ begriffen, diese Stoßrichtung begrüßten, gab es hierzu auch ablehnende Haltungen. Der Roman gehöre zur „Anklagelitteratur“ und verliere deswegen die „Möglichkeit zu höchsten, tendenzlosen Kunstwirkungen“. ${ }^{81}$ Bisweilen wurde bestritten, dass der Roman überhaupt als Anklage aufzufassen sei: „Ein Unding aber ist es, in dieser Leidensgeschichte eine soziale Anklage zu finden“ ${ }^{82}$

Als förderlich für Applikationen kann sich die in manchen Rezeptionsdokumenten dem Roman zugeschriebene Eigenschaft erweisen, Emotionen zu evozieren. Die Rede ist dann von „Grimm“ und „Empörung“ oder „Zorn“, 83 von ,Erschütterung“, ${ }^{84}$ von „Mitgefühl“ und „Mitleid“. ${ }^{85}$ Der Grund liegt auf der

80 Wolzogen: Münchner Neueste Nachrichten, S. 333; Servaes: Leidensbekenntnisse eines Mädchens, S. 1; Hans von Kahlenberg: Gabriele Reuter und ihr Werk. In: Der Tag. 13. Juli 1906, S. 1-3. Zitiert nach Mellmann: Dokumente, S. 492-497, hier S. 493.

81 Max Lorenz: Die Litteratur am Jahrhundert-Ende. Stuttgart 1900, Kap. „Frauenwerke“, S. 154-178, zu Reuters Roman S. 159 f., das Zitat S. 159.

82 Hans Olden: Die Leiden der jungen Agathe. In: [Unbekannte Quelle. o. D., vor dem 11. Juni 1896]. Zitiert nach Mellmann: Dokumente, S. 379-385, hier S. 384.

83 Wolzogen: Münchner Neueste Nachrichten, S. 334; Bergemann: Die werdende Frau in der neuen Dichtung, S. 8.

84 Beringer: Aus guter Familie, S. 400; Bergemann: Die werdende Frau in der neuen Dichtung, S. 8.

85 Bergemann: Die werdende Frau in der neuen Dichtung, S. 8. Vgl. dazu Hans Land: Einleitung. In: Gabriele Reuter: Eines Toten Wiederkehr und andere Novellen. Leipzig [1908], S. 3-6. Zitiert nach Mellmann: Dokumente, S. 507-509, hier S. 508. 
Hand: Die ,Mädchenfrage“ kann dann als besonders dringlich und eindrücklich erscheinen, wenn die Protagonistin Mitleid evoziert, ihre Geschichte erschüttert und die sozialen Verhältnisse als empörend wahrgenommen werden. ${ }^{86}$

Schließlich wurde vereinzelt der Mehrwert erwähnt, welcher sich daraus ergeben soll, dass es sich generisch und darstellungstechnisch um einen literarischen Text handelt. Eltern könnten aus dem Roman mehr lernen ,als aus den schönsten Traktaten über Kindererziehung“, er werde „wirksamer und nachhaltiger, als jeder Vortrag und jede Debatte auf einem Frauenkongreß, die Gemüter beschäftigen“. ${ }^{87}$ Im wirklichen Leben würde man Personen, die wie die Protagonistin sind, meiden, die literarische Darstellung sei jedoch geeignet, „das Gerechtigkeitsgefühl des Lesers zu einer wahren Wut gegen die Zustände [zu entflammen]“. ${ }^{88}$ Genuin künstlerisch sei das Buch darin, dass es eine „Entdeckung“ sei: „Denn die Kunst entdeckt - ungleich der Wissenschaft, die durch Neugefundenes, Niegeahntes überrascht - indem sie allgemein Gefühltes ausspricht, indem sie stets unbewußt Gesehenes scharf bestrahlt, indem sie Gleichgiltiges interessant macht." ${ }^{\text {89 }}$ Dem Roman oder der Literatur allgemein wurde also eine besondere Funktion oder Wirkung zugeschrieben. Entsprechendes trifft dann auf damit in Verbindung stehende Applikationen zu. Um es an dem zweiten der eben erwähnten Beispiele zu verdeutlichen: Während ein Mann im Alltag keine Kenntnis über die psychische Disposition eines „spinösen Jüngferchen[s]" und die dafür verantwortlichen gesellschaftlichen Ursachen erlange, leiste das der Roman und ermögliche die Applikation, dass Konventionen und Normen, welche die Erziehung bestimmen, kritikwürdig seien, insofern sie die Realisierung „vernünftiger Frauenrechte“ verhinderten. ${ }^{90}$

86 Vgl. dazu Mellmann: Die Mädchenfrage, S. 24 f., und die Einschätzung, wonach der Roman „the reader's identification with the protagonists” ermögliche, „through whose suffering the reader's own discontent with society can be channelled“ - Charlotte Woodford: Bertha von Suttner's Die Waffen nieder! and Gabriele Reuter's Aus guter Familie. Sentimentality and Social Criticism. In: Ch. W./Benedict Schofield (Hg.): The German Bestseller in the Late Nineteenth Century. Rochester, NY 2012, S. 206-223, hier S. 206.

87 [Anon.]: Ein neues Buch, S. 328; Lisco: [Rezension von Reuter: Aus guter Familie], S. 395.

88 Wolzogen: Münchner Neueste Nachrichten, S. 334.

89 Olden: Die Leiden der jungen Agathe, S. 379 f.

90 Wolzogen: Münchner Neueste Nachrichten, S. 334. 


\subsubsection{Alternative Applikationen}

Eine erste alternative Applikation stammt von der Verfasserin selbst. ${ }^{91}$ Reuter schrieb in ihrer 1921 erschienenen Autobiographie Vom Kinde zum Menschen, sie habe eine „stumme Tragik des Alltags“ zur Darstellung bringen wollen. Es sei ihr darum gegangen, „zu künden, was Mädchen und Frauen schweigend litten“. Die „Tragik in dem Los des Weibes“ sah sie darin, „geboren zu sein, erzogen zu werden für eine Berufung, die sie gelehrt ist, als ihr einziges Glück zu betrachten, und dieses Glück, diese Berufung wird ihr stets vor Augen gehalten und doch nie gewährt - niemals darf sie eintreten in den Tempel des Gottes, zu dessen Priesterin sie doch gebildet ist“. Besonders deutlich werde die Tragik bei jungen bürgerlichen Frauen, die unverheiratet bleiben: „Diese Menschentragik verkörperte sich mir am reinsten und stärksten in dem Mädchen aus bürgerlichen Kreisen - in der Tochter aus guter Familie. “92

Insofern Reuter beabsichtigte, dass Rezipient/-innen das Dargestellte auf die Realität beziehen und als zutreffende Schilderung tatsächlicher Verhältnisse ansehen, die als tragisch wahrgenommen werden sollen, lässt sich von einer intendierten Applikation sprechen. Sie deckt sich mit den im vorangehenden Teilkapitel identifizierten Applikationen nur insofern, als sie auf das der ,Mädchenfrage' zugrunde liegende Problem bezogen ist. Das Problem fasste Reuter allerdings in einer spezifischen, alternativen Weise auf. Ihr ging es nach eigenem Bekunden um einen rein ,anthropologischen“ Sachverhalt: „Mich fesselte an dem Stoff rein das Menschliche. "93 In einem sieben Jahre später erschienenen Beitrag für eine Zeitung, in dem sie Auskunft gab über die Entstehung des Romans, machte sie den Punkt noch deutlicher. Sie habe die „Tragik“ verständlich machen wollen, welcher die „bürgerlichen deutschen Mädchen“ unterworfen seien:

$91 \mathrm{Zu}$ Reuters Haltung zur Frauenbewegung vgl. Heide Soltau: Die Anstrengungen des Aufbruchs. Romanautorinnen und ihre Heldinnen in der Weimarer Zeit. In: Gisela Brinker-Gabler (Hg.): Deutsche Literatur von Frauen. Bd. 2: 19. und 20. Jahrhundert. München 1988, S. 220235, hier S. 224 f.; zu ihrer Karriere als Schriftstellerin Karin Tebben: „Gott im Himmel! Welche Aufgabe!“ Vom Glück der Berufung und der Mühsal des Berufs. Gabriele Reuter (1859-1941). In: K. T. (Hg.): Beruf Schriftstellerin. Schreibende Frauen im 18. und 19. Jahrhundert. Göttingen 1998, S. 276-310.

92 Gabriele Reuter: Vom Kinde zum Menschen. Geschichte meiner Jugend. Berlin 1921, alle Zitate S. 432.

93 Reuter: Vom Kinde zum Menschen, S. 434. 
Nicht um sie zu ändern oder um zu helfen, daß so viel wertvolles Menschenmaterial [!] nicht nutzlos mehr geistig und physisch zugrunde gehe. Denn ich will offen bekennen, daß ich damals durchaus keinen Weg sah, um die Tausende von Mädchen, die im Bürgertum und Adel rein für die Ehe und den Mann erzogen wurden und ihn, den Erfüller ihrer Existenz, doch nie bekamen, irgendwie in gesündere Bahnen tätigen Lebens zu bringen. ${ }^{94}$

Die Rezeption des Romans als Beitrag zur ,Mädchenfrage', als Kritik an damit verbundenen Gegebenheiten und dergleichen, und die Applikationen, waren also, zumindest ihrer eigenen Aussage nach, nicht intendiert.

Schon zu einem früheren Zeitpunkt, fünf Jahre nach Erscheinen des Romans, hatte sie geschrieben, dass er ,weder ein Erziehungs- noch ein Tendenzbuch“ sei, schon allein, weil sie bei dessen Konzeption „den ,Frauenfragen“ noch ganz fern" gestanden habe..$^{95}$ Die anders geartete Rezeption und Wirkung des Romans nahm sie nach eigener Aussage allerdings schon damals zur Kenntnis: „Aber schon während ich [...] das Buch beendete, fühlte ich ja, daß das Motiv in eine Bewegung, die in der Luft vibrierte, hineinklang, sich mit den Klagen aus vielen Frauenherzen gleichsam zu einem lauten Gesang vermischte und dadurch jene Macht bekam, die das Schicksal seiner stillen schmerzlichen Heldin allein niemals ausgeübt haben würde. " ${ }^{\text {96 }}$ In den späteren Selbstzeugnissen bezeichnete sie die von ihrer Intention abweichende Wirkung des Romans als „gut“. ${ }^{97}$ Zudem verwies sie auf positive Seiten der Wirkung: „Ernste, reife Männer haben mir noch nach Jahren versichert, die Lektüre habe ihr Herzensverhältnis zu ihren Töchtern von Grund auf verändert." "N88 Noch 1928 beharrte sie auf der Aktualität der geschilderten Problematik: „Noch ist die ,gute Familie“ nicht ausgestorben, in der die Töchter hart kämpfen müssen, um ihren Weg

94 Gabriele Reuter: Über die Entstehung meines Romans Aus guter Familie. In: Neue Freie Presse (Wien). Nr. 23033, 28. Oktober 1928, S. 30 f., hier S. 30. Vgl. dazu die Aussage an derselben Stelle: „[I]ch wollte gar nichts mit der Schilderung des Lebens der Agathe Heidling, der typischen jungen Tochter ,aus guter Familie‘, als eben eine sachliche Darstellung eines großen Teiles unseres deutschen Volkes, dessen Not mir gleichberechtigt schien der Not von Prostituierten und Arbeiterkindern, welche damals die Dichter vorzüglich beschäftigten.“ In einem frühen Beitrag, noch vor Erscheinen des Romans, gab sie zu verstehen, vor allem „wahre Kunst“ schaffen zu wollen - Gabriele Reuter: Mein liebes Ich. Skizze. In: Die Gesellschaft. Monatsschrift für Litteratur, Kunst und Sozialpolitik. H. 3, März 1892, S. 283-285. Zitiert nach Mellmann: Dokumente, S. 574.

95 Gabriele Reuter: Im Spiegel. Autobiographische Skizzen. V. Gabriele Reuter. In: Das litterarische Echo. Jg. 3, H. 9, Februar 1901, Sp. 592-596, hier Sp. 595.

96 Reuter: Im Spiegel, Sp. 595.

97 Reuter: Vom Kinde zum Menschen, S. 434.

98 Reuter: Vom Kinde zum Menschen, S. 474. Vgl. dazu die anschließenden Aussagen, S. 474 f., und ähnlich Reuter: Über die Entstehung meines Romans Aus guter Familie, S. 30 f. 


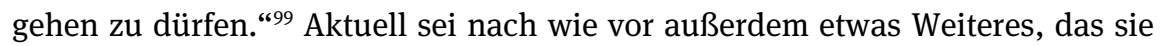
anhand der Protagonistin deutlich machen wollte: „Es wird immer zarte, empfindliche Agathen-Seelen geben, denen kein Wandel der Erziehung, der Anschauung zu helfen vermag - Seelen, die nur im Vollkommenen Befriedigung zu finden vermöchten und sich an der Unerfüllbarkeit ihres Verlangens verbluten. Auch von ihnen steht manches heimliche Wort in dem Buche. “100

Eine weitere alternative Applikation bestand darin, den Roman in einem weiterreichenden emanzipatorischen Sinne zu lesen. Er wurde nicht als ein Anlass zu moderaten Reformen gesehen, sondern es wurde angenommen, dass er in eine grundsätzlich andere Richtung weise. In einer Rezension wurde zustimmend festgestellt, dass der Roman ,das Weib unserer Tage [zeigt], das in dem Kampfe des Tages Schulter an Schulter mit dem Manne stehen, das die Rednertribüne und den Dozentensitz erobern will““ ${ }^{101}$ Der Rezensent sah in der Protagonistin eine Frau, die für ein Streben nach Gleichberechtigung im öffentlichen und politischen Bereich („Rednertribüne“) und nach der Ausübung bisher verwehrter Berufe („Dozentensitz“) steht. Er brachte den Roman folglich in Verbindung mit den Forderungen des radikaleren Teils der Frauenbewegung.

In die gleiche Richtung scheint eine andere Rezension zu gehen, die neben Reuters Roman Lou Andreas-Salomés Ruth und Helene Böhlaus Der Rangierbahnhof behandelt. Über die Protagonistin in Reuters Roman heißt es, sie sei „nur auf das eine gedrillt, einmal eine tüchtige Hausfrau zu werden; sie will das Ziel wenigstens erreichen“. ${ }^{102}$ Der Roman, so der Rezensent, „mahnt andere Wege einzuschlagen“ “. ${ }^{103}$ Damit könnte nur die Notlösung gemeint sein für den Fall, dass das eigentliche Ziel, Ehe und Mutterschaft, nicht erreicht wird. Zusammenfassend stellt er mit Blick auf alle drei Romane fest: „Es ist eine Kluft entstanden zwischen den berechtigten Wünschen des einzelnen auf Schicksalsführung und der Schicksalsfügung andererseits, die die moderne Gesellschaft schafft. Dem Wunsch auf Freiheit der Arbeit entspricht nicht einmal eine Erziehung zur Arbeit.“104 Zugleich ist er der Ansicht, alle drei Romane zeigten den „Entwicklungsgang des Mädchens, das seinen Zweck nicht mehr in dem Lieben und Geliebtwerden sieht“; ein Umstand, den er als realistische Alternative zu den verfehlten Idyllen in Familienblattromanen à la Marlitt vorbehaltlos be-

99 Reuter: Über die Entstehung meines Romans Aus guter Familie, S. 31.

100 Reuter: Über die Entstehung meines Romans Aus guter Familie, S. 31.

101 Pauli: Frauen-Litteratur, S. 369.

102 Heilbronn: Frauenantworten auf Frauenfragen, S. 387.

103 Heilbronn: Frauenantworten auf Frauenfragen, S. 387.

104 Heilbronn: Frauenantworten auf Frauenfragen, S. 390. 
grüßt: „Die Zeiten sind vorbei, in denen man ein Frauenschicksal von Amors lächelnden Gnaden abhängig sah. " ${ }^{105}$ Die Freiheit, einen Beruf zu ergreifen und zu arbeiten, scheint er als genuine Alternative zur überkommenen Lebensführung anzusehen und Reuters Text als einen, der zeigt, wie notwendig und wünschenswert derlei ist.

Wiederum sehr deutlich ist die konsequent emanzipatorische Applikation des Romans in einem Vortrag, den Paul Bergemann vor dem für weitreichende emanzipatorische Forderungen stehenden Verein Frauenwohl hielt. Er sprach über Konventionen und Vorurteile, die Frauen auf den häuslichen Bereich beschränken und ihnen darüber hinausgehende Tätigkeiten verbieten, zumal die Mitarbeit ,an den grossen und grössten Aufgaben des Lebens“. Die Protagonistin stehe für einen ersten und unvollkommenen Schritt in Richtung auf eine Loslösung von diesen Konventionen: „Agathe ist eine werdende Frau noch ganz im Anfangsstadium des Werdens. Eine Frau, die nur den ersten kleinen, schüchternen Schritt auf das Morgen zu zu thun wagt[.] Sie ist eine von den vielen, deren Kraft, deren Energie von dem Drucke ererbter Vorurteile noch zu stark belastet, zu sehr gelähmt ist, um sich davon befreien zu können." ${ }^{106}$ Sie stehe also stellvertretend für Frauen, die sich von Konventionen lösen wollten, es aber (bisher) nicht konnten.

Ein weiterer Gesichtspunkt ist die Frage der Sexualität. Er ist zu erwähnen, weil er, wie gesehen, sachlich mit der Frauenbewegung und emanzipatorischen Forderungen verbunden ist. In einem Nachruf auf Gabriele Reuter vermittelte der Verfasser 1942 den Eindruck, die gesellschaftliche Entwicklung mit Blick auf Erziehung, Bildung und berufliche Tätigkeit von Frauen sei mittlerweile soweit fortgeschritten, „daß die Gute Familie in dieser Hinsicht ein Kulturbild abgeschlossener der Vergangenheit überantworteter Epochen darstellt“. ${ }^{107}$ Die ,Mädchenfrage، hielt er also für nicht mehr aktuell. Als nach wie vor unbeantwortet betrachtete er allerdings die durch den Roman in seiner Wahrnehmung nur im Ansatz aufgeworfene „Frage nach der Existenzberechtigung eines Geschlechtslebens der unverheirateten Frau“ und „die Frage nach der Erfüllung seines Sinnes und Zweckes, auch außerhalb der Ehe“. ${ }^{108}$ Bezogen auf die Lebenswelt, ermöglicht der Roman weiterhin eine Applikation: Er verweist auf ein nach wie vor ungelöstes Problem. Derlei wurde in der zeitgenössischen Rezeption weit-

105 Heilbronn: Frauenantworten auf Frauenfragen, S. 386 und 390.

106 Bergemann: Die werdende Frau in der neuen Dichtung, S. 8 und 9.

107 E[rnst] Gottlieb: Gabriele Reuter t. In: Die Frau. Monatsschrift für das gesamte Frauenleben unserer Zeit. Bd. 49, H. 5/6, Februar/März 1942, S. 86-89, hier S. 87.

108 Gottlieb: Gabriele Reuter †, S. 88. 
gehend ignoriert oder nur angedeutet, zumindest zum Teil wohl aus Dezenzgründen. ${ }^{109}$ Das Sexualleben der Frau wurde weitgehend tabuisiert, insbesondere der Geschlechtsverkehr nicht verheirateter Frauen. ${ }^{110}$ In psychologischen Arbeiten wurde der Roman als Beispiel angesehen für die negativen psychischen Folgen, welche eine verfehlte Sexualerziehung oder die Unterdrückung des Geschlechtstriebes haben könne. ${ }^{111}$

Eine weitere Gruppe ist gegen Applikationen gerichtet, die den Roman in Verbindung mit der Mädchenfrage sehen und mit damit im Zusammenhang Stehendem sowie gegen emanzipatorische Applikationen wie die eben behandelten. Die Gruppe gewinnt durch diese ablehnende Haltung Kontur, weist aber in positiver Hinsicht einen gemeinsamen Nenner auf: Der Roman zeige ein individuelles Schicksal, verdeutliche eine charakterliche Tragik, präsentiere eine Figur, die an den Unzulänglichkeiten menschlicher Existenz leide. Bisweilen boten ihre Vertreter alternative Applikationen an. Ein Beispiel dafür wurde oben bereits erwähnt. An der Protagonistin zeige sich die letztlich zeitlose Tragik, anders zu sein als andere Menschen; wolle man überhaupt eine „Nutzanwendung“ von dem Gelesenen machen, dann bestehe sie darin, zu verdeutlichen, worin wirkliches weibliches Glück wesensmäßig bestehe, nämlich in Liebesehe und Mutterschaft. In die gleiche Richtung ging eine geistesgeschichtliche Les-

109 Vgl. z. B. Formulierungen wie „ein manchmal erschreckend wahres Bild der guten und bösen Instincte, die aus dem modernen, nervösen Kinde ein Problem machen, das von unseren Sittenschilderern viel $\mathrm{zu}$ wenig und mit viel zu geringem Ernste studirt wird“ ([Anon.]: Ein neues Buch, S. 328) oder „Psychologie des reifenden jungen Mädchens“ (Ettlinger: [Rezension von Reuter: Aus guter Familie], S. 346), welche Sexualität zumindest anzudeuten scheinen.

110 Vgl. dazu Frevert: Frauen-Geschichte, S. 128 und 132.

111 Vgl. Helene Simon: Zwei Bücher zur Psychologie des Weibes. In: Die neue Zeit. Revue des geistigen und öffentlichen Lebens. Jg. 16, Bd. 1 (1898), Rubrik „Frauenfrage“, S. 367-372. Zitiert nach Mellmann: Dokumente, S. 420-430, hier S. 430; Grete Meisel-Hess: Die sexuelle Krise. Eine sozialpsychologische Untersuchung. Jena 1909, S. 18 f. Zitiert nach Mellmann: Dokumente, S. 511 f.; Siegmund Freud: Zur Dynamik der Übertragung. In: Zentralblatt für Psychoanalyse. Jg. 2, H. 4, Januar 1912, S. 167-173. Zitiert nach Mellmann: Dokumente, S. 540. Gerade Fragen der Sexualität in Verbindung mit psychischen Problemen haben das Interesse der Forschung gefunden, vgl. dazu Annette Kliewer: „Sich selbst den Boden unter den Füßen wegziehen“. Weiblicher Wahnsinn bei Gabriele Reuter und Hedwig Dohm. In: Freiburger Frauenstudien 1 (1995), S. 43-59; Lilo Weber: „Fliegen und Zittern“. Hysterie in Texten von Theodor Fontane, Hedwig Dohm, Gabriele Reuter und Minna Kautsky. Bielefeld 1996, zu Reuters Roman S. 196240; Karin Tebben: Literarische Intimität. Subjektkonstitution und Erzählstruktur in autobiographischen Texten von Frauen. Tübingen/Basel 1997, S.133-178. Es wurde des Weiteren vorgeschlagen, dass die Protagonistin an Melancholie leide, vgl. Lisabeth M. Hock: Shades of Melancholy in Gabriele Reuter's Aus guter Familie. In: The German Quarterly 79 (2006), S. $443-$ 464. 
art, wonach der Roman ahistorisch und ohne Bezug auf die soziale Wirklichkeit die Unvollkommenheit der Welt exemplifiziere: „Ein Unding aber ist es, in dieser Leidensgeschichte eine soziale Anklage zu finden und gar eine frauenbewegliche Polemik herauszudestillieren. Ein trübes Menschenlos stellt sie dar: ein neues Beweisstück für die Unzulänglichkeit dieser besten Welt. “112 Stärker auf die Figur der Protagonistin bezogen, ist von der „Tragödie der ewig unbefriedigten, unerfüllten Lebenssehnsucht des Weibes“ die Rede oder von der „Tragödie unbefriedigter Mädchensehnsucht“. ${ }^{113}$

Der Roman konnte als Illustration eines abstrakten moralischen Dilemmas verstanden werden: Er verdeutliche die „Unmöglichkeit, in unserer Welt unbedingt wahrhaft vor sich und andern zu sein“. Zugleich sei er als pädagogische Aufforderung zu verstehen, die eigene Persönlichkeit aus sich selbst heraus zu bilden, da die innere Bildung gegenüber der äußeren Erziehung zu bevorzugen sei:

Gerade in einer Zeit, die der Erziehung von außen her so unheimlich viel zutraut, die den geheimnisvollen inneren Mächten und Anregungen so wenig Raum gönnt und Gewicht beilegt, hat das Buch eine ernste Mission zu erfüllen: Daß alle Anlernerei eitel und daß, was der Mensch an inneren Gütern sich selbst giebt, das Wertvolle und Bleibende ist. Das Buch bedeutet eine fortwährende Mahnung und eine stete Aufforderung, sich selbst klar zu werden und an seiner inneren Befreiung zu arbeiten. Und das ist das Pädagogische an der Sache. ${ }^{114}$

Es würde zu weit führen, eine solche Aussage geistesgeschichtlich einzuordnen, wohl in die Geschichte des deutschen Idealismus und deutscher Bildung. Deutlich dürfte jedenfalls sein, dass eine Applikation vorliegt, welcher der Rezensent einige Bedeutsamkeit zumisst: Die „Kulturthat“ und „ernste Mission“ des Ro-

112 Olden: Die Leiden der jungen Agathe, S. 384.

113 Krause: Gabriele Reuter, S. 325 und 333. Es kann nicht ausgeschlossen werden, dass Reuter bei ihren späteren Aussagen über den Roman auf Stellungnahmen wie die von Olden und Krause zurückgriff, mit denen ihre eigene Sicht auf den Roman manche Gemeinsamkeiten hat. Die Publikation von Olden findet sich in ihrem Nachlass. Sie zitierte zustimmend eine Einschätzung von Thomas Mann, der in Agathe eine „Künstlerseele“ gesehen habe, „die gefangen im Bürgerlichen sitzt und sich hinaus in die Freiheit sehnt, aber nicht die Kraft hat, sich die Freiheit selbsttätig zu erringen“ - Reuter: Vom Kinde zum Menschen, S. 434. Vgl. dazu Thomas Mann: Gabriele Reuter. In: Th. M.: Große kommentierte Frankfurter Ausgabe. Werke - Briefe Tagebücher. Bd. 14.1: Essays I. 1893-1914. Hg. von Heinrich Detering. Frankfurt a. M. 2002, S. 61-72, v. a. S. 66.

114 Beringer: Aus guter Familie, S. 402. 
mans bestehe darin, dem Publikum deutlich zu machen, dass die individuelle Bildung Vorrang haben soll vor der Sozialisation. ${ }^{115}$

Gegen die weiterreichenden Forderungen eines Teils der Frauenbewegung sind ferner Positionen gerichtet, welche die mit der ,Mädchenfrage“ verbundenen Implikationen anerkennen, aber im Rahmen der moderateren Forderungen der bürgerlichen Frauenbewegung bleiben. Schuld am Schicksal der Protagonistin seien, so wurde angenommen, nicht die sozialen Verhältnisse, sondern „die Ungerechtigkeit, welche die Natur selbst am Weibe begeht“, also letztlich vermeintliche biologisch beschreibbare Tatsachen. Folglich sollten „die Gesetzgeber mehr und mehr darauf hinarbeiten [...], dem Weibe gerecht zu werden, ohne dasselbe - wie es die Frauenbewegungen so häufig thun - zur Unnatur zu treiben“. ${ }^{116}$ Der Roman bediene „[k]ein einziges der Schlagworte moderner Frauenbewegung, Berufswahl, politische Gleichstellung der Geschlechter, Erwerbsthätigkeit der Frau“. Reuter selbst sei vielmehr davon überzeugt, dass „die volle Entfaltung der weiblichen Persönlichkeit nur in einer glücklichen Ehe denkbar ist“. Die „Tendenz des Buches“ bestehe darin, dass der Protagonistin aufgrund ihrer verfehlten Erziehung nach dem Scheitern ihrer eigentlichen Pläne keine Alternative zu Verfügung steht und ihr dadurch „ein erfreuliches und befriedigendes Dasein“ versagt wird. ${ }^{117}$

\subsubsection{Die Applikationen und der Text}

Die zeitgenössische Applikation von Reuters Roman war vielfältig. Es gab jedoch, wie gesehen, einen klaren Fokus auf die ,Frauen-“ oder ,Mädchenfrage“ und zugehörige Applikationen. Daneben konnte eine kleinere Gruppe von Applikationen ausgemacht werden, welche den Roman in einem weitergehenden emanzipatorischen Sinne auffasste, und eine ebenfalls kleinere Gruppe, die jegliche Bezüge auf die geschlechtergeschichtlichen Gegebenheiten ablehnte und stattdessen, vereinfacht gesagt, ahistorische und von sozialen Bezügen losgelöste Applikationen vornahm, wonach der Roman etwas über das Individuum, insbesondere das weibliche, aussage. Dieser Gruppe lässt sich die intendierte Applikation der Autorin zuordnen. In den verschiedenen Applikationen dokumentiert sich ein unterschiedlicher Umgang mit dem Gelesenen und zuweilen ein unterschiedliches Verständnis.

115 Beringer: Aus guter Familie, S. 407.

116 [Anon.]: Literarische Notizen, S. 419.

117 Lisco: [Rezension von Reuter: Aus guter Familie], S. 396. 
Was die Beschaffenheit des Textes hinsichtlich seiner Eignung für Applikationen dieser Art angeht, so ist festzustellen, dass nicht explizit gesagt wird, was die charakterliche Entwicklung der Protagonistin und den Gang der auf sie bezogenen Handlung in den einschlägigen Gesichtspunkten motiviert. Gleiches gilt für die Bewertung des Geschehens, selbst wenn der Erzähler verschiedentlich eine ironische oder sarkastische, jedenfalls negative Perspektive auf das Geschilderte entwirft. Wenn im Folgenden nach der Passung der identifizierten Applikationen mit dem Text gefragt wird, kann die Darstellung von Befunden nur exemplarisch geschehen.

Aus darstellungstechnischen Gründen bietet es sich an, mit der Auffassung $\mathrm{zu}$ beginnen, wonach es in dem Roman letztlich um eine charakterliche Tragik gehe, auch eine vermeintlich spezifisch weibliche oder im Zusammenhang mit den Unzulänglichkeiten der Welt stehende. Der Roman gewährt bereits in den ersten, expositorischen Kapiteln eine Reihe von Einblicken in die psychische Disposition der Protagonistin. Zu Beginn wird ihre Konfirmation geschildert, bei welcher sie Gewissensbisse (das Konfirmationsbekenntnis als „Meineid“ und „untilgbare Sünde“, S. 12) und Unsicherheit („Versuchte sie der Teufel?“, ebd.), Hochmut („hochmütige[] Mißachtung“ der Mitkonfirmandinnen, S.13) und Schwärmerei (,schmachtendes Begehren nach der geheimnisvollen Vereinigung“ mit Jesus Christus im Abendmahl, S. 14) an den Tag legt. ${ }^{118}$ Die Zeit zwischen der Konfirmation und der ersehnten Heirat betrachtet sie als „Noviziat“, häusliche Aufgaben erledigt sie „mit froher Andacht“ (S. 53). Ihr Dasein begreift sie als selbstlose und aufopferungsvolle Vorbereitung auf den idealen Partner:

Ach ja - so recht praktisch, liebevoll, aufopferungsfreudig und dabei gescheut und von gediegener Bildung! Um das zu erreichen, mußte man sich schon tummeln! Alles, alles für ihn - den geliebten, herrlichen, zukünftigen Unbekannten! - Für sich allein, nur aus Freude an den Dingen - nein, das wäre doch Selbstsucht gewesen! Und es war ja auch so schön, so süß, für andere zu leben. (S. 55)

Sie erscheint mithin als Figur, die bemüht ist, die an sie gestellten Erwartungen zu erfüllen, und hehre Ideale vertritt, die allerdings an der Wirklichkeit scheitern. Das gilt insbesondere für ihr Liebesideal. Sie fragt sich bisweilen, ob sie vielleicht „nicht zur Ehe bestimmt“ sei, „,sondern aufbewahrt für ein seltsames, romantisches, schauervolles Schicksal“ (S. 74). Sie beginnt „ein sonderbares Traumleben“ (S. 76), in dem sie sich als Geliebte von Lord Byron (!) imaginiert

118 Nachweise im Folgenden stets unmittelbar im Anschluss an das Zitat nach dieser Ausgabe: Gabriele Reuter: Aus guter Familie. Leidensgeschichte eines Mädchens. Bd. I: Text. Hg. von Katja Mellmann. Marburg 2006. 
(vgl. z. B. S. 77). Eine ähnliche Liebe hegt sie später für einen Künstler, Adrian von Lutz (vgl. z. B. S. 95 f.). Bezeichnenderweise ist die irreale schwärmerische Liebe dafür verantwortlich, dass sie einen nichtgenannten möglichen Heiratskandidaten zurückweist: „[E]r sollte sich nicht mit seinen Träumen in den Zauberkreis wagen, der um sie und den Einen gezogen war, dem ihr Herz gehörte“ (S. 119). Ähnlich exaltiert stellt sich ihre Religiosität dar, die an mehreren Stellen in der Handlung zum Tragen kommt (vgl. neben der Eingangsszene z. B. S. 157-167; später tritt sie zurück, vgl. S. 192-195, und schlägt dann in Ablehnung um, vgl. S. 198 und 209.).

Verschiedentlich wird herausgestellt, dass sie sich nicht eigne für die mit ihrer Rolle verbundenen sozialen Verpflichtungen. Das wird besonders deutlich bei ihrem ersten Ball, wo sie zunächst nicht aufgefordert wird und sich in ihrer Rolle unwohl fühlt (vgl. v. a. S. 66-68). Später lernt sie zwar „die Technik ihres Berufes als junge Dame der Gesellschaft endlich, wenn auch schwerer als ihre Freundinnen“, zu beherrschen (S. 114). Der Erzähler schränkt die Aussage im Folgenden allerdings ein und erklärt, sie sei „nun einmal keine von den einfachen Mädchen, deren inneres Wesen genau in die Schablone der frischen Tänzerin paßt“ (ebd.). Innerlich lehnt sie derartige Veranstaltungen ab: „Die Bälle und Gesellschaften waren ihr eine Qual.“(S. 165)

Aufschlussreich sind die Fremdcharakterisierungen. Ihre Mitschülerinnen halten sie für „prüde“ (S. 45), ebenso ihr Cousin Martin Greffinger (vgl. S. 255). Ihre Freundin Eugenie nennt sie eine „Tugendheuchlerin“ (S. 40) und spottet über die „keusche Agathe“ (S. 56). Ein aufgrund einer Erkrankung hinzugezogener Spezialarzt stellt fest, sie sei „sehr eindrucksfähig“ (S. 149) und „sehr sensibel“ (S. 151). Die Einschätzung wird durch die Wiedergabe eines Gedankenberichts bestätigt, in welchem die Protagonistin sich fragt: „Warum war sie so entsetzlich sensitiv gegen alle Unvollkommenheiten?“ (S. 163) Ein gutes Beispiel dafür ist die Aufklärung über Fortpflanzung durch ihre Freundin Eugenie in Kindertagen. Agathe reagiert mit Abscheu und Scham (vgl. S. 31). Die Episode hinterlässt bei ihr einen bleibenden Eindruck (vgl. S. 35 f.), der so groß ist, dass der Erzähler sie noch als Erklärung anführt im Zusammenhang mit ihrem Zusammenbruch und dem tätlichen Angriff auf die Freundin am Ende des Romans (vgl. S. 267). Gerade Fragen der Sexualität empören sie immer wieder. So verurteilt sie die Avancen ihrer Freundin gegenüber einem Kommis der väterlichen Firma (vgl. z. B. S. 50, aber noch S. 209; zu ähnlichem Verhalten der erwachsenen Eugenie S. 262). Bereits die körperliche Entwicklung ist schambesetzt (,sie schämte sich der ungewohnten Fülle ihrer Formen“, S. 54).

Innerlich scheint sie sich in „heimlich-leidenschaftliche[r] Opposition gegen ihre ganze Umgebung“ zu befinden, so jedenfalls die Beobachtung einer 
Nebenfigur, die aufgrund ihrer Wiedergabe im Rahmen eines Gedankenberichtes des Erzählers als zuverlässig eingeschätzt werden kann (S. 115). In denkbare Alternativen scheint sie sich jedoch nicht finden zu können. Das wird an einer Szene deutlich, in der sie bei einem Kreis von Lehrerinnen zu Besuch ist. Der Erzähler schildert die Episode mit erkennbar wenig Sympathie (vgl. S. 169-174). Agathe sagt im Anschluss, sie sei „schlechter Laune“ und „melancholisch“, weil sie bei „einem Thee mit alten Jungfern“ war (S. 176). Sie erklärt bezeichnenderweise, dass der Versuch, „unser Geschlecht voranzubringen“, sie „abstößt“" (S. 177).

Kurz vor Ende des Romans werden ihre diesbezüglichen Gedanken in einer Weise zusammengefasst, die als Kommentar zur ihrer ganzen Haltung erscheinen und eine gewisse Nähe aufweisen zu Aussagen der Autorin über ihren Roman:

$\mathrm{Da}$ - da - da traf sie ihn wieder, den großen Betrug, den sie alle an ihr verübt hatten - Papa und Mama und die Verwandten und Freundinnen und die Lehrer und Prediger .... Liebe, Liebe, Liebe sollte ihr ganzes Leben sein - nichts als Liebe ihres Daseins Zweck und Ziel .... .... Das Weib, die Mutter künftiger Geschlechter .... Die Wurzel, die den Baum der Menschheit trägt .... Ja - aber erhebt ein Mädchen nur die Hand, will sie nur einmal trinken aus dem Becher, den man ihr von Kindheit an fortwährend lockend an die Lippen hält - zeigt sie auch nur, daß sie durstig ist .... Schmach und Schande! Sünde - schamlose Sünde - erbärmliche Sünde - hysterische Verrücktheit! schreit man ihr entgegen - bei den Strengen wie bei den Milden, den Alten und den Jungen, den Frommen und den Freien. (S. 264)

Sie erlebt also letztlich die Realisierung des von ihr favorisierten Ideals als gefährdet durch das Verhalten ihrer Umwelt.

Es gibt mithin eine Reihe von Indizien, die darauf hindeuten, dass die charakterliche Disposition der Protagonistin ein wichtiger Faktor ist und wesentlich dazu beiträgt, dass sie nicht den vorgeschriebenen Lebensweg gehen kann. Besonders zu erwähnen ist die Freundin Eugenie, die als Kontrastfigur fungiert. Sie erweist sich als gut vorbereitet auf „den Kampf des Lebens“ (S. 56) und gibt an der Seite von Agathes Bruder Walter, den sie heiratet, „das Muster der deutschen Offiziersfrau“ ab (S. 111). Allerdings wirft der Befund sogleich die Frage nach der Genese dieser Persönlichkeit auf. Sie führt direkt zur Rolle des Umfeldes und verweist auf die Erziehung der Protagonistin und überhaupt das Verhalten der anderen Figuren. Dass es sich um gleichermaßen wichtige Faktoren handelt, wird im Text selbst nahegelegt. Eine solche Sicht ist nicht anachronistisch. Sie war vielmehr zeitgenössisch möglich, ja sie drängte sich aufgrund der Gegebenheiten geradezu auf, wenn man bedenkt, dass der Roman in der Zeit des Naturalismus geschrieben und publiziert wurde. In der Sache ist außerdem 
festzuhalten, dass der Hinweis auf charakterliche Faktoren als Einwand gegen die Rolle von Erziehung und Gesellschaft nur bedingt stichhaltig ist. Selbst wenn man anerkennt, dass es im Falle der Protagonistin vor allem individuelle Faktoren sind, die zu ihrem Scheitern führen, bleibt davon doch die Aussage unberührt, dass eine anders geartete Erziehung und überhaupt ein anderer Umgang mit ihr, zumindest mit einer gewissen Wahrscheinlichkeit, nach dem Scheitern der Heiratspläne ein anderes Leben ermöglicht hätte.

Dass der Roman aufgrund seiner Beschaffenheit ein hohes Maß an Eignung aufweist, mit der ,Mädchenfrage“ in Verbindung gebracht zu werden, hat schon die bisherige Forschung zeigen können: „Während der erste Teil vom Scheitern der vorgesehenen Lebensbahn erzählt, widmet sich der zweite Teil einer listenmäßigen Abarbeitung nahezu aller denkbaren Alternativen zur vorbestimmten Laufbahn als ,Hausfrau, Gattin und Mutter‘, die der Diskurs um die ,Mädchenfrage‘ aufbietet." ${ }^{119}$ Eine Nebenfigur wie Agathes Cousine Mimi Bär zum Beispiel wird Diakonissin (vgl. S. 140 f. und 226-228). Bereits bei der Schilderung der Konfirmation am Beginn des Romans wird deutlich, wie sehr die Protagonistin Adressatin von erzieherischen Ermahnungen und Belehrungen ist: „Ein jeder gab dabei noch in der Kirchthür dem Mädchen ein wenig Anleitung, wie sie sich dem kommenden Leben gegenüber als erwachsene Frau zu verhalten habe.“ (S. 15) Ihr Vater, der Regierungsrat Heidling, hält eine Tischrede über die „Pflichten der Staatsbürgerin“ und sagt unter anderem: „[D]as Weib, die Mutter künftiger Geschlechter, die Gründerin der Familie, ist ein wichtiges Glied der Gesellschaft, wenn sie sich ihrer Stellung als unscheinbarer, verborgener Wurzel recht bewußt bleibt.“ (S. 21) Der Erzähler kommentiert derartige Einlassungen als „rednerische Phrasen“ (S. 19). Eine besondere Rolle spielt ein Ratgeber, Des Weibes Leben und Wirken als Jungfrau, Gattin und Mutter, der verschiedentlich erwähnt wird (vgl. S. 17, 52 f. und 60 f.).

Agathes Mutter, durch mehrere Wochenbetten und den Verlust der Säuglinge gezeichnet, scheint mit der Erziehung ihrer Tochter überfordert zu sein. Mit deren Wissensdurst kann sie nicht umgehen und hält ihre Tochter für „schrecklich lebhaft und exaltiert“ (S. 36). Sie entschließt sich, Agathe in eine Pension zu geben (vgl. S. 37). Der erste Ball wird erkennbar als Veranstaltung geschildert, bei welcher ein erheblicher sozialer Zwang herrscht (vgl. S. 63-65 und die dort verwendete Kriegsmetaphorik) und man sich situativ verstellt (vgl. S. 70). Agathe wird mit nutzlosen Hausarbeiten beschäftigt. Nur innerlich lehnt sie sich auf gegen „Gardinenkanten häkeln und Deckchen sticken“ (S. 198). Die Nutzlosigkeit derartiger Aktivität kommt insbesondere darin zum Ausdruck,

119 Mellmann: Die Mädchenfrage, S. 23. 
dass sie allabendlich den Teppich im Wohnzimmer abbürsten und zusammenrollen muss, um die Farbe zu schonen:

Jeden Abend weinte Agathe ein paar heimliche Thränen auf den Teppich - sie fand es so mesquin und völlig unnötig und unpraktisch ihn fortwährend zusammenzurollen und wieder auseinanderzubreiten. $\mathrm{O}$ das Leben war langweilig - langweilig - langweilig, in dieser Fülle von zweckloser Arbeit! (S. 213)

Als sich abzeichnet, dass sie keinen Mann finden wird, behandeln ihre Eltern sie weiterhin als unmündiges ,Mädchen“. Das zeigt sich exemplarisch in einer Episode, in welcher sie Ernst Häckels Natürliche Schöpfungsgeschichte aus dem Bücherschrank des Vaters liest und sich daraufhin zu Weihnachten naturwissenschaftliche Werke wünscht. Stattdessen erhält sie Die Flora Mitteldeutschlands und eine Blumenpresse. Ihr Vater verbietet ihr die Lektüre solcher Schriften und verschließt forthin seinen Bücherschrank vor ihr (vgl. S. 215-219). Die Entscheidungen über sie treffen bis zuletzt andere. Als sie kurz vor Ende der Handlung Weinkrämpfe und Zornesausbrüche bekommt, entscheidet man gegen ihren Willen, dass sie einen Kurort aufsuchen soll (vgl. S. 257-260).

Für das Schicksal der Protagonistin sind darüber hinaus Ereignisse mitverantwortlich, die zunächst zufällig erscheinen mögen, jedoch auf milieuspezifische Probleme verweisen. Ihr Bruder wird eindeutig bevorzugt. Da er Offizier werden will, muss sich die Familie finanziell einschränken (vgl. z. B. S. 61). Um dessen Spielschulden zu bezahlen, verwendet ihr Vater das Geld, das eigentlich für ihre Mitgift vorgesehen war, sodass eine geplante Heirat nicht zustande kommt (vgl. S. 189). An ihrem Wohlergehen ist ihrem Vater wenig gelegen (vgl. z. B. S. 230). Zudem zeigt sich anhand des Bruders eine erhebliche Doppelmoral. Er vergewaltigt das Dienstmädchen (vgl. S. 79-85), das später aufgrund einer vorehelichen Schwangerschaft entlassen wird und vermutlich als Prostituierte stirbt (vgl. S. 196, 199-207). Bezeichnend ist ein Kommentar des Vaters: „Kein gefallenes Mädchen richtet sich wieder auf [...]. Wahrscheinlich hätte alles nichts genutzt, was für das kleine Hausmädchen geschehen konnte - also nur schnell und ordentlich in den Schlamm hinunter.“ (S. 209) Da die Rezipient/innen über den von seinem Sohn am Dienstmädchen verübten sexuellen Missbrauch informiert sind, ergibt sich eine Diskrepanz zwischen vermeintlicher Unmoral des Dienstmädchens und tatsächlicher Unmoral des Sohnes. Schließlich wird gesagt, dass es sich bei dem, was der Protagonistin widerfährt, um ein weitverbreitetes Phänomen handelt. Nach der Ankunft im Kurort ist von „Hunderten“ von Frauen die Rede, deren eine Hälfte „die bleichen, vom Nichtsthun, von Sehnsucht und Enttäuschung verzehrten Mädchen“ ausmachen (S. 261). 
Es gibt daher starke Indizien dafür, dass die Erziehung und überhaupt das Milieu einer preußischen Beamtenfamilie eine wesentliche Rolle spielt und die Protagonistin bei anderer Erziehung und anderem Umgang mit ihr ein anderes Leben hätte führen können. Letztendlich bleibt aber offen, ob in diesem Einzelfall charakterliche Dispositionen, die unabhängig von der Sozialisation und den Umständen vorhanden sind, den Ausschlag geben, oder Erziehung und Milieu. Das ist am Ende weniger eine Sache des Romans, in dessen Textwelt der Sachverhalt nicht explizit motiviert wird, sondern der lebensweltlichen Annahmen. Entscheidender sind also die lebensweltlichen Überzeugungen, mit denen das Gelesene in Verbindung gebracht werden kann. Darin dürfte hier und bei anderen literarischen Texten das besondere Interesse bestehen. Ein gewisses Maß an ,Offenheit‘ in einer zentralen Frage, hier der Frage, was genau den Ausschlag gibt hinsichtlich der Genese des Charakters der Hauptfigur und des damit verbundenen Ganges der Handlung, ist Anlass dazu, das Gelesene auf eigene Erfahrungen und Überzeugungen $\mathrm{zu}$ beziehen und $\mathrm{zu}$ applizieren.

Belege für die weiterreichenden emanzipatorischen Applikationen lassen sich im Text nur bedingt finden. Die Möglichkeit scheint insbesondere kurz vor Ende der Handlung auf, als Agathes Cousin Martin ihr bei ihrem Aufenthalt in der Schweiz begegnet, wo er im Exil lebt, weil er sozialdemokratische Ansichten vertrat. Er schlägt ihr vor, ihren Vater zu verlassen und sich „Arbeit und Freude“ zu suchen, die sie „befriedigt“ (S. 241). Dazu bietet er ihr an, mit ihm nach Zürich zu gehen, ihm bei seiner Arbeit zu helfen und erste Schritte auf dem Weg in ein selbstbestimmtes Leben zu gehen (vgl. S. 244-247). Er erklärt sogar explizit: „Du fängst ja schon an, Dich zu emanzipieren“ (S. 247). Zum ersten Mal überhaupt berichtet sie jemandem von ihren Leiden. Das veranlasst ihn zu dem Vorschlag, sie möge ihre Erfahrungen aufschreiben und publizieren:

\footnotetext{
Sag' Deinen lieben Mitschwestern nur ehrlich und deutlich, wie ihr Leben in Wahrheit beschaffen ist. Vielleicht bekommen sie den Mut, es selbst in die Hand zunehmen, statt sich von ihren Eltern und der Gesellschaft vorschreiben zu lassen, wie sie leben sollen, und dabei kranke, traurige, hysterische Frauenzimmer zu werden, die man mit dreißig Jahren am liebsten alle miteinander totschlüge. $\mathrm{Na}$ - lockt Dich das nicht? mitzuarbeiten für das Recht der Persönlichkeit? (S. 250)
}

Zunächst erscheint Agathe davon sehr angetan und sieht in dem Vorschlag eine „Befreiung“: „Etwas Werdendes ... Ein Kind - oder ein Werk - meinetwegen ein Wahn, jedenfalls etwas, das Erwartungen erregt und Freude verspricht, mit dem man der Zukunft etwas zu schenken hofft - das braucht der Mensch, und das braucht darum auch die Frau!“ (S. 251) Allerdings kommt es unmittelbar danach aufgrund eines Missverständnisses zum Bruch zwischen den beiden. Agathe hatte nämlich angenommen, er wolle ein Leben mit ihr führen, allerdings erwi- 
dert er ihre Liebe nicht (vgl. v. a. S. 252 und 255). Entsprechende Hinweise bleiben also eher beschränkt, der Text schließt es aber zumindest nicht aus, anhand des Geschilderten zu diesen weiterreichenden lebensweltlichen Schlussfolgerungen $\mathrm{zu}$ kommen, die aufgrund dessen, was im Roman über die Protagonistin berichtet wird, durchaus naheliegen. Falsch ist es allerdings, der Protagonistin emanzipatorische Ansichten zuzuschreiben oder sie als Beispiel dafür zu verwenden, wie es manche der oben zitierten Quellen tun. Dem widerspricht die Konzeption der Figur deutlich.

Es lässt sich festhalten, dass alle drei Gruppen von Applikationen im Prinzip mit Blick auf die Beschaffenheit des Textes erklärt werden können, allerdings mit Unterschieden. Am besten passen Applikationen bezüglich der ,Mädchenfrage،, insofern sie am umfassendsten das im Text Gesagte berücksichtigen. Bei den weiterreichenden emanzipatorischen Applikationen werden aus dem Roman weitergehende Schlüsse gezogen, die vom Text nur selten explizit angeboten, dafür aber nicht ausgeschlossen werden und durchaus plausibel erscheinen. Applikationen mit Blick auf individuelle Tragik passen nur zu einem Teil des Textes und blenden andere Aspekte aus - oder sie erkennen sie aufgrund bestimmter lebensweltlicher Annahmen nicht an, etwa Annahmen über das vermeintliche Wesen der Frau oder letztlich metaphysische Überzeugungen bezüglich des Individuums.

Die Untersuchung des Romans und seiner zeitgenössischen Rezeption zeigt, dass und wie die Applikation relevant war. Reuters Roman ist ein gutes Beispiel für einen Text, bei dem der Bezug auf die Lebenswelt in der Rezeption nicht peripher oder fakultativ, sondern aufgrund der Beschaffenheit des Textes zentral und obligatorisch ist. Er konnte und musste so verstanden werden, dass er etwas mit den zeitgenössischen Verhältnissen $\mathrm{zu}$ tun hatte und erlangte wohl nicht zuletzt dadurch seine Resonanz. In manchen der zitierten Quellen wurde bereits die Frage gestreift, wie andauernd die Relevanz des Romans sei. In einer Quelle von 1928 heißt es dazu:

Kommen die Tatsachen dieses Buches der heutigen Jugend fremd und absurd vor, so ist das ein Beweis dafür, wie gut es war, daß Gabriele Reuter vor dreiunddreißig Jahren den Mut hatte, auszusprechen, was war. Überdenkt die heutige Mädchenjugend mit heiterer Überlegenheit ihre eigene glücklichere Lage, so wäre es recht, wenn sie sich daran erinnerte, daß es vornehmlich die Dichter waren, die ihr den Weg freigemacht haben, und darunter vor allem die prophetische, hellsichtige, mutige Gabriele Reuter. ${ }^{120}$

120 Schwarzwald: Dreiunddreißig Jahre, S. 12. 
Selbst wenn man annähme, dass die Wirkung des Romans sich in der Aktualität des behandelten Themas erschöpfte, bliebe diese Wirkung ein historisches Verdienst. Literaturgeschichtlich betrachtet, handelt es sich jedenfalls um einen wichtigen, ja vielleicht sogar den Normalfall, dass die größte Resonanz eines literarischen Textes in die Zeit seiner Erstrezeption fällt. Die Frage, ob und wenn ja, welche ,überzeitliche‘, von den Gegebenheiten der Entstehung und Erstrezeption relativ unabhängige Wirkung ein literarischer Text haben kann, liegt außerhalb des Fokus der vorliegenden Arbeit. Man kann zugestehen, dass ein Roman wie der von Reuter in manchen Hinsichten tatsächlich so eng mit den Gegebenheiten verbunden ist, dass er in diesen Hinsichten in späteren Zeiten keine Relevanz mehr besitzt. Dass er hingegen überhaupt nicht mehr relevant und applizierbar sein sollte, erscheint allerdings als ein voreiliger Schluss. Gerade die historische Alterität oder, mit den Worten der eben zitierten Quelle, der Umstand, dass die geschlechtergeschichtlichen Verhältnisse einer früheren Zeit einem späteren Publikum „fremd und absurd“ anmuten, kann produktiv wirken und Applikationsmöglichkeiten eröffnen.

\subsection{Thomas Mann: Buddenbrooks (1901)}

Thomas Manns Buddenbrooks dürften einer der größten Erfolge auf dem Buchmarkt in der ersten Hälfte des 20. Jahrhunderts gewesen sein. Zwischen dem Erscheinen 1901 und dem Jahr 1936 sollen rund 1,3 Millionen Exemplare gedruckt worden sein. ${ }^{121}$ Der Autor selbst gab in einem Brief von 1953 die Gesamtauflage mit „anderthalb Millionen“ an. ${ }^{122}$ Maßgeblichen Anteil daran hatte zum einen die günstige ,Volksausgabe‘, welche der S. Fischer-Verlag 1929 herausbrachte, zum anderen der Nobelpreis für Literatur, welchen der zu diesem Zeitpunkt bekannte und etablierte Autor im selben Jahr für die Buddenbrooks erhielt: Waren bis 1929 rund 185.000 Exemplare gedruckt worden, bei einem Schnitt von sechs- bis siebentausend pro Jahr, so wurden von der Volksausgabe binnen weniger Wochen 700.000 Exemplare ausgeliefert. ${ }^{123}$ Über die kontinuier-

121 Vgl. Richards: The German Bestseller in the 20th Century, S. 55.

122 Brief an Louis Leibrich, 5. Februar 1953. Zitiert nach Hans Wysling (Hg.): Dichter über ihre Dichtungen. Bd. 14: Thomas Mann. Teil I: 1889-1917. München/Frankfurt a. M. 1975, S. 30-135, hier S. 128.

123 Vgl. zur Geschichte dieser sogenannten ,Volksausgabe‘ Wilhelm Haefs: Geist, Geld und Buch. Thomas Manns Aufstieg zum Erfolgsautor im S. Fischer Verlag in der Weimarer Republik. In: Michael Ansel/Hans-Edwin Friedrich/Gerhard Lauer (Hg.): Die Erfindung des Schriftstellers Thomas Mann. Berlin/New York 2009, S. 123-159, hier S. 146-153, zu den genannten 
liche und dann exponentiell gestiegene Beliebtheit des Romans beim Publikum äußerte sich Heinrich Mann in einer Rundfunksendung:

\begin{abstract}
Alle wissen, dass Thomas Mann den Roman ,Buddenbrooks' geschrieben hat. Das Buch erschien am Beginn des Jahrhunderts, hatte sofort viele Auflagen und wurde weitergelesen in fast dreissig Jahren von allen einander folgenden Geschlechtern. Vor wenigen Tagen veranstaltete der alte Verlag des Buches eine neue Volksausgabe des alten Buches, und schon im voraus wurden bestellt von Buchhandlungen und Warenhäusern eine Viertelmillion Exemplare. Daran ermesse man die Volkstümlichkeit des Romans! ${ }^{124}$
\end{abstract}

Im Folgenden soll, nach allgemeinen Aussagen zur Rezeption, zu den historischen Gegebenheiten und den zur Verfügung stehenden Quellen (Kap. 4.2.1), eine Applikation dargestellt werden, die in Rezensionen zu finden ist, welche in den ersten Jahren nach Erscheinen des Romans publiziert wurden (Kap. 4.2.2). Diese Applikation wird mit einem nicht realisierten, spezifischeren Applikationspotenzial in Beziehung gesetzt, welches der Roman aufgrund seiner Beschaffenheit und vor dem Hintergrund der zeitgenössischen Gegebenheiten besaß (Kap. 4.2.3). Da Mann sich verschiedentlich zu seinem Roman geäußert hat, erscheint es sinnvoll, seine Selbstaussagen auf intendierte Applikationen hin zu untersuchen (Kap. 4.2.4).

\title{
4.2.1 Zur Rezeption allgemein
}

Die überwiegend autorphilologisch orientierte Forschung zu Manns Romanen und insbesondere den Buddenbrooks hat Fragen der Rezeption durchaus beachtet. Davon zeugen schon allein die Kapitel in den beiden Handbüchern, die es

Zahlen S. 147 und 150. Vgl. zur Publikationsgeschichte und den damit in Verbindung stehenden Faktoren Katrin Bender: Buddenbrooks - Verfall einer Familie. Welterfolg mit Verzögerung. In: Petra Bohnsack/Hans-Friedrich Foltin (Hg.): Lesekultur. Populäre Lesestoffe von Gutenberg zum Internet. Marburg 1999, S. 163-175, und Pia Karst: Thomas Manns Buddenbrooks: Die „erstaunliche Popularität des Geistigen“. Die Hintergründe der Nobelpreisverleihung und der Erfolg der Volksausgabe. In: Walter Delabar/Bodo Plachta (Hg.): Thomas Mann (1875-1955). Berlin 2005, S. 153-167.

124 Heinrich Mann: Thomas Mann [später: Der Nobel-Preis. Gesprochen im Berliner Rundfunk am 12. November 1929]. In: H. M.: Essays und Publizistik. Kritische Gesamtausgabe. Bd. 4: 1926-1929. Teil 1: Texte. Hg. von Ariane Martin. Bielefeld 2018, S. 381-383, hier S. 381. Rückblickend schrieb Thomas Mann, der Roman sei „zu einem der größten deutschen Bucherfolge überhaupt, einer wahren deutschen Hauspostille“ geworden - Thomas Mann: Lebenslauf. In: Th. M.: Gesammelte Werke in zwölf Bänden. Bd. 11: Reden und Aufsätze 3. Frankfurt a. M. 1960, S. 450-456, hier S. 453. 
zum Autor und seinem Gesamtwerk gibt, und in zwei Handbüchern speziell zu den Buddenbrooks. ${ }^{125}$ Die Rezeption, vor allem in Rezensionen, ist zum Teil ausführlich untersucht worden. ${ }^{126}$ Aussagen zu Applikationen des Romans oder solche, die sich so verstehen lassen, dass sie der Sache nach darauf hinweisen, macht die Forschung nicht, die Rezeption des Textes als Schlüsselroman ausgenommen, welche sich dem Umstand verdankt, dass Mann beim Schreiben des Romans verschiedentlich auf eigene Erfahrungen und realweltliche Vorbilder zurückgriff. Über die Erstrezeption des Romans durch manche außerwissenschaftlichen, nichtprofessionellen Leser/-innen, die in den Figuren des Romans reale Personen zu erkennen glaubten, kann in einem Handbuch-Artikel festgestellt werden: „Deren private Lektüre verlief applikativ und ist durch Rezeptionszeugnisse besonderer Art belegt: die bis heute überlieferten Entschlüsselungslisten aus dem Kreis einiger Lübecker Familien. “127 Das ist ein instruktiver

125 Vgl. Hans Wißkirchen: Thomas Manns Romanwerk in der europäischen Literaturkritik. In: Helmut Koopmann (Hg.): Thomas-Mann-Handbuch. Stuttgart ${ }^{3} 2001$, S. 875-924, zu den Buddenbrooks S. 876-888; Andreas Blödorn/Friedhelm Marx (Hg.): Thomas Mann Handbuch. Leben - Werk - Wirkung. Stuttgart/Weimar 2015, S. 373-403, speziell zu den Buddenbrooks S. 20 f.; Gero von Wilpert: Die Rezeptionsgeschichte. In: Ken Moulden/G. W. (Hg.): Buddenbrooks-Handbuch. Stuttgart 1988, S. 319-341; Ken Moulden: Bearbeitungen. In: Moulden/Wilpert: Buddenbrooks-Handbuch, S. 343-347; John E. Fletcher: Übersetzungen. In: Moulden/Wilpert: Buddenbrooks-Handbuch, S. 349-352; Gertrud Maria Rösch u. a.: Die Rezeption. In: Nicole Mattern/Stefan Neuhaus (Hg.): Buddenbrooks-Handbuch. Stuttgart 2018, S. 3973.

126 Vgl. v. a. Hans Wißkirchen: Die frühe Rezeption von Thomas Manns Buddenbrooks. In: Andrea Bartl u. a. (Hg.): „In Spuren gehen ...“. Festschrift für Helmut Koopmann. Tübingen 1998, S. 301-321, und Eckhard Heftrich/Stephan Stachorski: Rezeptionsgeschichte. In: Thomas Mann: Große kommentierte Frankfurter Ausgabe. Werke - Briefe - Tagebücher. Bd. 1: Buddenbrooks. Verfall einer Familie. Roman. Teilbd. 2: Kommentar. Hg. von E. H./St. St. Frankfurt a. M. 2002, S. 118-228. Für eine Arbeit, welche die historischen Gegebenheiten, zumal die politischen, miteinbezieht, vgl. Thomas Goll: Die Deutschen und Thomas Mann. Die Rezeption des Dichters in Abhängigkeit von der politischen Kultur Deutschlands 1898-1955. BadenBaden 2000, zu den Buddenbrooks S. 85-89. Allgemein zu verschiedenen Formen der Rezeption, u. a. zur Lektüre des Romans als Schlüsselroman, vgl. Helmut Schanze: Thomas Mann: Buddenbrooks - im „Kontext“ um 1900 - Probleme einer Rezeptionsgeschichte. In: Roger Bauer/Eckhard Heftrich (Hg.): Fin de siècle. Zu Literatur und Kunst der Jahrhundertwende. Frankfurt a. M. 1977, S. 596-608.

127 Rösch u. a.: Die Rezeption, S. 39. Der Sachverhalt ist in der Forschung sehr gut belegt, vgl. exemplarisch: Heinrich Detering: Thomas Mann oder Lübeck und die letzten Dinge. Buddenbrooks, Stadtklatsch, Bilse und ich. In: H. D.: Herkunftsorte. Literarische Verwandlungen im Werk Storms, Hebbels, Groths, Thomas und Heinrich Manns. Heide 2001, S. 166-193; Gertrud Maria Rösch: Clavis Scientiae. Studien zum Verhältnis von Faktizität und Fiktionalität am Fall der Schlüsselliteratur. Tübingen 2004, S. 202-215. 
Sonderfall von Applikation. Vorausgesetzt ist ein spezielles Wissen über die lokalen Verhältnisse, über das nur wenige Zeitgenossen verfügt haben dürften. Ebenso klein ist dann auch der Kreis derjenigen, die den Roman auf dieser Grundlage applizieren und eine solche Applikation für relevant halten konnten. Die Applikation selbst ist dann gleichfalls eher speziell. Sie bestand darin, die Schilderungen der Figuren im Roman so zu verstehen, dass sie auf reale Personen übertragen werden können. Das mag dann der vermeintlichen Erkenntnis gedient haben oder ein Bedürfnis nach Skandalgeschichten befriedigt haben. Instruktiv ist der Fall insofern, als er auf eine Rezeptionsdisposition aufmerksam macht, über die Teile des Publikums zu verschiedenen Zeiten verfügen. Wie gesehen, gab es bereits bei Goethes Werther Versuche, reale Entsprechungen zu den Figuren und Orten des Romans ausfindig zu machen. Reuters Aus guter Familie konnte so verstanden werden, dass die Autorin ihre eigene Geschichte erzählt. Die Neigung, die fiktiven Figuren, Schauplätze und Handlungen als realweltlich referenzialisierbar zu betrachten, begünstigt Applikationen.

Im Einzelfall lassen sich Forschungsbeiträge, die den Roman auf seine mögliche Aktualität hin untersuchen, so auffassen, dass sie selbst Applikationen vornehmen. Das gilt für eine Publikation, in der die These vertreten wird, dass der Roman zeige, „wie es dem westlichen Selbst in dieser Zeit der Moderne ergeht und warum“, weswegen man aus ihm „Schlüsse für unsere Gegenwart ziehen“ könne. ${ }^{128}$

Was das Verhältnis des Romans zu den historischen Gegebenheiten der Zeit seiner Entstehung und Erstrezeption betrifft, gibt es in der Forschung eine klare Tendenz, geistesgeschichtliche Aspekte als besonders wichtig anzusehen und von der Person des Autors auszugehen. Bereits die älteste Forschung, die von Zeitgenossen Manns stammt, hat die im Untertitel des Romans benannte Verfallsthematik mit zeitgenössischen Vorstellungen der décadence verbunden und zumal die Philosophie Friedrich Nietzsches als Bezugspunkt für den Autor identifiziert. ${ }^{129}$ Neben dem Naturalismus mit seinen Annahmen über die Rolle des

128 Manfred Dierks: Buddenbrooks und die kapitalistische Moderne. In: Thomas Sprecher (Hg.): „Was war das Leben? Man wusste es nicht!“ Thomas Mann und die Wissenschaften vom Menschen. Frankfurt a. M. 2008, S. 111-126, hier S. 112. Vgl. für ein weiteres Beispiel Hans Wißkirchen: „Er wird wachsen mit der Zeit ...“. Zur Aktualität des Buddenbrooks-Romans. In: Thomas Mann Jahrbuch 21 (2008), S. 101-112. Ein marxistisches Beispiel ist Inge Diersen: Thomas Manns große Romane - Rezeptionsmöglichkeiten heute. In: Neue deutsche Literatur 23 (1975), S. 24-43.

129 Vgl. Ernst Bertram: Das Problem des Verfalls. In: Mitteilungen der Literarhistorischen Gesellschaft Bonn 2 (1907), S. 72-79; Hanne Back: Thomas Mann. Verfall und Überwindung. Diss. Wien 1925; Gerhard Jacob: Thomas Mann und Nietzsche. Zum Problem der Décadence. 
Milieus und der Vererbung erweisen sich, so der Artikel im BuddenbrooksHandbuch, insbesondere die Dekadenztheorien Paul Bourgets und Nietzsches (die u. a. die Abstammungslehre Charles Darwins rezipierten) als wichtige ,Einflüsse‘, die jedoch nur in ausgewählten Details und in eigenständiger Form in den Roman Eingang finden. ${ }^{130}$ Außerdem konnte gezeigt werden, dass der im Roman dargestellte Verfallsprozess mithilfe von Wissen erklärt werden kann, welches die Biologie und Medizin um 1900 zur Verfügung stellte. ${ }^{131}$ Es wird angenommen, dass der Bezug des Romans zur Zeitgeschichte nur von untergeordneter Bedeutung gewesen sei und sozialgeschichtliche Deutungen, die in dem Roman zum Beispiel einen Wandel im Bürgertum dargestellt sehen, abzulehnen seien. ${ }^{132}$ Arbeiten, welche die protestantische Ethik bei der Untersuchung des Romans heranziehen, die Figuren soziologisch als ,Bürger‘ oder ,Bourgeois“ zu klassifizieren versuchen oder die These vertreten, dass der Roman das Scheitern einer „Ökonomisierung des Lebens“ zeige, sind eher die Ausnahme. ${ }^{133}$

Diss. Leipzig 1926; Helmut R. Boeninger: Bild und Symptom der Dekadenz in Thomas Manns Buddenbrooks und Novellen. Wisconsin 1934.

130 Vgl. Ernst Keller: Das Problem „Verfall“. In: Moulden/Wilpert: Buddenbrooks-Handbuch, S. 157-172, hier S. 157 f. Daneben wurde ein Bezug zur Philosophie Schopenhauers hergestellt, vgl. Peter Pütz: Die Stufen des Bewußtseins bei Schopenhauer und den Buddenbrooks. In: Hermann Kurzke (Hg.): Stationen der Thomas-Mann-Forschung. Aufsätze seit 1970. Würzburg 1985, S. 15-24; dagegen Terence J. Reed: Thomas Mann und die literarische Tradition. In: Koopmann: Thomas-Mann-Handbuch, S. 95-136, hier S. 100 f., sowie Dieter Liewerscheidt: Thomas Manns Buddenbrooks. Wie der Verfall erzählbar wurde. In: Wirkendes Wort 62 (2012), S. 359-337, hier S. 259-362; zu Manns Rezeption von Schopenhauer und Nietzsche allgemein vgl. Børge Kristiansen: Thomas Mann und die Philosophie. In: Koopmann: Thomas-MannHandbuch, S. 259-282.

131 Vgl. Katrin Max: Niedergangsdiagnostik. Zur Funktion von Krankheitsmotiven in Buddenbrooks. Frankfurt a. M. 2008.

132 Vgl. Kenneth B. Beaton: Die Zeitgeschichte und ihre Integrierung im Roman. In: Moulden/Wilpert: Buddenbrooks-Handbuch, S. 201-211; Martin H. Ludwig: Perspektive und Weltbild in Thomas Manns Buddenbrooks. In: Manfred Brauneck (Hg.): Der deutsche Roman im 20. Jahrhundert. Analysen und Materialien zur Theorie und Soziologie des Romans. 2 Bde. Bamberg 1976, Bd.1, S. 82-106; Gero von Wilpert: Das Bild der Gesellschaft. In: Moulden/Wilpert: Buddenbrooks-Handbuch, S. 245-258, hier S. 246.

133 Vgl. Andreas Urs Sommer: Der Bankrott ,protestantischer Ethik‘. Thomas Manns Buddenbrooks. In: Wirkendes Wort 44 (1994), S. 88-110; Michael Zeller: Bürger oder Bourgeois? Eine literatursoziologische Studie zu Thomas Manns Buddenbrooks und Heinrich Manns Im Schlaraffenland. Stuttgart 1976; Birger P. Priddat: Über das Scheitern der Familie, nicht des Kapitalismus. Neue Einsichten in die ökonomischen Aspekte in Thomas Manns Buddenbrooks. In: Thomas-Mann-Jahrbuch 25 (2012), S. 259-273. 
Als wichtigste Quellen für die zeitgenössische Rezeption des Romans haben sich in der Forschung Rezensionen erwiesen. In den Jahren zwischen 1901 und 1910 erschienen mindestens 62 Besprechungen. ${ }^{134}$ Allerdings sind sie als „eine höchst fragwürdige Quelle“ angesehen worden, da sie allein die Sicht professioneller Literaturvermittler/-innen widerspiegeln, die sich von der Rezeption nicht-professioneller Rezipienten unterscheide. ${ }^{135}$ Letztere ließe sich kaum mehr rekonstruieren, der Schluss von den Aussagen der Rezensenten auf die Rezeption des Romans durch das Publikum sei unzulässig. ${ }^{136}$ Dass die Rezeption, wie sie sich aus Rezensionen rekonstruieren lässt, nicht ,die‘ Rezeption schlechthin abbildet, ist unstrittig. Es ist die Rezeption einer Gruppe von Akteur/-innen, die von generischen, medialen und situativen Bedingungen geprägt ist. Der Untersuchung solcher Quellen jedoch mehr oder weniger jeden Wert abzusprechen, ist nicht angemessen. Zum einen kann man festhalten, dass man zumindest über diese Gruppe von Rezipienten Aussagen treffen kann. Zum anderen handelt es sich um eine besonders einflussreiche Gruppe von Akteur/-innen. Was sie über den literarischen Text sagten und wie sie ihn bewerteten, erreichte qua Medium viele potenzielle Rezipienten des literarischen Textes und es konnte qua Textsorte als Expertenmeinung wahrgenommen werden. Rezensionen sind zur fraglichen Zeit die ersten und wohl mit Abstand wichtigsten öffentlichen Stellungnahmen zu einem literarischen Text. Es erscheint daher zulässig, anzunehmen, dass Rezensionen eine Orientierungsfunktion erfüllen und in einem gewissen Umfang steuern können, wie andere, zumal nicht-professionelle Rezipienten einen literarischen Text aufnehmen. Damit erlauben die Befunde in einem gewissen Umfang verallgemeinerbare Thesen über die Rezeption.

134 Vgl. Thomas Sprecher/Katrin Bedening: Quellen und Dokumente zu Buddenbrooks im Thomas-Mann-Archiv der ETH Zürich. In: Manfred Eickhölter/Hans Wißkirchen (Hg.): Buddenbrooks. Neue Blicke in ein altes Buch. Begleitband zur neuen ständigen Ausstellung Die ,Buddenbrooks' - ein Jahrhundertroman im Buddenbrookhaus. Lübeck 2000, S. 22-35, hier S. 32; in der älteren Forschung wurden für die Jahre 1901-1904 allein 37 Besprechungen ermittelt, vgl. Wilpert: Die Rezeptionsgeschichte, S. 325 und 330-332.

135 Hermann Kurzke: Thomas Mann. Epoche - Werk - Wirkung. München ${ }^{4} 2010$, S. 307.

136 Vgl. Hans Rudolf Vaget: Rezeptionsästhetik: Schwierigkeiten mit dem Erwartungshorizont am Beispiel der Buddenbrooks. In: Monatshefte für deutschen Unterricht, deutsche Sprache und Literatur 71 (1979), S. 399-409, hier S. 404. 


\subsubsection{Eine zeitgenössische Applikation}

Obwohl die Rezensionen, die $\mathrm{zu}$ den Buddenbrooks erschienen, verschiedentlich untersucht wurden, hat man weder dem Begriff noch der Sache nach eine Applikation festgestellt, die von manchen Rezensenten vorgenommen wurde. Sie besteht in der Auffassung, dass die Romanhandlung zeige, wie das Leben an sich ist. Es erscheine als unverständliche und sinnlose, letztlich unkontrollierbare Macht. ${ }^{137}$ Aussagen dieser Art kommen in den Rezeptionsdokumenten immer wieder vor. Der Roman zeige „das Leben“, genauer: „das grausame Leben“, wie der Autor es sich vorstelle, nämlich „als ein unentrinnbares Verhängnis armer, schuldloser, meist lächerlicher Menschen“. ${ }^{138}$ Der Autor „gibt uns allen einen Eindruck von der grausam lastenden Schwere des Lebens“. ${ }^{139}$ Er „malt das Leben wie es nun einmal grausam und unerbittlich ist“ und sei gerade deswegen „modern“. ${ }^{140}$ Das im Roman Geschilderte wurde also als zutreffende Darstellung des Lebens wahrgenommen. Es wurde nicht allein eine Aussage darüber gemacht, was in der erzählten Welt des Romans der Fall ist. Das Gelesene wurde als zutreffende Darstellung der realen Welt angesehen und appliziert: Modernes menschliches Leben ist ,grausam‘.

Andere Rezensenten teilten diese Einschätzung, setzten allerdings im Detail andere Akzente. So wurde beobachtet, dass der Roman die Form einer „Chronik“ habe, was dem Dargestellten besonders angemessen sei: „Denn das Leben ist etwas ungeheuer Einförmiges und zugleich Erschütterndes, ein immer gleicher Kreislauf trotz des Wechsels der Generationen - immer dasselbe." ${ }^{\text {141 }}$ Rainer

137 Dass der Roman als Aussage über das Leben in diesem Sinne aufgefasst werden konnte, ist in der bisherigen Forschung an einer Stelle bereits aufschlussreich anhand einer Untersuchung der Quellen gezeigt worden, allerdings ohne die damit verbundene Applikation zu thematisieren, vgl. Fotis Jannidis: „Unser moderner Dichter“ - Thomas Manns Buddenbrooks. Verfall einer Familie (1901). In: Matthias Luserke-Jaqui (Hg.): Deutschsprachige Romane der klassischen Moderne. Berlin/New York 2008, S. 47-72, hier S. 58 f.

138 Kurt Martens: Der Roman einer Familie. In: Das literarische Echo. Jg. 4, H.6., 2. Dezemberheft 1901, Sp. 380-383. Zitiert nach Klaus Schröter (Hg.): Thomas Mann im Urteil seiner Zeit. Dokumente 1891-1955. Frankfurt a. M. ${ }^{2} 2000$, S. 19-23, hier S. 20.

139 [Anon.]: [Rezension von Mann: Buddenbrooks]. In: Magdeburgische Zeitung. Nr. 280, 5. Juni 1903, n. p.

140 [Anon.]: Was soll der Buchhändler lesen? In: Börsenblatt für den deutschen Buchhandel. Nr. 148, 30. Juni 1903 [nicht 30. Mai], S. 5162. Zitiert nach Jannidis: „Unser moderner Dichter“, S. 58.

141 Samuel Lublinski: [Rezension von Mann: Buddenbrooks]. In: Berliner Tageblatt. Jg. 21, Nr. 466, Abendausgabe, 13. September 1902. Zitiert nach Jochen Vogt: Thomas Mann: Buddenbrooks. München 1983, S. 147 f., hier S. 148. 
Maria Rilke lobte die „Objektivität“; sie sei „[e]in Akt der Ehrfurcht vor dem Leben, welches gut und gerecht ist, indem es geschieht““. ${ }^{142}$ Man könne in dem Roman „das Leben selber mit geheimnisvoller Stimme von seltsam unfaßbarer Ewigkeit alles Seienden erzählen“ hören. ${ }^{143}$ Hervorgehoben wurden also verschiedene Aspekte: Der Roman zeige, dass das Leben wesentlich einförmig und erschütternd sei. Es sei bereits dadurch gerechtfertigt, dass es geschehe. Durch den Roman artikuliere sich das letztlich unbegreifliche Leben selbst, zumindest andeutungsweise. Anders gesagt: Der Roman gibt einen ungefähren Eindruck von etwas, das letztlich unverständlich bleibt. Solche Aussagen sind Applikationen. Es wird angenommen, dass das durch den Roman Vermittelte - das Leben ist einförmig, durch sich selbst gerechtfertigt, geheimnisvoll und unverständlich - als zutreffende Schilderung des realen Lebens angesehen werden kann und dass es sich um eine relevante Feststellung handelt: über den Roman und wie man ihn lesen soll und über die Lebenswelt und wie das Leben ist.

Als gleichfalls aufschlussreich erweisen sich Stellungnahmen, in welchen die Applikationsmöglichkeit distanziert betrachtet oder abgelehnt wird, weil man sie als einseitig und unangemessen wahrnimmt. Es sei zulässig, Kritik an der künstlerischen Konzeption zu üben, welche dem Roman zugrunde liege und deren Ziel es sei, „die sonnenlosen Flächen des Lebens photographisch getreu wiederzugeben“. ${ }^{144}$ Eine solche Konzeption, die „nur den Jammer des Lebens und nicht seine Schönheit“ zum Gegenstand mache, sei nicht wirklichkeitsgetreu, da sie dazu führe, „das Leben zu zeichnen, wie es nicht ist“. ${ }^{145}$ Aussagen dieser Art erweisen sich als Beispiele für Negativ-Applikationen: Der Roman wird so wahrgenommen, dass er ein Bild des Lebens entwerfe. Der Vergleich dieses Bildes mit der Realität, so wie die Rezensenten sie auffassen, zeigt jedoch, dass es unzutreffend und unangemessen, weil einseitig und übertrieben ist.

142 Rainer Maria Rilke: Thomas Mann's ,Buddenbrooks‘ [Bremer Tageblatt und GeneralAnzeiger. Jg. 6, Nr. 88, 16. April 1902]. In: R. M. R.: Werke. Kommentierte Ausgabe in vier Bänden. Bd. 4: Schriften. Hg. von Horst Nalewski. Frankfurt a. M./Leipzig 1996, S. 255-258, hier S. 258 .

143 Wilhelm von Wymetal: [Rezension von Mann: Buddenbrooks]. In: Die Woche. Wiener Montags-Zeitung. Nr. 37, 24. August 1903, S. 5. Zitiert nach Jannidis: „Unser moderner Dichter“, S. 59.

144 O. Brüssau: Um der Gerechtigkeit willen! In: Reformation. Jg. 3, H. 3 (1904), S. 523 f., hier S. 524.

145 M. Wagner-Braunsdorf: Noch einmal: Thomas Mann's Buddenbrooks. In: Reformation. Jg. 3, H. 3 (1904), S. 569-571, hier S. 570. 
Diese Beispiele für Applikationen stehen in den Rezensionen im Zusammenhang mit anderen Annahmen über den Roman, wie zumindest anzudeuten ist. Die Handlung des Romans wurde verschiedentlich beschrieben und klassifiziert. Die Abfolge der vier Generationen konnte organizistisch aufgefasst werden als „Aufblühen“, „Blüthe“ und „Zusammenfallen und Hinsinken in den Staub“. ${ }^{146}$ Biologische Annahmen konnten mit solchen über die Dekadenz verbunden werden: „Es ist einfach ein natürlicher Prozeß des Alterns und Absterbens, dem Familien und Gemeinschaften wie die Einzelnen unterliegen. Und seine Erscheinungen sind die allgemeinen aller Dekadenz: fortschreitende Verfeinerung und Differenzierung, Ausbildung der abgeleiteten und spezialisierten Vorgänge des seelischen Lebens auf Kosten der einfachen, primitiven, zentralen Lebensenergie.“147 Andere sahen „die Lehre von der Vererbung“ als Grundlage der negativen Entwicklung an, die allerdings ,im Hintergrund“ bleibe und „nur sehr diskret angedeutet“ werde. ${ }^{148}$ Gertrud Bäumer meinte, dass der Roman in der Abfolge der Generationen ein Nachlassen des „verborgenen, gleichsam organischen Lebenswillen[s]“ zeige, von dem menschliches Schicksal abhänge. ${ }^{149}$ Derartige Deutungsansätze sind es, welche die unmittelbare zeitgenössische Rezeption zu bestimmen scheinen. Die Annahme, Buddenbrooks seien ein „philosophischer Roman“, der, an Arthur Schopenhauer und Nietzsche geschult, zeige, dass „[e]ine letzte Analyse des Wesens und der Bedingungen des Lebens [...] unvereinbar [ist] mit der naiven Lebenslust und ungeteilten Tatenfreudigkeit“, findet sich erst etwas später. ${ }^{150}$ In jedem Fall handelt es sich um ein spezielleres Verständnis dessen, was in der Welt des Textes der Fall ist. Es bildet die Grundlage für Spezifikationen der Applikation, wonach der Roman Aufschluss gebe über das Leben an sich.

146 Otto Grautoff: Thomas Mann. In: Die Gegenwart. Jg. 32, Bd. 64, Nr. 33, 15. August 1903, S. 102 f. Zitiert nach Schröter: Dokumente, S. 24 f., hier S. 24. Vgl. dazu [Otto Grautoff]: Thomas Manns Buddenbrooks. In: Münchner Neueste Nachrichten. Jg. 54, 24. Dezember 1901. Zitiert nach Rudolf Wolff (Hg.): Thomas Manns Buddenbrooks und die Wirkung. 2 Teile. Bonn 1986, 1. Teil, S. 13 f., hier S. 13.

147 Heinrich Meyer-Benfey: Thomas Mann. In: Beilage zur Allgemeinen Zeitung. Nr.67, 22. März 1904, S. 529-532. Zitiert nach Schröter: Dokumente, S. 30-37, hier S. 33.

148 Samuel Lublinski: Die Bilanz der Moderne. Berlin 1904, S. 225.

149 Gertrud Bäumer: Thomas Mann, der Dichter der Buddenbrooks. In: Die Frau. Monatsschrift für das gesamte Frauenleben unserer Zeit. Jg. 11, H. 1 (1903), S. 32-36, hier S. 34, vgl. dazu S. 32-34.

150 Fredrik Böök: Verleihungsrede anläßlich der feierlichen Überreichung des Nobelpreises für Literatur an Thomas Mann am 10. Dezember 1929. In: Thomas Mann: Buddenbrooks. Auf den Kreis der Nobelpreisfreunde beschränkte Aufl. Zürich 1969, S. 19-21, hier S. 20. 
Während in Rezensionen wie den vorangehenden eine Motivierung des Geschehens postuliert wird, nahmen andere die gegenteilige Position ein: „Warum verfällt die Familie Buddenbrook? Auch nachdem ich den ganzen Roman gelesen habe, vermag ich es nicht zu sagen. Gewiß liegen eine große Zahl von Anlässen vor; aber es sind äußere Anlässe, Zufälligkeiten; es sind nicht Gründe mit inneren Notwendigkeiten. “151 Die Frage, was genau dazu führt, dass sich die Mitglieder der Familie über vier Generationen so entwickeln, ist zentral für das Verständnis der Gesamthandlung. Eine ausführliche Untersuchung der zeitgenössischen Rezeption konnte zeigen, dass die Frage (der Sache nach) in zahlreichen Rezensionen eine Rolle spielte. ${ }^{152}$ Es habe Einigkeit geherrscht, dass dem Gang der Handlung eine Konzeption von Dekadenz zugrunde liege. Uneinigkeit habe es jedoch mit Blick auf die Ursachen gegeben, die im Roman zwar angedeutet werden, nicht jedoch klar benannt. Der Roman lege zum einen eine kausale Motivierung nahe, bei welcher die Vererbung und die sich aus den entsprechenden Eigenschaften ergebenden psychischen Dispositionen der Figuren ausschlaggebend sind. Bei einem solchen Verständnis hätten die Rezensenten Wissen über die Vererbungslehre einbezogen. Der Roman lege zum anderen eine finale Motivierung nahe, bei welcher das Geschehen vor dem Hintergrund eines allgemeinen Vitalismus verstanden wurde. Der Niedergang der Familie sei als gleichsam natürliches, schicksalhaftes Nachlassen der Lebenskraft aufgefasst worden. Es ist zu beobachten, dass der Roman einen gewissen Verständnisspielraum eröffnet. Als besonders aussagekräftig kann der Befund angesehen werden, dass es unterschiedliche Einschätzungen gab zum Verhältnis der Figuren zu ihrem Milieu. Es wurde auf der einen Seite gelobt, dass „das Wesen des Menschen“ im Mittelpunkt stehe und nicht die Umstände, unter denen die Figuren handeln. Dadurch sei der Roman gerade kein einseitiger sozialer Roman wie bei Émile Zola und dessen Nachfolgern im deutschsprachigen Raum. ${ }^{153}$ Auf der anderen Seite wurde kritisiert, dass die Figuren „eigentlich nur des Milieus halber da“ seien, es handele sich um ein „Epigonenwerk“, das „nach strengster naturalistischer Methode“ geschrieben worden sei. ${ }^{154}$

Es stellt sich die Frage nach der Passung der identifizierten Applikationen mit der Beschaffenheit des Textes. Die Form des Romans ist verschiedentlich

151 Max Lorenz: [Rezension von Mann: Buddenbrooks]. In: Preußische Jahrbücher. Bd. 110, H. 1, Oktober 1902, S. 149-152, hier S. 150.

152 Vgl. zum Folgenden Jannidis: „Unser moderner Dichter“, S. 54-57.

153 Arthur Eloesser: Neue Bücher. In: Neue Deutsche Rundschau. Jg. 12., H. 12, Dezember 1901, S. 1281-1290, hier S. 1288.

154 Hermann Andreas Krüger: Romane. In: Die schöne Literatur. Beilage zum Literarischen Zentralblatt für Deutschland. Jg. 3, Nr. 2, 18. Januar 1902, Sp. 17-21, hier Sp. 19. 
eingehend untersucht worden. Die wichtigsten Befunde sollen kurz summarisch benannt werden. ${ }^{155}$ Zunächst fällt auf, dass die geschilderte Handlung nicht auf einzelne besondere Ereignisse fokussiert ist. Vielmehr werden alltägliche Ereignisse detailliert geschildert und der Verfall über vier Generationen hinweg gezeigt; beides wichtige Faktoren, die zum relativ großen Umfang des Textes beitragen. Das wurde zeitgenössisch unterschiedlich bewertet. Während die einen „die lange Reihe der Wiederholung“ aus „Geburten, Todesfälle[n], Taufen, Hochzeiten, Reisen, Besuche[n] und besonders geschäftliche[n] Vorfälle[n]“ als „monoton“ kritisierten, lobten die anderen die „Kunst, die kleine Dinge schlicht und völlig erzählt““. ${ }^{156}$ Außerdem wird häufig die Technik des showing verwendet. Dazu gehört etwa die Wiedergabe direkter Figurenrede, durch welche die Figuren aussagekräftig charakterisiert werden, die detaillierten Beschreibungen, die Kreisstruktur der Erzählung und die Verwendung von Leitmotiven. Die Darstellung ist chronikartig, weist aber ein unterschiedliches Erzähltempo auf. Auf wertende Erzählerkommentare wird weitgehend verzichtet. Die Erzählhaltung ist ironisch, Humor und Ironie kommen verschiedentlich zum Einsatz. ${ }^{157}$

155 Vgl. zum Folgenden die Zusammenstellung in Jannidis: „Unser moderner Dichter“, S. 6272. Befunde dieser Art sind bereits kodifiziert, vgl. Christian Grawe: Struktur und Erzählform. In: Ken Moulden/Gero von Wilpert (Hg.): Buddenbrooks-Handbuch. Stuttgart 1988, S. 69-107; Manfred Jurgensen: Die Erzählperspektive. In: Moulden/Wilpert: Buddenbrooks-Handbuch, S. 109-127; Ernst Keller: Leitmotive und Symbole. In: Moulden/Wilpert: BuddenbrooksHandbuch, S. 129-143; Gero von Wilpert: Sprachliche Polyphonie: Sprachebenen und Dialekte. In: Moulden/Wilpert: Buddenbrooks-Handbuch, S.145-156. Vgl. dazu Arbeiten zum Roman allgemein, etwa Eberhard Lämmert: Thomas Mann. Buddenbrooks. In: Benno von Wiese (Hg.): Der deutsche Roman vom Barock bis zur Gegenwart. Struktur und Geschichte. 2 Bde. Düsseldorf 1963, Bd. 2, S. 190-233; Herbert Lehnert: Thomas Mann: Buddenbrooks (1901). In: Paul Michael Lützeler (Hg.): Deutsche Romane des 20. Jahrhunderts. Neue Interpretationen. Königstein i. Ts. 1983, S. 31-49; Georg Wenzel: Buddenbrooks. In: Volkmar Hansen (Hg.): Thomas Mann. Romane und Erzählungen. Stuttgart 1993, S. 11-46; Jochen Vogt: Thomas Mann: Buddenbrooks. München 1983.

156 Eloesser: Neue Bücher, S. 1288; Franz Blei: Thomas Manns Buddenbrooks. Verfall einer Familie. In: Die Insel. Jg. 3, H. 4, Januar 1902, S. 115-117. Zitiert nach Wolff: Thomas Manns Buddenbrooks und die Wirkung, S. 25 f., hier S. 25.

157 Vgl. dazu Jürgen Petersen: Die Rolle des Erzählers und die epische Ironie im Frühwerk Thomas Manns. Ein Beitrag zur Untersuchung seiner dichterischen Verfahrensweise. Diss. Köln 1967; Paul Böckmann: Der Widerstreit von Geist und Leben und seine ironische Vermittlung in den Romanen Thomas Manns. In: Renate von Heydebrand/Klaus Günter Just (Hg.): Wissenschaft als Dialog. Studien zur Literatur und Kunst seit der Jahrhundertwende. Stuttgart 1969, S. 194-215; Helmut Koopmann: Thomas Mann. Theorie und Praxis der epischen Ironie. In: H. K. (Hg.): Thomas Mann. Darmstadt 1975, S. 351-383. 
Es lassen sich verschiedene Aspekte der Beschaffenheit des Textes nennen, die zusammengenommen geeignet sind, die in Rede stehende Applikation zu plausibilisieren. Sie ist in einem nicht geringen Maße durch die Beschaffenheit des Textes gedeckt. Ein erster wichtiger Befund ist der bereits erwähnte Umstand, dass die Motivierung des Geschehens in einem gewissen Maße offenbleibt und verschiedene Motivierungen nahegelegt werden (Vererbung, Dekadenz, Schicksal), die sich dann unter einer allgemeinen - „das Leben ist so“ subsummieren lassen. Gerade mit diesem für den Gesamttext zentralen und für das Verständnis bedeutsamen Befund sind weitere mehr oder weniger eng verbunden.

Ein zweiter Gesichtspunkt ist die Struktur der Gesamthandlung, die sich als Abfolge von gesellschaftlichem Aufstieg und Abstieg beschreiben lässt. Die Ausgangskonstellation zu Beginn der Handlung kehrt am Ende unter umgekehrten Vorzeichen wieder. Am Beginn wird erwähnt, dass die Familie Buddenbrook ein Haus bezieht, welches eine andere, Ratenkamps, nach geschäftlichem Scheitern verkaufen musste. ${ }^{158}$ Parallel zur wirtschaftlichen Entwicklung der Firma Buddenbrook vollzieht sich der Aufstieg der Hagenströms, die schließlich ihrerseits das Haus erwerben (vgl. S. 670, dazu detailliert S. 652-671), nachdem der soziale Abstieg der Buddenbrooks relativ weit fortgeschritten ist. Dadurch wird nahegelegt, dass das Geschehen nicht linearen Charakters ist, sondern zyklischer Natur. Es ist also nicht der Fall, dass in der Abfolge Ratenkamp, Buddenbrook, Hagenström ein historischer Prozess gezeigt wird, bei welchem diejenigen Erfolg haben, die sich dem wirtschaftlichen und technischen Fortschritt am besten anpassen können. Es wird keine Modernisierungsgeschichte oder dergleichen erzählt. Vielmehr kann der angedeutete Zyklus vom Aufstieg der einen und Abstieg der anderen als gleichsam ,natürlicher' Prozess erscheinen, der auf etwas Allgemeineres als die spezifischen sozialen und historischen Gegebenheiten verweist.

Die Handlung trägt, drittens, analytische Züge, was sich insbesondere daran zeigt, dass die Figuren, zumal die der dritten Generation, auf der in vielerlei Hinsicht der Fokus liegt, ausgesprochen statisch sind. Es hat den Anschein, als seien sie charakterlich von Beginn an so, wie sie im Roman auftreten. Sie machen keine Entwicklung durch. Allenfalls verstärken sich bestehende Eigenschaften. Thomas ist bereits als Knabe, so das Urteil einer Nebenfigur, „ein solider und ernster Kopf“, Christian dagegen ein „Tausendsassa“, „witzig und

158 Vgl. Thomas Mann: Große kommentierte Frankfurter Ausgabe. Werke, Briefe, Tagebücher. Bd. 1,1: Buddenbrooks. Verfall einer Familie. Roman. Hg. von Eckhard Heftrich. Frankfurt a. M. 2002, S. 25 f. Nachweise im Folgenden im Text unmittelbar im Anschluss an das Zitat. 
brillant veranlagt“ (S. 17). Wie zutreffend die Einschätzung ist, wird durch den Gang der Handlung gezeigt und in einem expliziten Erzählerkommentar gesagt: „Jean Jacques Hoffstede hatte, was die beiden Söhne des Konsuls Buddenbrook anging, sicherlich ein treffendes Urteil gefällt.“ (S. 71) Tony zeigt von Beginn an „feudale[] Neigungen“ und verhält sich „wie eine kleine Königin“, sie ist sich ihrer Stellung in der Stadt als Tochter eines angesehenen Kaufmanns aus einer der ersten Familien sehr wohl bewusst (S. 65 und 71) - Eigenschaften, die sie, von kindlichen Zügen befreit, ihr Leben lang aufweist. Die Konzeption der Figuren trägt dazu bei, dass die Frage nach den Gründen für ihre Eigenschaften und ihr Verhalten aufgeworfen wird, aber nicht oder jedenfalls nicht ohne Weiteres mit Blick auf den Gang der Handlung und entsprechende Faktoren beantwortet werden kann.

Viertens fehlt den Figuren der dritten (und vierten) Generation eine selbstverständliche und unkomplizierte ,metaphysische‘ Sinngebung für ihr Leben, wie sie die Vertreter der ersten und zweiten Generation in Gestalt einer aufklärerischen Geisteshaltung oder einer pietistischen Frömmigkeit besitzen; einer Sinngebung, die es Letzteren weitgehend ermöglicht, im Leben zu bestehen. An verschiedenen Stellen im Roman wird das gezeigt; an einer Stelle, an der Thomas mit Vater und Großvater kontrastiert wird, darüber hinaus explizit thematisiert. Sein Großvater, der alte Johann Buddenbrook, hatte stets „den ersten und letzten Dingen [...] weltmännische Skepsis entgegengebracht“ (S. 719), während sein Vater, Konsul Johann Buddenbrook, „Buchstabenglaube, das schwärmerische Bibel-Christentum [...] mit einem sehr praktischen Geschäftssinn zu verbinden gewußt“ hatte (S.718 f.). Diese Frömmigkeit kennzeichnet, zumal nach dem Tod ihres Mannes, auch Elisabeth Buddenbrook. Beides ist Thomas versagt. Er hat „sich die Fragen der Ewigkeit und Unsterblichkeit historisch beantwortet und sich gesagt, daß er in seinen Vorfahren gelebt habe und in seinen Nachfahren leben werde“ (S. 719). Diese Antwort hat ihn zwar „in seiner Thätigkeit, seinem Ehrgeiz, seiner ganzen Lebensführung unterstützt und bekräftigt“ (ebd.), auf die Dauer scheint sie allerdings nicht tragfähig zu sein. Was eine religiöse Sinngebung angeht, trifft der Befund zugleich auf Tony zu, wie sich an einem Beispiel illustrieren lässt. In einer Situation nächtlichen Nachdenkens über die Frage, ob sie zum zweiten Mal heiraten soll, fällt ihr Blick auf einen eingerahmt an der Wand hängenden Psalmvers: „Befiehl dem Herrn deine Wege ...“ (S. 369). ${ }^{159}$ Unmittelbar im Anschluss wird die rhetorisch $\mathrm{zu}$ verstehende Frage „aber ist das ein Trost [...]?“ aufgeworfen

159 Ps 37,5; die im Roman nicht zitierte, aber wohl als zeitgenössisches Wissen vorauszusetzende Fortführung des Verses lautet: „und hoffe auf ihn, er wird’s wohl machen“. 
(ebd.), bei der es sich wohl nicht um einen Erzählerkommentar handelt, sondern um Gedankenrede. Die Figuren werden also bei scheiternder oder erfolgreicher Sinngebung gezeigt, allerdings ohne dass sich in der Perspektivenstruktur des Textes eine als die privilegierte Form erweist, dem Leben Sinn zu verleihen.

Damit steht, fünftens, der Befund in Verbindung, dass ein religiöser Bezugsrahmen verschiedentlich angedeutet wird, aber nicht zum Tragen kommt, sondern vom Erzähler oder von Figuren relativiert wird, wie einige Beispiele zeigen können. Am Beginn der Handlung soll Tony auf Geheiß des Großvaters die Erläuterung des ersten Teils des Glaubensbekenntnisses aus dem Kleinen Katechismus aufsagen (vgl. S. 9 f.). Die Absicht des Großvaters ist es, „sich über den Katechismus moquieren zu können“ (S.10) - und mithin über die im Roman nicht zitierte, als zeitgenössisches Wissen aber durchaus vorauszusetzenden Inhalte der besagten Erläuterung, in welcher Gott als Schöpfer, Erhalter und Versorger des einzelnen Gläubigen beschrieben wird. Die Bekräftigung des Glaubens an ein jenseitiges Wiedersehen - „Es ist so!“ (S. 837) - wird ganz am Ende des Romans von Sesemi Weichbrodt gesprochen, einer durchweg komisch dargestellten Figur. Nicht sie hat das letzte Wort, sondern der Erzähler, der sie als „bucklig, winzig und bebend vor Überzeugung“ sowie als „kleine, strafende, begeisterte Prophetin“ karikiert (ebd.). Relativ zu Beginn wird erwähnt, dass über dem neu bezogenen Haus die Inschrift „Dominus providebit“ eingemeißelt ist (S. 47). Als es an Hermann Hagenström verkauft werden soll, erwähnt Thomas die Inschrift und bemerkt, ihren religiösen Anspruch relativierend, „daß nicht der Herr, sondern er [Hagenström] ganz allein der Firma Strunck \& Hagenström zu einem so erfreulichen Aufschwung verholfen hat“ (S. 661). Daneben werden verschiedentlich Geistliche oder Formen der Frömmigkeit satirisch dargestellt, etwa die Andachten im Hause der verwitweten Konsulin Buddenbrook (vgl. z. B. S. 303-309). Eine religiöse Perspektive auf das Geschehen wird somit ausgeschlossen, ebenso wie andere ,metaphysische‘. Die Schopenhauer-Lektüre verhilft Thomas nicht zu überzeugenden, geschweige denn bleibenden Einsichten. Zugleich wird dadurch die Suche nach einer anderen, ähnlich allgemeinen Erklärung für das Geschehen provoziert.

Sechstens fällt auf, dass zentrale Ereignisse den Charakter von Zufällen haben und als ,Schicksalsschläge‘ zwar nicht selbst motiviert sind, aber genau diese Frage nach dem Warum aufwerfen. Das betrifft Grünlichs Betrug, den Konsul Buddenbrook wohl nicht hätte durchschauen können, da andere daran beteiligt waren, die ihm aus eigenen geschäftlichen Interessen falsche Tatsachen vorspiegelten (vgl. insbesondere S. 249 und 252). Ein weiteres Beispiel ist der Verlust der ,auf dem Halm‘ gekauften Ernte; ein Kauf, zu dem sich Thomas 
gegen seine Überzeugungen auf Anraten Tonys einmal entschließt (vgl. insbesondere S. 542).

Schließlich kann festgestellt werden, dass ,das Leben' auf verschiedene Weise explizit thematisiert wird. In ironisch gebrochener Weise geschieht das wiederholt bei Tony. Nach der Scheidung von Grünlich heißt es über sie: „Im Übrigen begann Tony um diese Zeit, sich sehr oft der Redewendung ,Wie es im Leben so geht ...' zu bedienen, und bei dem Worte ,Leben' hatte sie einen hübschen und ernsthaften Augenaufschlag, welcher zu ahnen gab, welch tiefe Blicke sie in das Menschenleben und -Schicksal gethan ...“ (S. 256). Vergleichbare Aussagen, bei welchen sie sich unterschiedlicher Wendungen bedient, kommen mehrfach im Laufe der Handlung vor (vgl. z. B. S. 262 und 263, 424 und 488). Thomas definiert an einer Stelle Erfolg als Fähigkeit, das Leben zu den eigenen Gunsten zu beeinflussen: „Was ist der Erfolg? Eine geheime, unbeschreibliche Kraft, Umsichtigkeit, Bereitschaft ... das Bewußtsein, einen Druck auf die Bewegungen des Lebens um mich her durch mein bloßes Vorhandensein auszuüben ... Der Glaube an die Gefügigkeit des Lebens zu meinen Gunsten ...“ (S. 473). Im Zusammenhang mit seiner Schopenhauer-Lektüre wird deutlich, dass er das Leben als „stark[], grausam[] und höhnisch[]“ wahrnimmt und ihm „Kälte und Härte“ zuschreibt (S.721, vgl. dazu S. 725). Ein drittes Beispiel: Der Erzähler kommentiert die Einstellung der meisten Schüler, die in einer Latein-Stunde von Hanno Zeuge werden, wie einige beim Abprüfen des Vorzubereitenden betrügen und einer entdeckt und bestraft wird, mit den folgenden Worten: „Wer unter diesen fünfundzwanzig jungen Leuten von rechtschaffener Konstitution, stark und tüchtig für das Leben war, wie es ist, der nahm in diesem Augenblicke die Dinge völlig wie sie lagen, fühlte sich nicht durch sie beleidigt und fand, daß Alles selbstverständlich und in der Ordnung sei.“ (S. 808). ${ }^{160}$ Hanno gehört zu denjenigen, für die das nicht gilt; später im Verlauf des Schultages sagt er in anderem Zusammenhang zu Kai: „Nun frage ich aber Jedermann: ist dies ein Leben? Alles ist verzerrt ...“ (S. 819). Es wird also, sei es komisch gebrochen, sei es existenziell-ernsthaft, die Möglichkeit, das im Roman Dargestellte als Aussage über das Leben an sich zu begreifen, explizit und wiederholt aufgezeigt und als relevant ausgewiesen.

Es lässt sich festhalten, dass der Text aufgrund seiner Beschaffenheit eine Applikation wie die festgestellte durchaus ermöglicht und nahelegt, jedenfalls

160 Thomas Mann weist in einer Selbstdeutung auf diese Stelle hin, vgl. Brief an Hugo Marcus, 11. Mai 1902. In: Th. M.: Große Kommentierte Frankfurter Ausgabe. Werke - Briefe - Tagebücher. Bd. 21: Briefe I. 1889-1913. Hg. von Thomas Sprecher/Hans R. Vaget/Cornelia Bernini. Frankfurt a. M. 2002, S. 199-201, hier S. 199. 
nicht in Widerspruch dazu steht. Was den Bezug auf die historischen Gegebenheiten angeht, hat die Forschung, wie gesehen, überwiegend geistesgeschichtlich argumentiert und die Person des Autors fokussiert. Es wurde aber in überzeugender Weise $\mathrm{zu}$ bedenken gegeben, dass solche einflussphilologischen Annahmen zu kurz greifen. Es sei am Ende weniger entscheidend, dass Mann Nietzsche und Schopenhauer und dergleichen rezipierte. Solche Erklärungen setzten bei den Symptomen an und verkennten die eigentlichen Ursachen, nämlich „die schon vorher vorhandene Bereitschaft aufseiten des Autors, gerade diese Ideen und Konzepte plausibel und überzeugend $\mathrm{zu}$ finden, eine Bereitschaft, die sich nicht auf die Philosophen und andere Stichwortgeber selbst, sondern auf etwas Allgemeineres stützen muss“. ${ }^{161}$ Das ,Allgemeinere‘ ist etwas, das nicht nur den Autor betrifft, sondern auch von den Rezipient/-innen geteilt werden konnte und, zumindest von manchen Rezensenten, tatsächlich geteilt wurde. Es ist wohl nicht in erster Linie als Menge von Ideen (philosophischen Positionen, weltanschaulichen Annahmen) zu konzeptualisieren, selbst wenn sie, gerade in der Wahrnehmung, markant sind. Sie verweisen auf etwas Allgemeineres, das hier als Mentalität aufgefasst werden soll.

Es ist, so soll angenommen werden, die moderne Mentalität um 1900 (unter den spezifischen Bedingungen des deutschen Kaiserreiches), die den Rahmen für die identifizierte Applikation bereitstellt. ${ }^{162}$ Die Forschung zu Manns Roman hat auf „Pessimismus und Krisenbewußtsein“ der Zeit verwiesen. ${ }^{163}$ Ferner dürften „die populäre Lebensmystik und die ebenso populäre Darwinrezeption“ $\mathrm{zu}$ der identifizierten Applikation beigetragen haben. ${ }^{164}$ Eine eindeutige Konturierung der besagten Mentalität(en) fällt nicht ganz leicht, was durchaus mit dem in Rede stehenden Sachverhalt zu tun hat, da Mentalitäten weniger eindeutig greifbar sind als andere historische Phänomene. Eine wichtige Rolle dürfte die Wahrnehmung der Zeit und die Erfahrung der Moderne mit ihren Begleiterscheinungen als krisenhaft gespielt haben (décadence, fin de siècle). Beschleunigter sozialer, technischer und wirtschaftlicher Wandel, naturwissenschaftliche Erkenntnisse, der zunehmende Verfall der überkommenen christlichen

161 Jannidis: „Unser moderner Dichter“, S. 58.

162 Vgl. Christian Schwaabe: Die deutsche Modernitätskrise. Politische Kultur und Mentalität von der Reichsgründung bis zur Wiedervereinigung. München 2005, S. 170-180; Martin Doerry: Übergangsmenschen. Die Mentalität der Wilhelminer und die Krise des Kaiserreichs. 2 Bde. Weinheim/München 1986, Bd. 1, S. 44-58.

163 Ulrich Karthaus: Buddenbrooks von Thomas Mann im literarischen Kontext ihrer Entstehungszeit. In: Herbert Grabes (Hg.): Text - Leser - Bedeutung. Untersuchungen zur Interaktion von Text und Leser. Großen-Linden 1977, S. 121-143, hier S. 123.

164 Jannidis: „Unser moderner Dichter“, S. 59. 
Orientierung, innen- und außenpolitische Konflikte des 1871 gegründeten Reiches dürften als Faktoren zu nennen sein. Es scheint jedenfalls, und dass ist entscheidend, gerade in der Zeit um 1900 ein gesteigertes und spezifisches Bedürfnis danach gegeben $\mathrm{zu}$ haben, Sinnfragen zu stellen, und eine Bereitschaft, sie negativ zu beantworten.

Sowohl mit Blick auf die Beschaffenheit des Textes als auch mit Blick auf die historischen Gegebenheiten lässt sich mithin plausibilisieren, warum eine solche Applikation vorgenommen werden konnte. In den Rezensionen ist sie, soweit sich das sagen lässt, die einzige, die greifbar ist. Sie ist sehr umfassend: Der gesamte Roman, so wird angenommen, zeigt, wie das Leben ist. Es handelt sich um eine Applikation, die eine allgemeine Überzeugung bezüglich der Lebenswelt bildet oder modifiziert. Da, wo sie konkreter gefasst wird, etwa biologisch oder lebensphilosophisch, ist sie von der Beschaffenheit des Textes bedingt gedeckt, insofern Belege andeutungsweise vorhanden sind und alternative Erklärungen möglich scheinen. Der Roman verfügt darüber hinaus, wie sich zeigen lässt, über ein zeitgenössisch durchaus realisierbares und demgegenüber konkreteres Applikationspotenzial, das sich jedoch, zumindest in den ausgewerteten Quellen, nicht nachweisen lässt.

\subsubsection{Ein nicht realisiertes Applikationspotenzial}

Die Buddenbrooks lassen sich, so die These, so verstehen, dass der Roman umfänglich und an vielen Stellen zeigt, dass und wie die Figuren der dritten und vierten Generation an Rollenerwartungen scheitern, welche ihnen aufgrund ihres Herkommens in der Familie und außerhalb zugewiesen werden. Das Scheitern kann als zusätzliche Motivierung für den Gang der Handlung dienen. Gleichwohl ist das unabhängig davon ein wichtiger Gesichtspunkt. Dass die Figuren an und in ihren Rollen scheitern, ist von der Frage zu unterscheiden, warum dem so ist. Der Roman ermöglicht eine Applikation: Das Publikum kann aufgrund der Lektüre zu der Überzeugung gelangen oder darin bestärkt werden, dass soziale Rollen für den individuellen Lebensweg bedeutsam sind und in manchen Fällen problematisch sein können. Es ist eine Spezifikation der Applikation, wonach der Roman zeige, wie das Leben an sich ist; eine Spezifikation, die sich auf relativ eindeutige Hinweise im Text stützen kann und den Text umfassend einbezieht.

Um die These zu begründen, sollen im Folgenden ausgewählte Beobachtungen zu den Figuren zusammengestellt werden, angefangen bei den Vertretern der ersten beiden Generationen, welche ein Leben im Einklang mit den 
ihnen zukommenden Rollen in Familie und Gesellschaft führen können, und als Kontrastfiguren fungieren, über die Vertreter der dritten bis hin zur vierten Generation, jeweils unter Einschluss der Neben- und Randfiguren. Nicht bei allen Figuren ist die Problematik in gleicher Weise prominent, sie kommt aber ausnahmslos bei allen vor und kann schon allein durch eine eher einfache Beschreibung der Figuren ersichtlich werden.

Die Vertreter der ersten und der zweiten Generation leben in Einklang mit ihren sozialen Rollen und füllen sie unproblematisch und konsequent aus. Das zeigt sich am alten Johann Buddenbrook, der die „Mesalliance“ seines Sohnes Gotthold nicht akzeptiert (S. 52). Ein weiteres Beispiel ist die Heirat des Konsuls Buddenbrook mit Elisabeth Kröger. Es war keine „Liebesheirat“: „Sein Vater hatte ihm auf die Schulter geklopft und ihn auf die Tochter des reichen Kröger, die der Firma eine stattliche Mitgift zuführte, aufmerksam gemacht, er war von Herzen einverstanden gewesen und hatte fortan seine Gattin verehrt, als die ihm von Gott vertraute Gefährtin ...“ (S. 59). Anders verhält es sich allein mit Gotthold, der aus Liebe eine nicht standesgemäße Ehe eingeht und bereit ist, die Konsequenzen zu tragen, darunter den Bruch mit dem Vater und die damit verbundenen finanziellen Einbußen (vgl. dazu z. B. die Sicht von Thomas, S. 302).

Tony ist neben Thomas die wichtigste Figur im Roman, gemessen daran, dass sie im gesamten Handlungsverlauf präsent ist und relativ viel und ausführlich von ihr die Rede ist. Bereits am Beginn der Romanhandlung sagt ihre Mutter über sie, sie werde sich ,bemühen, eine kluge und tüchtige Frau zu werden“, und bezeichnet damit die Anforderungen, welche an sie gestellt werden (S. 16). Tony nimmt die ihr zugewiesene Rolle bereitwillig an. In jugendlichem Alter erklärt sie den Freundinnen in der Pension, dass sie „natürlich einen Kaufmann heiraten“ werde, und formuliert ihre Vorstellungen: „Er muß recht viel Geld haben, damit wir uns vornehm einrichten können; das bin ich meiner Familie und der Firma schuldig“(S. 97). Der gesamte Dritte Teil des Romans ist Tony und der Heirat mit Bendix Grünlich gewidmet (vgl. S. 100-184). Es wird deutlich, dass sie sich der ihr zugedachten Stellung und den damit verbundenen Erwartungen, nämlich standesgemäß und vorteilhaft zu heiraten, sehr bewusst ist und davon überzeugt, im Sinne der Familie und ihrer Tradition zu handeln (vgl. z. B. S. 115 und 116 sowie 172-174). Ihr Vater reagiert auf ihre Weigerung, Grünlich zu heiraten, mit Unverständnis (vgl. S. 122 f.) und macht ihr das ausdrücklich deutlich (vgl. z. B. S. 160 f.). Tatsächlich scheint sie sich dazu entschließen zu können, die Heirat als Glück anzusehen, jedenfalls, wenn man den Worten ihres Vaters glaubt: „Ach, Betsy, sie ist zufrieden mit sich selbst; das ist das solideste Glück, das wir auf Erden erlangen können.“ (S. 180) Aller- 
dings erweist sich nach der Zahlungsunfähigkeit Grünlichs und der damit verbundenen Enthüllung, dass er die Heirat allein aus finanziellen Erwägungen angestrebt hatte, das Scheitern des Plans. Es kommt hinzu, dass sie ihrem Vater mit Blick auf vier Jahre Ehe erklärt: „Ich habe ihn niemals geliebt ... er war mir immer widerlich ...“ (S. 237, vgl. dazu S. 238, insbesondere die Reaktion des Konsuls). Tony mag zwar eine Figur sein, die komische Züge trägt, es zeigt sich jedoch, welchen erheblichen Preis sie dafür gezahlt hat, die ihr zugewiesene Rolle zu erfüllen. Die zweite, mit Alois Permaneder geschlossene Ehe verdankt sich ihrem Bestreben, das Desaster der ersten Ehe zu kompensieren. Aufgrund in Teilen völlig verschiedener Ansichten und Ideale kann allerdings die Ehe keinen Bestand haben und wird nach einem Eklat auf ihr Betreiben hin aufgelöst. Das Ziel einer standesgemäßen Heirat, welches in diesem Milieu das einzige für eine Frau wie sie vorgesehene war, verfehlt Tony dauerhaft. Als bisweilen komischer Kontrast und als Parallelfiguren fungieren die drei Töchter Gottholds, Friederike, Henriette und Pfiffi, die unverheiratet bleiben, vor allem, weil sie aufgrund ihrer finanziellen Situation keine vorteilhafte Partie sind.

Die von der familiären Ordnung und dem Herkommen bestimmte Rollenerwartung, die bei Tony explizit und ausführlich thematisiert wird, kommt bei Thomas gleichfalls zum Tragen. Er ist fähig und willens, die ihm als Erstgeborenem zukommende Rolle als Firmenchef und Familienoberhaupt auszufüllen (vgl. z. B. S. 81 f., 257 und 259). Nachdem er die Firma übernommen hat, führt er sie mit großem Erfolg und Ehrgeiz (vgl. S. 292 f., dazu 277 und 332). Eine nicht standesgemäße Liebesbeziehung vermag er rechtzeitig aufzulösen (vgl. S. 182184, dazu bereits S. 169 f.). Die Heirat mit Gerda Arnoldsen ist in finanzieller Hinsicht aufgrund der stattlichen Mitgift eine hervorragende Partie und es soll sich um eine Liebesheirat handeln (vgl. S. 708 und bereits S. 332). Seine Stellung im Gemeinwesen wird durch die Wahl zum Senator noch erheblich erhöht. Äußerliches Zeichen des Wohlstandes ist der Bau eines eigenen Hauses. Sein Einsatz als Hausvater, Firmenchef und führendes Mitglied des Gemeinwesens bringt jedoch psychische und physische Beeinträchtigungen mit sich. In geschäftlichen Dingen stellen sich Misserfolge ein, Hanno erweist sich nicht als der gewünschte Stammhalter, andeutungsweise ist von einer Affäre Gerdas die Rede. Über weite Teile des Buches werden sein Alltag und seine Befindlichkeiten beschrieben (vgl. nur S. 392-400, 460-474, 511-523; ferner beinahe der gesamte Zehnte Teil, S. 672-764). Dass er am Ende vorzeitig stirbt, scheint damit zu tun zu haben, dass er auf die Dauer den beträchtlichen Anstrengungen nicht gewachsen ist, welche seine Stellung und seine Erwartung an sich selbst ihm abverlangen. 
Werden mit Tony und Thomas zwei Figuren gezeigt, die ihre sozialen Rollen erfüllen, wenn nicht übererfüllen wollen, so fungieren Christian und Clara als Kontrastfiguren. Anders als Thomas hat Christian große Schwierigkeiten, seiner Rolle gemäß zu leben, die aufgrund des Umstandes, dass er der zweite Sohn ist, in manchen Hinsichten wohl schwieriger ist. Das für ihn vorgesehene Studium bricht er ab, die kaufmännische Ausbildung ist mit Schwierigkeiten verbunden, die Tätigkeit in der väterlichen Firma ist nicht von Dauer, Versuche selbstständigen kaufmännischen Arbeitens scheitern. Er führt die meiste Zeit das Leben eines Junggesellen und bewegt sich am Rande dessen, was die herrschenden Konventionen gestatten. Seine Heirat mit einer Prostituierten und die Adoption ihrer drei Kinder, von denen eines von ihm sein soll, stellt den ultimativen Bruch mit seinem Milieu dar. Außerdem scheint er psychisch krank zu sein, jedenfalls führen seine schon früh vorhandenen und dann immer ausgeprägter werdenden „Wahnideen und Zwangsvorstellungen“ (S. 772) dazu, dass er in eine geschlossene Anstalt eingewiesen wird. Nach Meinung Gerdas ist er „kein Bürger“ beziehungsweise „noch weniger ein Bürger“ als Thomas (S. 495), fällt also gänzlich aus seiner sozialen Rolle.

Anders als Tony scheint Clara keinerlei Ambitionen zu haben, ihrer sozialen Rolle zu entsprechen. Das betrifft zum einen die Teilnahme am gesellschaftlichen Leben, zum anderen Ehe und Mutterschaft. Sie zeichnet sich durch „Strenge und Bigotterie“ aus (S. 301). Aufgrund ihres Charakters und ihres Verhaltens, so scheint es ihrer Mutter, sei es schwer, für sie einen geeigneten Ehemann zu finden: „Die Konsulin [...] konnte sich nicht verhehlen, daß es trotz der stattlichen Mitgift und Claras häuslicher Tüchtigkeit schwer halten werde, dies Kind zu verehelichen“ (S. 312). Sie heiratet Pastor Tiburtius und zieht mit ihm nach Riga, wo sie an „Gehirn-Tuberkulose“ stirbt (S. 471). Die Ehe bleibt kinderlos. Auf ihren angeblichen Wunsch hin erhält ihr Gatte mit Zustimmung ihrer Mutter und gegen den Widerstand von Thomas das ihr zustehende Erbe.

Erika, neben Hanno Vertreterin der vierten Generation, scheitert unverschuldet daran, ihre Rolle als Mädchen und dann Frau aus den besseren gesellschaftlichen Kreisen auszufüllen. Ihre Mutter Tony lebt in dem wohl nicht oder nur bedingt zutreffenden Bewusstsein, aufgrund ihrer zweimaligen Scheidung sozial geächtet zu sein, und verkehrt daher nicht in den Kreisen, zu denen sie sozial gehört (vgl. S. 482). Das mindert Erikas Chancen beträchtlich, eine angemessene Ehe einzugehen, was nicht zuletzt der dringliche Wunsch ihrer Mutter ist, die um das Ansehen der Familie besorgt ist und durch eine Heirat Erikas hofft, ihre gescheiterten Ehen vergessen zu machen. Die maßgeblich von Tony betriebene Heirat mit Hugo Weinschenk ist schon für sich genommen ein sozialer Abstieg, da der Ehemann nicht demselben Milieu entstammt, weniger wohl- 
habend und nicht von Familie ist, ferner nicht über die notwendige Bildung und die erforderlichen gesellschaftlichen Umgangsformen verfügt (vgl. z. B. S. 496 f.). Weil er aufgrund geschäftlichen Fehlverhaltens zu einer mehrjährigen Haftstrafe verurteilt wird, ist er sozial vernichtet. Nachdem einem Gnadengesuch stattgegeben wurde, verlässt er die Stadt und bricht den Kontakt zu Erika $\mathrm{ab}$.

Bei Hanno, dem jüngsten Buddenbrook, der in der Romanhandlung auftritt, kommt es noch nicht einmal mehr zu einem Konflikt, weil er nicht allein eine seiner sozialen Stellung entsprechende Rolle ablehnt, sondern sich, gerade auch in der Selbstwahrnehmung, als überhaupt lebensuntüchtig erweist. Seine labile Gesundheit, seine wenig ausgebildete Leistungsbereitschaft, zum Beispiel in schulischen Belangen, und seine stattdessen ausgeprägte Neigung zur Musik werden ausführlich geschildert. Den Zwang und die Anstrengung, welche es seinen Vater kostet, sich seiner sozialen Stellung gemäß zu verhalten, beobachtet er genau; solche Erfahrungen hinterlassen bei ihm einen negativen Eindruck (vgl. z. B. S. 690-692). Im Gespräch mit Kai sagt er ausdrücklich: „Seit mein Vater tot ist, haben Herr Stephan Kistenmaker und Pastor Pringsheim es übernommen, mich täglich zu fragen, was ich werden will. Ich weiß es nicht. Ich kann nichts antworten. Ich kann nichts werden. Ich fürchte mich vor dem Ganzen ...“(S. 819, vgl. dazu S. 820).

Diese Beobachtungen $\mathrm{zu}$ den Figuren verdanken sich keiner komplexen Analyse und Interpretation. Vielmehr handelt es sich um einfache Beschreibungen. Das spricht allerdings nicht gegen ihren Erkenntniswert im Rahmen der hier interessierenden Frage. Zusammengenommen fällt auf, dass sich zu allen Figuren Textbeobachtungen anführen lassen, welche mit Blick auf die Rollenproblematik einschlägig sind, und dass mitunter weite Teile der Schilderung im Roman genau diesem Thema gewidmet sind. Während die ersten beiden Generationen weitestgehend ihre Rollen erfolgreich ausfüllen, gelingt das den Angehörigen der dritten und vierten Generation nicht: Die männlichen Figuren scheitern daran, angemessen erwerbstätig zu sein und an der Öffentlichkeit des Gemeinwesens zu partizipieren; die weiblichen Figuren daran, eine standesgemäße und ökonomisch vorteilhafte Ehe einzugehen und als verheiratete Frau und Mutter zu leben. Im Rahmen einer auf Applikation ausgerichteten Lektüre, welche auf die Gehalte fokussiert ist, kann daher mit einer gewissen Wahrscheinlichkeit diese Dimension des Romans auffallen. Man kann also sagen, dass der Roman durchaus ein Applikationspotenzial im eingangs erwähnten Sinne aufweist. Um für die Plausibilität der These zu argumentieren, kann ergänzend darauf hingewiesen werden, dass die Forschung die damit eng verbundene Thematik von Ehe und Familie in ihrer Bedeutung bereits seit Länge- 
rem erkannt hat. ${ }^{165}$ Der Roman wurde verschiedentlich als Familienroman nach skandinavischem Vorbild klassifiziert. ${ }^{166}$

Die in Rede stehende Applikation ist nicht anachronistisch und erfordert nicht eine heutige Sicht auf den Roman, selbst wenn Wissen über soziale Rollen und ihre Auswirkungen heute präsenter sein mag als damals. Dass diese Sicht auf den Roman und seine potenzielle Applikation zeitgenössisch prinzipiell möglich war, zeigt bereits der Umstand, dass der Roman als naturalistisch wahrgenommen wurde - von professionellen Rezipient/-innen ebenso wie vom Autor. Die Buddenbrooks sind als der ,erste und einzige naturalistische Roman“ bezeichnet und dem „gleichen ästhetischen Umkreis“ wie naturalistische Dramen (Die Familie Selicke, Meister Oelze, Die Weber) zugeordnet worden. ${ }^{167}$ Wort-

165 Vgl. allein Eric Herd: Ehe und Familie. In: Moulden/Wilpert: Buddenbrooks-Handbuch, S. 213-228, und für einen Vorschlag zur sozialgeschichtlichen Klassifikation Julian Reidy: „Das ganze Haus“. Wilhelm Riehls Die Familie (1855) und Thomas Manns Buddenbrooks. In: Monatshefte für deutschsprachige Literatur und Kultur 106 (2014), S. 583-617.

166 Vgl. z. B. Leonie Marx: Thomas Mann und die skandinavischen Literaturen. In: Koopmann: Thomas-Mann-Handbuch. S. 164-199, hier S. 182-184; Ernest Schonfield: Buddenbrooks as Bestseller. In: Charlotte Woodford/Benedict Schofield: The German Bestseller in the Late Nineteenth Century. Rochester, NY 2012, S. 94-112, hier S. 96 und 99; Jannidis: „Unser moderner Dichter“, S. $51 \mathrm{f}$. Von der ursprünglichen Absicht, einen Familienroman zu schreiben, sprach Mann selbst, vgl. die Widmung für William Sawitzky, November 1906. In: Hans Wysling (Hg.): Thomas Mann, Selbstkommentare: Buddenbrooks. Frankfurt a. M. 1990, S. 35 f., hier S. 35. Vgl. zur allgemeinen literaturgeschichtlichen Einordnung und zum Bezug auf die literarische Tradition M. A. L. Brown: Thomas Manns Buddenbrooks and the Turn of the Century. In: James M. Ritchie (Hg.): Periods in German Literature. Bd. 2. London 1969, S. 221-244; Terence J. Reed: Thomas Mann. The Uses of Tradition. Oxford 1974. Es wurde betont, dass der Roman Merkmale verschiedener Gattungen - Bildungs-, Zeit-, Gesellschafts- bzw. Generationsroman aufweise, vgl. Roger Hillman: Zum Gattungstyp. In: Moulden/Wilpert: BuddenbrooksHandbuch, S. 63-68, hier S. 68. Das erklärt vielleicht abweichende Klassifikationen des Romans, etwa als Gesellschaftsroman in Fritz Kraul: Die Buddenbrooks als Gesellschaftsroman. In: Der Deutschunterricht 11 (1959), S. 88-103; als Antibildungsroman in Jürgen Scharfschwerdt: Thomas Mann und der deutsche Bildungsroman. Stuttgart 1967, S. 34; als ,intellektueller Roman' in Helmut Koopmann: Die Entwicklung des ,intellektuellen Romans‘ bei Thomas Mann. Untersuchungen zur Struktur von Buddenbrooks, Königliche Hoheit und Der Zauberberg. Bonn 1962; als realistischer und philosophischer Roman in Erich Heller: Thomas Mann: Buddenbrooks. In: Jost Schillemeit (Hg.): Deutsche Romane von Grimmelshausen bis Musil. Frankfurt a. M. 1966, S. 230-268, hier S. 230; als Heimatroman in Elizabeth Boa: Thomas Mann, Buddenbrooks. In: Peter Hutchinson (Hg.): Landmarks of the German Novel. Bd.1. Oxford u. a. 2007, S. 99-115.

167 Lublinski: Die Bilanz der Moderne, S. 226 und 227. Vgl. dazu Krüger: Romane, Sp. 19, wo der Roman gar als „Epigonenwerk“ des „naturalistischen Gesellschaftsromans“ angesehen wird. Deutlich weniger stark wurde der Zusammenhang in einer anderen Quelle gemacht: 
gleich sprach Mann in den Betrachtungen eines Unpolitischen davon, es sei „für Deutschland der vielleicht erste und einzige naturalistische Roman“. ${ }^{168}$ Derartige Aussagen lassen sich über die Jahre immer wieder finden und insbesondere für die 1920er nachweisen. ${ }^{169}$ Noch in On Myself, also 1940, nutzte er den Ausdruck „naturalistisch-fatalistisch“, um den Roman zu charakterisieren. ${ }^{170}$ Der Naturalismus wiederum rezipierte bekanntlich Annahmen der zeitgenössischen Soziologie, zu denen die Vorstellung gehört, dass soziale Phänomene bestimmten Gesetzen folgen und dass Milieu und Sozialisation determinierende Faktoren sind für die Entwicklung des Individuums. Für ein Verständnis des Romans und zur Realisierung seines Applikationspotenzials bedarf es allerdings nicht eines spezifischen, etwa soziologischen Expertenwissens. Alltagswissen über Milieus und Rollen, das unter Umständen eine popularisierte Version des besagten Expertenwissens darstellt, reicht aus.

Überlegungen dazu, warum dieses Applikationspotenzial dem Anschein nach nicht realisiert wurde, müssen an dieser Stelle Spekulation bleiben. Ruft man sich die Diskussion über Reuters Aus guter Familie in Erinnerung, dann ließe sich vermuten, dass eine Rezeption bezüglich der Rollenproblematik dem Verdikt ausgesetzt gewesen sein könnte, den Roman als ,Tendenzliteratur` zu behandeln und damit unangemessen, weil vermeintlich unliterarisch zu sein. Ferner ließe sich vermuten, dass die identifizierte zeitgenössische Applikation sich zumindest zum Teil der Rezeptionslenkung durch den Autor verdankt und damit zugleich andere verhinderte oder weniger wahrscheinlich machte. Letztlich wäre allerdings wohl zunächst der Ausgangsbefund angemessen einzuordnen: Die Zahl der ausgewerteten Quellen ist wohl nicht groß genug, um aus dem

Mann sei, wie die Buddenbrooks zeigten, vom Naturalismus ausgegangen, versuche aber, ihn zu überwinden, vgl. Karl Muth: Vom kalten Künstler. In: Hochland. Bd. 2 (1904), S. 614-616, hier S. 615.

168 Thomas Mann: Große kommentierte Frankfurter Ausgabe. Werke - Briefe - Tagebücher. Bd. 13.1: Betrachtungen eines Unpolitischen. Hg. von Hermann Kurzke. Frankfurt a. M. 2009, S. 98.

169 Vgl. z. B. Brief an Carl Helbling, 24. April 1922. In: Thomas Mann: Große kommentierte Frankfurter Ausgabe. Werke - Briefe - Tagebücher. Bd. 22: Briefe II. 1914-1923. Hg. von Thomas Sprecher/Hans R. Vaget/Cornelia Bernini. Frankfurt a. M. 2004, S. 434 f., hier S. 435; Thomas Mann: Nationale und internationale Kunst. Brief an den Redakteur. In: Th. M.: Große kommentierte Frankfurter Ausgabe. Werke - Briefe - Tagebücher. Bd. 15.1: Essays II. 19141926. Hg. von Hermann Kurzke. Frankfurt a. M. 2002, S. 505-512, hier S. 510; Thomas Mann: Lübeck als geistige Lebensform. In: Th. M.: Gesammelte Werke in zwölf Bänden. Bd. 11: Reden und Aufsätze 3. Frankfurt a. M. 1960, S. 376-398, hier S. 386.

170 Thomas Mann: On Myself. In: Th. M.: Gesammelte Werke in dreizehn Bänden. Bd.13: Nachträge. Frankfurt a. M. 1974, S. 127-169, hier S. 143. 
Befund, dass in ihnen ein bestimmtes Applikationspotenzial nicht realisiert wurde, darauf zu schließen, dass dies grundsätzlich nicht der Fall war.

\subsubsection{Verschiedene auktoriale Applikationen}

Mann hat sein Leben lang kontinuierlich über sich, sein Schreiben und seine literarischen Texte Auskunft gegeben sowie $\mathrm{zu}$ poetologischen und zeitgeschichtlichen Fragen Stellung genommen. Seine Äußerungen dienten „der Selbstprofilierung, der Selbststilisierung und der Rezeptionssteuerung “. ${ }^{171}$ Er war „ein glänzender Rezeptionslenker“, was bei den Buddenbrooks die Rezeption und Beurteilung mancher Akteur/-innen, darunter mancher Rezensent/innen, beeinflusst haben mag. ${ }^{172}$ Ein aussagekräftiges Beispiel ist ein Brief an Otto Grautoff, in welchem Mann ihm „[e]in paar Winke“ gibt, was er in zwei Besprechungen der Buddenbrooks erwähnen und wie beurteilen könne; dabei handelt es sich um durchaus weitreichende Lektüreanweisungen. ${ }^{173} \mathrm{Zu}$ beachten ist, dass Mann wahrnahm, wie die zeitgenössische Literaturwissenschaft seine literarischen Texte interpretierte, und darauf reagierte, zum einen, um die Rezeption zu steuern und Aufmerksamkeit zu generieren, zum anderen aber, indem er daraus Konsequenzen für seine weitere literarische Produktion zog. ${ }^{174}$

Die Forschung konnte zeigen, dass Manns Selbstäußerungen zu den Buddenbrooks „sich oft widersprechen“, trotz Akzentverlagerungen aber „Grundzü-

171 Thomas Sprecher: Strategien der Ruhmesverwaltung. Skizzen zu Thesen. In: Michael Ansel/Hans-Edwin Friedrich/Gerhard Lauer (Hg.): Die Erfindung des Schriftstellers Thomas Mann. Berlin/New York 2009, S. 37-46, hier S. 37.

172 Wißkirchen: Die frühe Rezeption von Thomas Manns Buddenbrooks, S. 301.

173 Brief an Otto Grautoff, 26. November 1901. In: Thomas Mann: Große Kommentierte Frankfurter Ausgabe. Werke - Briefe - Tagebücher. Bd. 21: Briefe I. 1889-1913. Hg. von Thomas Sprecher/Hans R. Vaget/Cornelia Bernini. Frankfurt a. M. 2002, S. 179 f., hier S. 179. Vgl. für ein etwas anders gelagertes Beispiel einen früheren Brief an denselben, in welchem er die eigene Familiengeschichte als Degenerationsgeschichte deutet: Brief an Otto Grautoff, [Ende Mai 1895]. In: Mann: Briefe I. 1889-1913, S. 57-59, hier S. 58.

174 Vgl. Steffen Martus: Die Geistesgeschichte der Gegenwartsliteratur. Wissenschaftliche Aufmerksamkeit für Thomas Mann zwischen 1900 und 1933. In: Michael Ansel/Hans-Edwin Friedrich/Gerhard Lauer (Hg.): Die Erfindung des Schriftstellers Thomas Mann. Berlin/New York 2009, S. 47-84, hier S. 49-53; Friedhelm Marx: „Lauter Professoren und Docenten“. Thomas Manns Verhältnis zur Literaturwissenschaft. In: Ansel/Friedrich/Lauer: Die Erfindung des Schriftstellers Thomas Mann, S. 85-96, insbesondere S. 95. 
ge“ erkennbar sind.$^{175}$ Es soll nicht in Abrede gestellt werden, dass es sich um wichtige Befunde handelt. Es kann im Folgenden aber nicht das Ziel sein, die Selbstaussagen hermeneutisch und autorphilologisch, biographisch und werkbiographisch zu erschließen. Entscheidender als eine umfassende Interpretation der Quellen, sei es für sich oder im Gesamtzusammenhang, ist die Frage, ob und welche intendierten Applikationen sich aus ihnen rekonstruieren lassen. Manns Aussagen mögen situativ bedingt sein oder sich aus Wirkungsabsichten oder den jeweiligen biographischen oder allgemeinen zeitgeschichtlichen Gegebenheiten erklären lassen. Es interessiert weniger, warum er solche Aussagen machte, die sich als Applikationen auffassen lassen, sondern dass er sie machte und sie folglich soziale Tatsachen und kommunikative Ereignisse waren, ob sie nun im öffentlichen Rahmen stattfanden oder in privater Kommunikation. Ausgewertet wurde in erster Linie eine einschlägige Quellensammlung. ${ }^{176}$ Andere Sammlungen, etwa eine Zusammenstellung der Interviews, die mit Mann geführt wurden, enthalten überraschenderweise keine für die Fragestellung relevanten Aussagen. ${ }^{177}$

Die Selbstaussagen sind auf verschiedene Aspekte des Romans und seiner Rezeption bezogen, von denen einige exemplarisch genannt werden können. Sie betreffen zum Beispiel das, was in seiner Wahrnehmung Fehlrezeptionen sind. In Anbetracht des oben erwähnten Vorwurfes, einen Schlüsselroman geschrieben zu haben, hat Mann den Unterschied zwischen der Faktualität des Stoffes und der Fiktionalität des literarischen Textes hervorgehoben. ${ }^{178}$ Andere betreffen die Rezeption und ihr Verhältnis zu seinen Intentionen allgemein. Rückblickend hat er festgestellt, dass die tatsächliche Rezeption und Wirkung

175 James Northcote-Bade: Selbstäußerungen und Selbstinterpretationen. In: Moulden/ Wilpert: Buddenbrooks-Handbuch, S. 353-363, hier S. 353.

176 Vgl. Hans Wysling (Hg.): Dichter über ihre Dichtungen. Bd.14: Thomas Mann. Teil I: 1889-1917. München/Frankfurt a. M. 1975, S. 30-135; auch separat: Hans Wysling (Hg.): Thomas Mann. Selbstkommentare: Buddenbrooks. Frankfurt a. M. 1990. Zitate im Folgenden (und bereits vorangehend) nach der Großen kommentierten Frankfurter Ausgabe und in Fällen, wo die Bände noch nicht vorliegen, nach den Gesammelten Werken.

177 Vgl. Volkmar Hansen/Gert Heine (Hg.): Frage und Antwort. Interviews mit Thomas Mann 1909-1955. Hamburg 1983.

178 Vgl. Thomas Mann: Bilse und ich. In: Th. M.: Große kommentierte Frankfurter Ausgabe. Werke - Briefe - Tagebücher. Bd. 14.1: Essays I. 1893-1914. Hg. von Heinrich Detering. Frankfurt a. M. 2002, S. 95-111, hier S. 101. Vgl. für eine späte Selbstaussage zur Rezeption des Romans als Schlüsselroman: Brief an Martha Hartmann, 15. April 1955. In: Thomas Mann: Briefe 1948-1955 und Nachlese. Hg. von Erika Mann. Frankfurt a. M. 1965, S. 393. 
seines Romans weit über seine Absichten hinausgegangen sei. ${ }^{179}$ Vereinzelt gibt es Aussagen, welche auf eine skeptische Einschätzung der Fortdauer der Rezeption schließen lassen. In einem Brief an Heinrich Mann aus dem Jahr 1913 hatte er dem Roman zwischenzeitlich jegliche Aktualität abgesprochen: „,Buddenbrooks‘ waren ein Bürgerbuch und sind nichts mehr fürs 20. Jahrhundert. “180 Unter den Selbstaussagen zum Roman sind solche, die auf Applikationen schließen lassen.

Eine erste Gruppe solcher Äußerungen stimmt mit der Applikation überein, die in den Rezeptionsdokumenten identifiziert wurde. In einem Brief an Hugo Marcus erläuterte Mann die Figur Hannos und die Konzeption des ,Schulkapitels‘. Er habe den „Contrast“ darstellen wollen „zwischen der scheuen Lebensunfähigkeit dieses nervös-künstlerischen Individuums und dem Leben wie es ist und wie es in Gestalt der Schule dem jungen Menschen zuerst entgegentritt“. Über dieses Leben, wie es sich in der Schule zeige, heißt es: „[D]as Leben selbst ist dumm und brutal, und das Leben hat immer recht und nicht Diejenigen, welche zu schwach und zu gut dafür sind“. ${ }^{181}$ Gegen die Wahrnehmung von Kurt Martens, der Roman sei „zersetzend“, hat er diese Sicht auf das Leben zu verteidigen versucht: „Noch jedes gute Buch, das gegen das Leben geschrieben wird, ist eine Verführung zum Leben ...". ${ }^{182}$ Seine Darstellungsabsicht hat er später in den Betrachtungen eines Unpolitischen wiederholt: Hanno „versagt am Leben überhaupt““. ${ }^{183}$ Außerdem hat er sie dort in eine künstlerische Konzeption einge-

179 Vgl. Thomas Mann: Zur Gründung einer Dokumentensammlung in Yale University. In: Th. M.: Gesammelte Werke in zwölf Bänden. Bd. 11: Reden und Aufsätze 3. Frankfurt a. M. 1960, S. 458-467, hier S. 461; Mann: On Myself, S. 138 f.; Thomas Mann: Der Künstler und die Gesellschaft. In: Th. M.: Gesammelte Werke in zwölf Bänden. Bd.10: Reden und Aufsätze 2. Frankfurt a. M. 1960, S. 386-399, hier S. 388 f.

180 Brief an Heinrich Mann, 8. November 1913. In: Th. M.: Große Kommentierte Frankfurter Ausgabe. Werke - Briefe - Tagebücher. Bd. 21: Briefe I. 1889-1913. Hg. von Thomas Sprecher/Hans R. Vaget/Cornelia Bernini. Frankfurt a. M. 2002, S. 534 f., hier S. 535.

181 Brief an Hugo Marcus, 11. Mai 1902, S. 199.

182 Brief an Kurt Martens, 28. März 1906. In: Thomas Mann: Große Kommentierte Frankfurter Ausgabe. Werke - Briefe - Tagebücher. Bd. 21: Briefe I. 1889-1913. Hg. von Thomas Sprecher/Hans R. Vaget/Cornelia Bernini. Frankfurt a. M. 2002, S. 356-362, hier S. 357. Vgl. zur dort zu findenden Einschätzung, dass die Darstellung „kritisch“ und „spöttisch“ sei, die spätere Rede von einem „pessimistischen Moralismus“ (Mann: Betrachtungen eines Unpolitischen, S. 584) und „pessimistischen Humor[]“ - Thomas Mann: Humor und Ironie. Beitrag zu einer Rundfunkdiskussion. In: Th. M.: Gesammelte Werke in zwölf Bänden. Bd. 11: Reden und Aufsätze 3. Frankfurt a. M. 1960, S. 801-805, hier S. 803.

183 Mann: Betrachtungen eines Unpolitischen, S. 624. Dort verwahrte er sich gegen die Annahme, der Roman habe eine kritische Absicht und sei ein Plädoyer für „Schulreform“; das geschehe bestenfalls auf „eine höchst vage und mittelbare Weise“. Außerdem deutete er Han- 
ordnet: „Die Kunst - ist sie nicht immer eine Kritik des Lebens, ausgeübt durch einen kleinen Hanno?"184 Mann ist wohl so $\mathrm{zu}$ verstehen, dass er die Absicht gehabt habe, eine Sicht auf das Leben zu vermitteln, wie sie in den ausgewerteten Rezeptionsdokumenten als Gegenstand einer Applikation vorkommt.

Vereinzelt lassen sich Indizien für eine Praxis des Umgangs mit dem Roman ausmachen, bei welcher er als ,Lebenshilfe‘ fungierte. Mann gibt Publikumsäußerungen wieder, die darauf schließen lassen. In einem Brief an Paul Amann schrieb er:

In Briefen, die ich bekomme, kehrt eine bestimmte Wendung wieder: die, daß ich mit meinen Sachen den Leuten ,leben geholfen' hätte. Nun, ich bin von dem sozialen Begriff des Helfens nicht ausgegangen, das gestehe ich; ich hatte zu sehr mit mir selbst zu thun, um mir einzubilden, anderen helfen zu können. Und doch habe ich anderen und zwar ganz offenbar vielen anderen, leben geholfen! $!^{185}$

Was damit im Einzelnen gemeint ist, wird nicht deutlich. Es liegt jedoch ausgesprochen nahe, darin Applikationen zu sehen, bei welchen das im Roman Dargestellte so gelesen wird, dass es, angewandt auf die eigene Situation, zu einem besseren Verständnis des eigenen Lebens beiträgt und in Fragen des Entscheidens und Handelns eine orientierende Funktion erfüllt.

Daneben äußerte er sich, in der Regel zu einem späteren Zeitpunkt, verschiedentlich in einer Form, die Rückschlüsse auf intendierte Applikationen zulässt. Die Äußerungen sind zwar eher randständig, aber dennoch von einer gewissen Aussagekraft. Mann hat verschiedentlich angenommen, dass der Roman Aufschlüsse gebe über das Bürgertum und bürgerliche Welt. So fand er sich durch einen Brief erneut in der Auffassung bestätigt, „daß dieses Jugendwerk den Leser mit einer kleinen bürgerlichen Welt und ihren Menschen wirklich und auf die Dauer vertraut macht“. ${ }^{186}$ Außerdem hat er in dem Roman einen

no im Sinne eines Dekadenzmodells als „Verfallsprinz und Musikexzedent“ (S. 624, vgl. dazu S. 116). Für ein weiteres Beispiel, dass der Roman „das Problem der Décadence behandelt“, vgl. den Brief an Paul Raché, 2. Dezember 1902. In: Thomas Mann: Große Kommentierte Frankfurter Ausgabe. Werke - Briefe - Tagebücher. Bd. 21: Briefe I. 1889-1913. Hg. von Thomas Sprecher/Hans R. Vaget/Cornelia Bernini. Frankfurt a. M. 2002, S. 221 f., hier S. 221.

184 Mann: Betrachtungen eines Unpolitischen, S. 624.

185 Brief an Paul Amann, 25. März 1917. In: Thomas Mann: Große kommentierte Frankfurter Ausgabe. Werke - Briefe - Tagebücher. Bd. 22: Briefe II. 1914-1923. Hg. von Thomas Sprecher/Hans R. Vaget/Cornelia Bernini. Frankfurt a. M. 2004, S. 178-182, hier S. 181. Vgl. für eine ähnliche Aussage Mann: Betrachtungen eines Unpolitischen, S. $241 \mathrm{f}$.

186 Brief an Jean Schlumberger, 18. September 1931. In: Thomas Mann: Große kommentierte Frankfurter Ausgabe. Werke - Briefe - Tagebücher. Bd. 23.1: Briefe III. 1924-1932. Hg. von Thomas Sprecher/Hans R. Vaget/Cornelia Bernini. Frankfurt a. M. 2001, S. 549 f., hier S. 549. 
Prozess der Genese des Bürgertums, genauer einer ,Entbürgerlichung‘ dargestellt wissen wollen, der, so hätten ihm andere versichert, auf andere europäische Länder übertragbar sei: „In der Schweiz, in Holland, in Dänemark habe ich junge Leute und Familiensöhne ausrufen hören: ,Dieser Prozeß der Entbürgerlichung durch Differenzierung, durch ein Überhandnehmen der Sensibilität genau wie bei uns!““187 Er habe mit dem Roman „ein Stück Seelengeschichte des deutschen Bürgertums überhaupt“ und des „europäischen“ geschrieben. ${ }^{188}$ Die Applikation, auf welche solche Angaben hinweisen, besteht darin, dass die Darstellung eines Milieus und seiner Veränderung über die Zeit als zutreffend für entsprechende Prozesse gesellschaftlicher Differenzierung und sozialen Wandels in der Realität angesehen wird.

An anderer Stelle hat Mann der Überzeugung Ausdruck verliehen, dass Thomas Buddenbrook nicht allein als deutscher Bürger konzipiert gewesen sei, sondern darüber hinaus einen modernen Bourgeois und ,Leistungsethiker verkörpere. $\mathrm{Zu}$ dieser zeitdiagnostischen Einsicht und $\mathrm{zu}$ der Erkenntnis, wonach es einen Zusammenhang gebe zwischen Kapitalismus und Protestantismus, will er unabhängig von der zeitgenössischen Soziologie (Max Weber, Ernst Troeltsch, Werner Sombart) gekommen sein:

Ich lege einigen Wert auf die Feststellung, daß ich den Gedanken, der modernkapitalistische Erwerbsmensch, der Bourgeois mit seiner asketischen Idee der Berufspflicht sei ein Geschöpf protestantischer Ethik, des Puritanismus und Kalvinismus, völlig auf eigene Hand, ohne Lektüre, durch unmittelbare Einsicht erfühlte und erfand und erst nachträglich, vor kurzem, bemerkt habe, daß er gleichzeitig von gelehrten Denkern gedacht und ausgesprochen worden. ${ }^{189}$

Unabhängig davon, für wie plausibel man die Selbsteinschätzung halten mag, lässt sich doch sagen, dass eine Applikation vorliegt. Die fiktive Figur exemplifiziert einen sozialen Typus und seine milieuspezifischen Gegebenheiten, die es

187 Thomas Mann: Pariser Rechenschaft. In: Th. M.: Große kommentierte Frankfurter Ausgabe. Werke - Briefe - Tagebücher. Bd.15.1: Essays II. 1914-1926. Hg. von Hermann Kurzke. Frankfurt a. M. 2002, S. 1115-1214, hier S. 1191. Vgl. für ähnliche Aussagen Mann: Lübeck als geistige Lebensform, S. 384; On Myself, S. 141 f. Vgl. dazu Lothar Pikulik: Leistungsethik contra Gefühlskult. Über das Verhältnis von Bürgerlichkeit und Empfindsamkeit in Deutschland. Göttingen 1984, S. 16-67.

188 Mann: Lübeck als geistige Lebensform, S. 383.

189 Vgl. Mann: Betrachtungen eines Unpolitischen, S. 158 f., das Zitat S. 159. Dazu auch: Brief an Pierre-Paul Sagave, Küsnacht, 23. Februar 1937. In: Dichter über ihre Dichtungen, S. 96. Vgl. ferner Sommer: Der Bankrott ,protestantischer Ethik', und Zeller: Bürger oder Bourgeois? 
tatsächlich geben soll, sowie eine ätiologische Deutung, die realweltlich zutreffen soll.

Schließlich hat Mann den nationalen Charakter des Romans betont. Es handele sich um „ein sehr deutsches Buch“. ${ }^{190}$ Diese Deutung verbindet sich mit weiterreichenden Aussagen. Die „Geschichte der Veredelung, Sublimierung und Entartung eines deutschen Bürgerstammes“, sei „zweifellos [ein] sehr deutsche[s] Buch, welches aber ebenso unzweifelhaft auch ein Merkmal nationalen Gesundheitsabstieges ist“. ${ }^{191}$ Die Applikation besteht mithin darin, das im Roman Dargestellte als typisch anzusehen für nationale Befindlichkeiten und es als Ausdruck einer Entwicklung, nämlich einer Dekadenz im nationalen Maßstab, zu sehen.

Zusammenfassend lässt sich für dieses Unterkapitel festhalten: Manns Buddenbrooks sind, soviel sich aufgrund der ausgewerteten Quellen sagen lässt, zeitgenössisch appliziert worden. Die Applikation, die möglich schien, bestand darin, in dem Roman eine Aussage darüber zu sehen, wie das Leben ist. Weitere Applikationen lassen sich nicht nachweisen. Eine Untersuchung der Beschaffenheit des Textes kann verständlich machen, was die Rezipient/-innen, überwiegend ,professionelle‘ Leser/-innen, zu dieser Applikation veranlasste. Aufgrund einer herrschenden Mentalität, dem Krisenbewusstsein um die Jahrhundertwende, schienen die Zeitgenossen disponiert, eine solche Applikation vorzunehmen. Außerdem weisen Selbstäußerungen Manns auf diese Applikation hin. Darüber hinaus scheint er, allerdings eher am Rande, in späteren Jahren seinen Roman in einer Weise gesehen zu haben, die sich als Aussage über intendierte Applikationspotenziale des Textes rekonstruieren lässt. Es fällt auf, dass eine aufgrund der Beschaffenheit des Textes naheliegende Applikation dem Anschein nach nicht realisiert wurde. Dass der Roman geeignet sein kann, etwas über die Bedeutsamkeit und Problematik sozialer Rollen auszusagen, wurde nicht wahrgenommen. Den Roman hinsichtlich der zeitgenössisch vorkommenden Applikationen, der intendierten Applikationen und des Applikationspotenzials des Textes zu untersuchen, erbringt, wie gezeigt werden konnte, durchaus neue Einsichten, selbst bei einem derart vielgelesenen und oft interpretierten, kanonischen, als Inbegriff klassisch-modernen Erzählens geltenden Roman.

190 Mann: Betrachtungen eines Unpolitischen, S. 97, vgl. dazu S. 97 f. und z. B. Brief an Kurt Martens, S. 357.

191 Mann: Betrachtungen eines Unpolitischen, S. 637. 


\subsection{Erich Maria Remarque: Im Westen nichts Neues (1928/1929)}

Erich Maria Remarques Im Westen nichts Neues erschien ab dem 8. November 1928 als Fortsetzungsabdruck in der Vossischen Zeitung. Das Datum dürfte nicht ganz zufällig gewählt worden sein, jährten sich doch in diesen Tagen zum zehnten Mal die Novemberrevolution und die Ausrufung der Republik am 9. November 1918. Die Erwartungen des Ullstein-Konzerns bezüglich der Resonanz seien, so die Selbstdarstellung, „in einer unerhörten Weise von der Wirklichkeit übertroffen worden“: „Denn noch niemals ist der Widerhall einer Romanpublikation mit einer solchen ungestümen Wucht zu uns gedrungen." ${ }^{192} \mathrm{Am}$ 31. Januar 1929 kam die Buchausgabe auf den Markt, die ein sensationeller Verkaufserfolg wurde. Schon am Erscheinungstag war die Startauflage von 30.000 Exemplaren vergriffen, zwei Wochen später wurde das 100. Tausend erreicht und rund zwölf Wochen später eine halbe Million. Nach sechzehn Monaten, also im Juni 1930, wurde die Millionengrenze überschritten. ${ }^{193}$ Bereits im gleichen Jahr erklärte Benno von Wiese in einem Artikel über aktuelle Kriegsromane das Buch zu einem „Volksbuch“. ${ }^{194}$ Ähnlich außergewöhnlich verlief die internationale Rezeption. Das Buch wurde rasch in zahlreiche Sprachen übersetzt und erreichte hohe Auflagen. ${ }^{195}$

Das erhebliche und kontroverse publizistische Echo, welches der Roman hervorrief, nahm der Propyläen-Verlag zum Anlass, bei Erscheinen des 500. Tausends eine Broschüre zu veröffentlichen, die den „Kampf um Remarque“, so der Titel, dokumentieren sollte. ${ }^{196}$ Einleitend verwahrte man sich ausdrücklich

192 [Anon.]: „Im Westen nichts Neues“. Remarques Buch erscheint. In: Vossische Zeitung. Nr. 26, 31. Januar 1929, Das Unterhaltungsblatt, S. [9].

193 Vgl. zu diesen Angaben Fritz Gaupp: Ein Million Remarque. In: Börsenblatt für den deutschen Buchhandel. Bd. 97, Nr. 131, 10. Juni 1930, S. 540 f.

194 Benno von Wiese: Das Bild des Krieges in der deutschen Literatur der Gegenwart. In: Zeitschrift für deutsche Bildung. Bd. 6, H. 1 (1930), S. 8-15, hier S. 9.

195 Eine zeitgenössische Quelle nennt die folgenden, wohl von Mitte 1929 stammenden Zahlen: Frankreich und England kommen auf jeweils 300.000 Exemplare, die US-Ausgabe auf 215.000; im fünfstelligen Bereich bewegen sich die dänische und norwegische Übersetzung (60.000 Exemplare), die schwedische und niederländische (jeweils 50.000), die spanische (25.000) und die tschechoslowakische (20.000); die rumänische Auflage betrug 6.000 Exemplare, die finnische 5.000. Vgl. dazu Sir Ian Hamilton/Erich Maria Remarque: The End of War? A Correspondence Between the Author of All Quiet on the Western Front and General Sir Ian Hamilton. In: Life and Letters (London). Vol. III, No. 18, November 1929, S. 399-411, hier S. 400 .

196 Vgl. [Anon.]: Der Kampf um Remarque. [Berlin 1929]. 
gegen die Vorstellung, der Erfolg des Romans sei „künstlich herbeigeführt worden““ ${ }^{197}$ Man reagierte damit nicht zuletzt auf Vorwürfe, Autor und Roman für eigene Zwecke zu instrumentalisieren. So hieß es zum Beispiel, der unpolitische Remarque habe das Buch allein aus psychohygienischen, rein privaten Motiven geschrieben und werde nun vom Ullstein-Konzern für die Propagierung pazifistischer Vorstellungen missbraucht. ${ }^{198}$ Dagegen wurde in der Broschüre geltend gemacht, dass vielmehr „die Wahrhaftigkeit des Werkes“ ursächlich sei, die „uns alle unser größtes Erlebnis noch einmal erleben ließ und uns zwang, jederzeit und zu jedem darüber zu sprechen“. ${ }^{199}$ Anhand zahlreicher Zitate aus Besprechungen und Artikeln zu dem Roman wird ein Eindruck davon gegeben, wie kontrovers er aufgenommen wurde, etwa hinsichtlich der Frage, ob er eine ,wahre' Darstellung des Krieges biete und ob er pazifistisch sei. Gerahmt werden die Zitate von einem Brief, den ein Kriegsblinder an Remarque schrieb, und Auszügen aus einem Gespräch mit dem Autor, sowie von einhellig positiven Stellungnahmen, die Politiker und Autoren zu dem Buch abgaben, und zwei etwas ausführlicher zitierten Rezensionen. Die ganze Broschüre soll erkennbar belegen, dass Remarque in einmaliger Weise eine zutreffende und exemplarische Schilderung der Fronterfahrung gelungen sei, in der sich die Überlebenden wiedererkennen können und die neutral berichtet, ohne eine bestimmte, etwa politische oder pazifistische Perspektive auf das Kriegsgeschehen zu vermitteln.

Die Strategie des Propyläen-Verlages war folglich darauf angelegt, dass der Roman als Kriegsliteratur wahrgenommen werden sollte. Ein solcher Text, so die zeitgenössische Erwartung, musste von einem Kriegsteilnehmer verfasst worden sein, ganz oder zumindest in wesentlichen Teilen auf eigenem Erleben beruhen, zeigen, wie es im Kriegseinsatz tatsächlich gewesen ist, literarische Darstellungstechniken lediglich unterstützend einsetzen und keine politischen

197 [Anon.]: Der Kampf um Remarque, S. [1].

198 Vgl. für ein aussagekräftiges Beispiel Martin Stoß: Die Front marschiert! Die Tragödie Remarque. In: Die Tat. Monatsschrift zur Gestaltung neuer Wirklichkeiten. Jg. 20, Bd. 2 (1928/1929), S. 934-937. Dort heißt es u. a.: „Remarque schreibt gegen seine Lehrer, gegen den Unteroffizier Himmelstoß, der ihn viehisch drangsalierte, gegen den Wahnsinn, mit dem junge Menschen, geistig wie körperlich, im Weltkrieg ausgelöscht wurden. Das aber heißt für Ullstein: Pazifismus. Und gerade dafür kämpft der Verlag in seinen Blättern, und deshalb setzt er auf das Manuskript Remarques den Stempel: angenommen. Remarque weiß nichts von Politik, Ullstein umsomehr. Leitartikel erscheinen, abstrakt und politisch: ,Hier redet zum ersten Mal der Krieg. Hier ringt sich aus einem einfachen Menschen das große Erleben los, und seht, es ist pazifistisch. Nie wieder Krieg!““ (S. 934).

199 [Anon.]: Der Kampf um Remarque, S. [1]. 
Botschaften vermitteln. ${ }^{200}$ In den Jahren ab 1926 wurden vermehrt Romane über den Krieg publiziert. Zu den bekannteren - in Form und Inhalt durchaus unterschiedlichen - Kriegsromanen dürften Georg von der Vrings Soldat Suhren (1927), Ernst Glaesers Jahrgang 1902 (1928), Ludwig Renns Krieg (1928) und Arnold Zweigs Der Streit um den Sergeanten Grischa (1928) gehören. ${ }^{201}$ Es war umstritten, ob Remarques Roman den generischen Anforderungen genügte. Die höchst aufschlussreiche zeitgenössische Rezeption des Romans soll im folgenden Abschnitt in Grundzügen dargestellt werden, um daraus Konsequenzen für das weitere Vorgehen abzuleiten. Wie gezeigt werden soll, war für den Umgang mit dem Roman die Applikation des Geschilderten zentral - mit Blick auf den Autor ebenso wie hinsichtlich der Vermittler/-innen und der Rezipient/-innen. ${ }^{202}$

\subsubsection{Zur Rezeption allgemein}

Die außergewöhnliche zeitgenössische Resonanz, welche der Roman im deutschsprachigen Raum und international hervorrief, dürfte mit dafür verantwortlich sein, dass die Forschung Fragen der Rezeption besondere Aufmerksamkeit widmete. Mitunter wurde sogar angemahnt, darüber nicht das „Werk

200 Vgl. Thomas F. Schneider: Das Genre bestimmt die Quelle. Anmerkungen zum Einfluß der Publikation und Rezeption auf die Entstehung und Quellenlage von Erich Maria Remarques Im Westen nichts Neues 1928/1929. In: Anton Schwob/Erwin Streitfeld/Karin Kranich-Hofbauer (Hg.): Quelle - Edition - Text. Ergebnisse der österreichisch-deutschen Fachtagung der Arbeitsgemeinschaft für germanistische Edition in Graz vom 28. Februar bis 3. März 1996. Tübingen 1997, S. 361-368, hier S. 362 f. Die Klassifikation des Romans als „Adoleszenzroman par excellence", wie sie an anderer Stelle vorgenommen wird, erweist sich demgegenüber als weniger informativ - Erhard Schütz: Nicht Manns genug? Remarque, Im Westen nichts Neues, 1928. In: Klaus-Michael Bogdal/Clemens Kammler (Hg.): (K)ein Kanon. 30 Schul-Klassiker neu gelesen. München 2000, S. 113-118, hier S. 117.

201 Vgl. zur aussagekräftigen literaturgeschichtlichen Einordnung Gregor Streim: Einführung in die Literatur der Weimarer Republik. Darmstadt 2009, S. 80 f.; Helmuth Kiesel: Geschichte der deutschen Literatur von den Anfängen bis zur Gegenwart. Bd. 10: Geschichte der deutschsprachigen Literatur 1918 bis 1933. München 2017, S. 770-798.

202 Sogar die jüngere Forschung liefert vereinzelt Beispiele für Applikationen. Das gilt etwa für die Annahme, der Roman könne eine überzeitliche Einsicht vermitteln, nämlich eine postheroische Sicht auf das Töten - vgl. Tilman Westphalen: „Kultur von Jahrtausenden“ und „Ströme von Blut“. Erich Maria Remarque: Im Westen nichts Neues. In: Erich-Maria-RemarqueJahrbuch 21 (2011), S. 47-64, hier S. 61-64. Vgl. dazu Tilman Westphalen: „Mein Thema ist der Mensch dieses Jahrhunderts, die Frage der Humanität“. Erich Maria Remarque als Chronist Deutscher Geschichte. In: T. W. (Hg.): Erich Maria Remarque 1898-1970. Bramsche 1988, S. 1328. 
selbst“ und dessen Interpretation zu vernachlässigen. ${ }^{203}$ Während sich erste, vereinzelte Forschungsbeiträge bereits zur Zeit des Erscheinens nachweisen lassen, ${ }^{204}$ findet eine umfangreichere Auseinandersetzung mit dem Roman aus offenkundigen historischen und fachgeschichtlichen Gründen erst ab den 1970er Jahren statt. Sie ist nicht auf die germanistische Literaturwissenschaft beschränkt. ${ }^{205} \mathrm{Zu}$ Entstehung und Distribution, (Erst-)Rezeption und Wirkung des Romans liegen mittlerweile zahlreiche Arbeiten vor. ${ }^{206}$ Ähnliches gilt für die Aufnahme der US-amerikanischen Verfilmung (All Quiet on the Western Front, 1930, Regie: Lewis Milestone) und für die nationalsozialistische Agitation dagegen. ${ }^{207}$ Eingehender untersucht wurde die vielfältige Übersetzung und Rezepti-

203 Harald Kloiber: Struktur, Stil und Motivik in Remarques Im Westen nichts Neues. In: ErichMaria-Remarque-Jahrbuch 4 (1994), S. 65-78, hier S. 65. Vgl. für ein weiteres Beispiel, das Aspekte des Textes in den Vordergrund stellt, Howard M. De Leeuw: Remarque's Use of Simile in Im Westen nichts Neues. In: Erich-Maria-Remarque-Jahrbuch 4 (1994), S. $45-64$.

204 Vgl. z. B. Herbert Cysarz: Zur Geistesgeschichte des Weltkrieges. Die dichterischen Wandlungen des deutschen Kriegsbildes 1910-1930. Halle a. d. S. 1931, S. 138-143.

205 Vgl. als Beispiele aus der angloamerikanischen Forschung Alan F. Bance: Im Westen nichts Neues: A Bestseller in Context. In: Modern Language Review 72 (1977), S. 359-373; Brian Murdoch: Habent sua fata libelli: Ernst Johannsen's Vier von der Infantrie and Remarque's Im Westen nichts Neues. In: Erich-Maria-Remarque-Jahrbuch 5 (1995), S. 19-38; Brian Murdoch/ Mark Ward/Maggie Sargeant (Hg.): Remarque Against War. Essays for the Centenary of Erich Maria Remarque 1898-1970. Glasgow 1998; Harold Bloom (Hg.): Erich Maria Remarque's All Quiet on the Western Front. Philadelphia 2001; Brian Murdoch (Hg.): All Quiet on the Western Front. Pasadena, CA 2010.

206 Vgl. z. B. Johannes Brautzsch: Untersuchungen über die Publikumswirksamkeit der Romane Im Westen nichts Neues und Der Weg zurück von Erich Maria Remarque vor 1933. Diss. Potsdam 1970; Richard A. Firda: Erich Maria Remarque. A Thematic Analysis of His Novels. New York u. a. 1988, S. 29-64; Hubert Rüter: Erich Maria Remarque: Im Westen nichts Neues. Ein Bestseller der Kriegsliteratur im Kontext. Paderborn u. a. 1990, S. $13-64$ und 150-173; Thomas Becker: Literarischer Protest und heimliche Affirmation. Das ästhetische Dilemma des Weimarer Antikriegsromans. Butzbach-Griedel 1994, S. 20-34; Imke Harjes: Im Westen nichts Neues. Bestseller und politischer Skandal. In: Petra Bohnsack/Hans-Friedrich Foltin (Hg.): Lesekultur. Populäre Lesestoffe von Gutenberg zum Internet. Marburg 1999, S. 176-188; Günther Oesterle: Das Kriegserlebnis im für und wider. Im Westen nichts Neues von Erich Maria Remarque (1929). In: Dirk van Laak (Hg.): Literatur, die Geschichte schrieb. Göttingen 2011, S. 213-223.

207 Richard Albrecht: Erich Maria Remarques Im Westen nichts Neues - Kleine Hinweise auf große Wirkung 1930 bis 1932 oder Noch einmal über Aspekte des Abwehrkampfes gegen den Nationalsozialismus und die Rolle einiger Intellektueller. In: Krieg und Literatur. Internationale Beiträge zur Erforschung der Kriegs- und Antikriegsliteratur 1 (1989), S. 65-78; Peter Dörp: Goebbels' Kampf gegen Remarque. Eine Untersuchung über die Hintergründe des Hasses und der Agitation Goebbels' gegen den Roman Im Westen nichts Neues von Erich Maria Remarque. In: Erich-Maria-Remarque-Jahrbuch 1 (1991), S. 48-64; Peter Dörp: Goebbels' Kampf gegen 
on des Romans (und der Verfilmung) in anderen Ländern. ${ }^{208}$ Nicht zuletzt fanden die Gegenschriften Beachtung, die der Roman provozierte. ${ }^{209}$

\begin{abstract}
Remarque (2). Eine Untersuchung über die Hintergründe des Hasses und der Agitation Goebbels' gegen den amerikanischen Spielfilm Im Westen nichts Neues nach dem gleichnamigen Bestsellerroman von Erich Maria Remarque. In: Erich-Maria-Remarque-Jahrbuch 3 (1993), S. 45-72; Hans Beller: Der Film All Quiet on the Western Front und die Feindbildproduktion in Hollywood. In: Thomas F. Schneider (Hg.): Erich Maria Remarque. Leben, Werk und weltweite Wirkung. Osnabrück 1998, S. 187-204; Kai Nowak: Die Politik des Filmskandals. Die kommunikativen Folgen des Skandals um den Film Im Westen nichts Neues (USA 1930). In: Hans Peter Brecht (Hg.): Politik, Kommunikation und Kultur in der Weimarer Republik. Heidelberg 2009, S. 161-178. Quellen zur Rezeption des Films in Deutschland und Österreich sind zusammengestellt in Bärbel Schrader (Hg.): Der Fall Remarque: Im Westen nichts Neues. Eine Dokumentation. Leipzig 1992, S. 103-288. Dort ist ferner das Drehbuch in deutscher Übersetzung abgedruckt (vgl. S. 289-408).
\end{abstract}

208 Vgl. Hubert Orlowski: Die polnische Kriegsliteratur und Erich Maria Remarque. In: ErichMaria-Remarque-Jahrbuch 1 (1991), S. 18-29; Qinghua Li: Remarque-Rezeption in China. In: Erich-Maria-Remarque-Jahrbuch 1 (1991), S. 30-47; Roman Dziergwa: Die Rezeption und der Streit um den Roman Im Westen nichts Neues von E.M. Remarque in der literarischen Öffentlichkeit des Vorkriegspolen. In: Studia Germanica Posnaniensia 20 (1993), S. 59-68; Karen M. Beukers: Die Remarque-Rezeption in den Niederlanden. In: Erich-Maria-Remarque-Jahrbuch 7 (1997), S. 73-92; Rainer Bendick: Im Westen nichts Neues und die pädagogisch-didaktischen Diskussionen in Deutschland und Frankreich Ende der 20er/Anfang der 30er Jahre. In: Thomas F. Schneider (Hg.): Erich Maria Remarque. Leben, Werk und weltweite Wirkung. Osnabrück 1998, S. 151-185; Heather Valencia: Ostjüdische Rezeption von Remarque. Drei jiddische Übersetzungen von Im Westen nichts Neues. In: Thomas F. Schneider (Hg.): Erich Maria Remarque. Leben, Werk und weltweite Wirkung. Osnabrück 1998, S. 431-444; Uwe Zagratzki: Remarque und seine britischen Kritiker. Rezensionen und Korrespondenzen zwischen 1928 und 1938. In: Erich-Maria-Remarque-Jahrbuch 10 (2000), S. 9-30, hier S. 10-14; Jesper Düring Jørgensen: Karl Larsen und Erich Maria Remarque. Aspekte der Rezeption und Übersetzung von Im Westen nichts Neues in Dänemark. In: Erich-Maria-Remarque-Jahrbuch 11 (2001), S. 9-46; Susana Cañuelo Sarrión: Die Rezeption von Im Westen nichts Neues und All Quiet on the Western Front in Spanien. In: Erich-Maria-Remarque-Jahrbuch 11 (2001), S. 47-70; Wesselin Diankov: Im Westen nichts Neues in Bulgarien (Roman, Film, Theater). In: Erich-Maria-Remarque-Jahrbuch 11 (2001), S. 71-86; Marcela Müllerová-Pavličková: Zur tschechischen übersetzerischen Rezeption von E.M. Remarques Roman Im Westen nichts Neues. In: Germanoslavica 9 (2002), S. 7795; Thomas F. Schneider/Roman R. Tschaikowski (Hg.): In 60 Sprachen. Erich Maria Remarque: Übersetzungsgeschichte und -probleme. Osnabrück 2002; Roman R. Tschaikowski u. a.: Erste Übersetzung des Romans Im Westen nichts Neues von Erich Maria Remarque ins Russische. In: Erich-Maria-Remarque-Jahrbuch 24 (2014), S. 33-44; Jordi Jané-Lligé: Res de nou a l'oest. Remarques Rezeption in Katalonien. In: Erich-Maria-Remarque-Jahrbuch 26 (2016), S. $27-48$.

209 Vgl. Brian Murdoch: All Quiet on the Trojan Front. Remarque, Homer and War as the Targets of Literary Parody. In: German Life and Letters 43 (1989), S. 49-62; Günter Hartung: 
Es stellt sich die Frage, wie Resonanz und Erfolg des Romans erklärt werden können. Das hat schon die Zeitgenossen beschäftigt. Wohl bereits als Teil der Vermarktungsstrategie ist die Aussage anlässlich des Erscheinens zu bewerten, dass man nun, zehn Jahre nach Ende des Krieges, „die wohltätige Distanz zu den Greueln der vier blutigen Jahre gewonnen habe[]“, und dass die „Ergriffenheit“ des Autors nicht ohne Wirkung auf die Rezipient/-innen bleiben könne. ${ }^{210}$ Schon der Fortsetzungsabdruck in der Vossischen Zeitung war mit einem ausführlichen Artikel auf der ersten Seite angekündigt worden, in dem sinngemäß das folgende Bild vermittelt wurde: Mit dem erforderlichen zeitlichen Abstand habe sich nun, nach langen Jahren des Schweigens, in welchen sich nur die ranghohen Militärs über den Krieg äußerten, endlich einer aus der ,verlorenen Generation' gefunden, um das Erleben der einfachen Soldaten zu schildern. Der Autor sei kein professioneller Schriftsteller, sondern ein junger Mann, der aus innerem Antrieb gehandelt habe, sein Text sei weder Roman noch Tagebuch, sondern gestaltetes Erleben, dabei wahr und allgemeingültig, tendenzlos und erschütternd. ${ }^{211}$ Eine derartige Inszenierung des Autors und seines Textes dürfte potenziell ein wichtiger Faktor für den Erfolg gewesen sein, zumal man damit, wie erwähnt, generische Erwartungen bediente.

Die Vermarktungsstrategien sind eingehender untersucht worden. Dazu gehörten neben dem Vorabdruck und dessen Bewerbung der Abdruck von Leserbriefen sowie der Versand von Vordrucken und Leseproben, das Schalten von Anzeigen und Plakatwerbung sowie die Besprechung des Romans in Publikationen des Ullstein-Konzerns. ${ }^{212}$ Neben der Inszenierung des Autors und der

Gegenschriften zu Im Westen nichts Neues und Der Weg zurück. In: Thomas F. Schneider (Hg.): Erich Maria Remarque. Leben, Werk und weltweite Wirkung. Osnabrück 1998, S. 109-150.

210 [Anon.]: „Im Westen nichts Neues“. Remarques Buch erscheint, S. [9].

211 Vgl. [Anon.]: Nichts Neues im Westen. In: Vossische Zeitung. Nr. 529, 8. November 1928, S. [1].

212 Vgl. Angelika Howind: Ein Antikriegsroman als Bestseller. Die Vermarktung von Im Westen nichts Neues 1929-1930. In: Tilman Westphalen (Hg.): Erich Maria Remarque 1898-1970. Bramsche 1988, S. 55-64; Rüter: Erich Maria Remarque, S. 54-56; Thomas F. Schneider: „Die Meute hinter Remarque“. Zur Diskussion um Im Westen nichts Neues 1929-1930. In: Jahrbuch zur Literatur der Weimarer Republik 1 (1995), S. 143-170, hier S. 145 f.; Thomas F. Schneider: „Am besten nichts Neues“? Zum Stand der Remarque-Forschung. In: Th. F. Sch. (Hg.): Erich Maria Remarque. Leben, Werk und weltweite Wirkung. Osnabrück 1998, S. 27-39, hier S. 36 f.; Christian Salzmann: „Im Westen“, Ullstein und das Internet. Im Westen nichts Neues im Internet und der Zusammenhang mit der Marketing-Strategie des Ullstein-Verlages für den Remarque-Bestseller. In: Erich-Maria-Remarque-Jahrbuch 14 (2004), S. 34-54; Thomas F. Schneider: Das virtuelle Denkmal des unbekannten Soldaten. Erich Maria Remarques Im Westen nichts Neues und die Popularisierung des Ersten Weltkrieges. In: Barbara Korte/Sylvia Palet- 
Vermarktung des Romans sind der Text und seine Beschaffenheit als Faktoren für den Erfolg ausgemacht worden. Hingewiesen wurde etwa auf die „Besonderheit seiner künstlerischen Gestalt“, die darin zu sehen sei, dass das Kriegserlebnis nicht durch Zuschreibung eines Sinns idealisiert werde: „In der Erfahrung des Vernichtetwerdens, des langsamen, blinden und völlig unheldischen Vernichtetwerdens, werden alle Ideen und Maße sinnlos“. ${ }^{213}$ Dagegen wurde aber zum Beispiel die „rücksichtslose und naturalistische Derbheit“ der Darstellung kritisiert, welche „dem Buche den reißenden Absatz sicherte“. ${ }^{214}$ In der Forschung wurde die These vertreten, dass der Roman Züge eines populären oder trivialen Romans trage, der ein verallgemeinerbares, auf Deutung des Geschehens verzichtendes Identifikationsangebot gemacht habe. ${ }^{215}$

Des Weiteren können die Umstände als Faktor angeführt werden. In einer zeitgenössischen Quelle wurde der Erfolg damit erklärt, dass der Roman „den Bankrott des demokratischen Militarismus“ zeige: Man habe in der Mehrzahl Männer in den Krieg geschickt, die sich nicht als Soldaten eigneten und den Krieg daher so erlebten, wie im Roman geschildert. ${ }^{216}$ An diesem spezielleren Beispiel zeigt sich der wohl weitgehend unstrittige Befund, dass der Erste Weltkrieg und das Schreiben darüber in der Weimarer Republik ein Politikum war; ein Umstand, der dazu beiträgt, Art und Ausmaß der positiven und negativen Reaktionen auf den Roman verständlich zu machen. Das Spektrum der politisch-weltanschaulichen Reaktionen reichte von bellizistisch-nationalistischen über liberale und pazifistische bis hin zu kommunistischen. ${ }^{217}$

schek/Wolfgang Hochbruck (Hg.): Der Erste Weltkrieg in der populären Erinnerungskultur. Essen 2008, S. 89-98, hier S. 93.

213 Wiese: Das Bild des Krieges in der deutschen Literatur der Gegenwart, S. 9 und 10.

214 [Anon.]: Im Westen nichts Neues. Der Dichter ... ... und wir Jungen. In: Die Kommenden. Überbündisches Blatt der volksbewußten Jugend. H. 18, 3. Mai 1929, S. 208. Zitiert nach Schrader: Dokumentation, S. 88-92, hier S. 91.

215 Vgl. Jost Hermand: Versuch, den Erfolg von Erich Maria Remarques Im Westen nichts Neues zu verstehen. In: Dieter Borchmeyer/Till Heimeran (Hg.): Weimar am Pazifik. Literarische Wege zwischen den Kontinenten. Festschrift für Werner Vordtriede zum 70. Geburtstag. Tübingen 1985, S. 71-78, insbesondere S. 74-76. Vgl. dazu Jan Süselbeck: Reflexionslosigkeit als Erfolgsrezept. Zum soldatischen Identifikationspotential in Erich Maria Remarques Bestseller Im Westen nichts Neues (1929). In: Wirkendes Wort 59 (2009), S. 383-403.

216 Rudolf Ibel: Remarque oder Der Bankrott des demokratisierten Militarismus. In: Der Kreis. Zeitschrift für künstlerische Kultur. Jg. 7, 3. März 1930, S. 169-173. Zitiert nach Schrader: Dokumentation, S. 96-102, hier S. 96.

217 Als maßgeblich kann nach wie vor gelten: Michael Gollbach: Die Wiederkehr des Weltkrieges in der Literatur. Zu den Frontromanen der späten Zwanziger Jahre. Kronberg i. Ts. 1978. Die Arbeit untersucht neben Remarques Roman die Rezeption anderer, kommunistischer und 
Es wurde gezeigt, dass Remarques Roman insofern innovativ war, als er eine Alternative anbot zur bis dato dominierenden ,referenzialisierenden Kriegsliteratur' (Kriegstagebücher, Kriegsberichte und Offiziersmemoiren), die zunehmend als nicht mehr relevant wahrgenommen wurde. ${ }^{218}$ Der Roman habe so gelesen werden können, dass er Probleme behandelte, welche viele Rezipienten an sich selbst wahrnahmen und die gerade am Ende der 1920er Jahre akut wurden, und dafür eine Erklärung anbot:

[E]ine Vielzahl von Lesern hatte das Problem, ein Berufsziel nicht erreicht, einen selbstgesetzten Karrierefahrplan nicht realisiert, mit einem anderen als dem angestrebten Beruf vorlieb genommen oder einen Statusverlust bzw. andere ihre Lebensgeschichte einschneidend verändernde Verluste erlitten zu haben. Sowohl der Krieg selbst als auch die Nachkriegskrisen und die Inflation stellten mögliche Ursachen solcher Verluste von einer Reichweite dar, von der kaum eine Schicht der Bevölkerung nicht betroffen wurde. In den Nachkriegskrisen selbst konnten derartige Verluste, das Scheitern von Hoffnungen und die Unmöglichkeit, selbstgesetzte Ziele zu erreichen, angesichts der allgemeinen Krisenhaftigkeit des gesellschaftlichen Lebens noch mit der Hoffnung auf spätere Kompensation ,bewältigt‘ werden; in einer Phase der Normalisierung und Stabilisierung der gesellschaftlichen Verhältnisse wurden die bezeichneten Probleme jedoch lösungsbedürftig. ${ }^{219}$

Der Roman konnte so aufgefasst werden, dass die Ursache für individuelles Scheitern im Krieg und seinen Folgen zu sehen sei, und eine entlastende Funktion erfüllen: Er reduzierte Komplexität und bot eine Erklärung für die eigene Lage an, bei welcher die Rezipienten die Schuld nicht bei sich selbst suchen mussten. ${ }^{220}$ Es lässt sich davon sprechen, dass der Sache nach eine Applikation vorliegt: Die Rezipienten bezogen das Gelesene auf sich und ihre Situation und kamen zu dem Schluss, dass das Geschilderte auf sie anwendbar ist und Einsichten in ihre Biographie und jetzige Lebenssituation ermöglicht.

Remarque hat in einem anscheinend unveröffentlicht gebliebenen Text den Erfolg seines Romans damit erklärt, dass ihm eine zugängliche und zutreffende Schilderung des Alltags im Krieg gelungen sei: „Mein Buch hatte Erfolg, weil es in aller Einfachheit die menschliche Seite des Lebens in den Schützengräben

nationalistischer, Kriegsromane der Zeit und stellt ausführlich die nationalistische und marxistische Kritik an Im Westen nichts Neues dar, vgl. S. 293-305 und S. 309-314. Vgl. dazu HansHarald Müller: Der Krieg und die Schriftsteller. Der Kriegsroman der Weimarer Republik. Stuttgart 1986, S. 66-93.

218 Vgl. Müller: Der Krieg und die Schriftsteller, S. 36-39 und dazu S. 11-35.

219 Müller: Der Krieg und die Schriftsteller, S. 62 f.

220 Müller: Der Krieg und die Schriftsteller, S. 63. 
wiedergab, menschliche Größe und Gebrechlichkeit, Mut und Schneid. “221 Welche Faktoren mit welcher Gewichtung den Erfolg des Romans erklären, muss und kann an dieser Stelle offen bleiben.

Als maßgebliches Standardwerk zur Entstehung, Vermittlung und Rezeption des Romans kann eine umfangreiche Arbeit angesehen werden, deren Ergebnisse etwas ausführlicher darzustellen sind. Ursprünglich habe Remarque einen Roman über den Krieg geplant, der nicht oder nur zum Teil autobiographisch angelegt sein sollte, und das bereits sehr früh, nämlich noch während oder kurz nach dem Krieg (1917 bis 1921/22). ${ }^{222}$ Dann habe er sich entschlossen, einen überwiegend autobiographischen Roman mit fiktiven Elementen zu verfassen und den Plan 1927 dahingehend geändert, dass autobiographische Elemente wieder in den Hintergrund traten. Die Absicht sei nun gewesen, „einen Kommentar der Nachkriegsgesellschaft“ zu verfassen, in dessen Rahmen er zum einen eine „fundamentale[] Kritik der Vorkriegswerte [...], die durch den Krieg zerstört wurden“, leisten und zum anderen „die Nachkriegsereignisse im Hinblick auf die Schwierigkeiten der Kriegsteilnehmer bei der Re-Integration in die zivile Gesellschaft“ darstellen wollte. ${ }^{223}$ An dieser Konzeption, die auf eine Trilogie angelegt war, hat Remarque bis zuletzt nichts mehr geändert.

Das Bestreben des Verlages sei es dagegen gewesen, den Text der Kriegsliteratur oder Kriegserinnerungsliteratur zuzuordnen und als eine ,authentische‘, ,wahre' und nicht wertende Kriegsbeschreibung erscheinen zu lassen, ohne den Bezug auf die Nachkriegszeit. Der Text sollte ,entpolitisiert' und als kriegskritisch wahrnehmbare Aussagen gestrichen werden. Die als erforderlich angesehenen Änderungen habe der Verfasser auf Wunsch des Verlages vorgenommen. Verfasser und Verlag seien nach außen hin bemüht gewesen, ein bestimmtes Bild der Entstehung des Romans und seiner Beschaffenheit zu vermitteln. ${ }^{224}$ Mit diesen Informationen über die Genese des Textes lässt sich in Teilen seine Beschaffenheit erklären sowie die öffentlichen Verlautbarungen des Autors und mancher der an der Distribution beteiligten Akteure.

Besonders aufschlussreich sind die Befunde einer qualitativen Auswertung und statistischen Aufbereitung von weit über vierhundert Rezeptionsdokumen-

221 Erich Maria Remarque: Haben meine Bücher Tendenz? (1931/1932). Zitiert nach E. R. M.: Ein militanter Pazifist. Texte und Interviews 1929-1966. Hg. von Thomas F. Schneider. Köln 1998, S. 62-65, hier S. 65.

222 Vgl. hierzu und zum Folgenden Thomas F. Schneider: Erich Maria Remarques Roman Im Westen nichts Neues. Text, Edition, Entstehung, Distribution und Rezeption (1928-1930). Tübingen 2004, S. 277-283, zusammenfassend S. 409.

223 Schneider: Erich Maria Remarques Roman Im Westen nichts Neues, S. 278.

224 Vgl. Schneider: Erich Maria Remarques Roman Im Westen nichts Neues, S. 281 f. 
ten. ${ }^{225}$ Darunter stellen die Rezensionen die Mehrzahl (70\%), neben Gegenschriften, Leserbriefen, Werbematerial und Interviews. Die meisten Texte erschienen zwischen Februar und Juli 1929. Manche Befunde erweisen sich als relevant für die hier interessierende Fragestellung. In 41 Quellen wurden Vermutungen zur Intention des Verfassers angestellt. In 30 Fällen wurde dem Autor die Absicht zugeschrieben, er habe mit dem Roman eigene Kriegserlebnisse aufarbeiten und bewältigen wollen, nur siebenmal wurde angenommen, er habe die zerstörte Generation der Kriegsteilnehmer schildern wollen. ${ }^{226}$ Weitaus häufiger wurden Angaben zum Thema des Romans und dessen Behandlung gemacht. Von insgesamt 188 Quellen, in denen sich Hinweise darauf finden, nahmen 95\% an, der Roman handele vom Krieg (nicht vom Nachkrieg). ${ }^{227}$ 62\% (von 208 Quellen) hielten den Text für literarisch (statt dokumentarisch). ${ }^{228}$ In 142 Fällen wurde die Ansicht vertreten, der Roman habe eine ,Tendenz', ca. zwei Drittel der Verfasser bewerteten dies negativ; in 79 Fällen wurde die Ansicht vertreten, der Roman habe keine ,Tendenz', rund 70\% bewerteten dies positiv. ${ }^{229}$ Bei denen, die dem Roman eine Tendenz zuschrieben, hielten 48\% den Text für kriegskritisch, 20\% für pazifistisch und rund 18\% für die Darstellung einer verlorenen Generation (,kriegsdiffamierend“ kommt auf 8\%, ,antideutsch' auf 2\%). ${ }^{230}$

Von besonderem Interesse war die Frage, ob das im Roman Dargestellte Faktizität und Authentizität beanspruchen kann. Von insgesamt 114 Quellen, in denen sich die Verfasser zu dieser Frage äußerten, waren rund 66\% der Meinung, der Roman schildere eigenes Erleben (nicht nur teilweise oder gar nicht). ${ }^{231}$ Rund 78\% (von insgesamt 228) waren überzeugt, der Roman gebe Kriegsereignisse faktisch richtig wieder (und nicht nur überwiegend oder überwiegend nicht oder gar nicht). ${ }^{232}$ Rund 64\% (von insgesamt 292) nahmen an, der Roman sei in seinen Schilderungen ,authentisch', vermittle also die Atmosphäre im Kriegseinsatz, das Denken der Soldaten und dergleichen in zutreffender Weise, 30\% nahmen an, dies sei nicht der Fall. ${ }^{233}$ Es lässt sich ein Phasenverlauf feststellen: Von November 1928 bis Februar 1929 wurde der Roman überwiegend

225 Vgl. zum Folgenden Schneider: Erich Maria Remarques Roman Im Westen nichts Neues, S. 288-342.

226 Vgl. Schneider: Erich Maria Remarques Roman Im Westen nichts Neues, S. 355-358.

227 Vgl. Schneider: Erich Maria Remarques Roman Im Westen nichts Neues, S. 359.

228 Vgl. Schneider: Erich Maria Remarques Roman Im Westen nichts Neues, S. 361.

229 Vgl. Schneider: Erich Maria Remarques Roman Im Westen nichts Neues, S. 365.

230 Vgl. Schneider: Erich Maria Remarques Roman Im Westen nichts Neues, S. 368.

231 Vgl. Schneider: Erich Maria Remarques Roman Im Westen nichts Neues, S. 373.

232 Vgl. Schneider: Erich Maria Remarques Roman Im Westen nichts Neues, S. 377.

233 Vgl. Schneider: Erich Maria Remarques Roman Im Westen nichts Neues, S. 379. 
als faktisch und authentisch wahrgenommen, von März bis Juli 1929 entwickelte sich eine kontroverse Sicht auf diese Dinge, ab August 1929 waren die Meinungen in diesen Fragen polarisiert. ${ }^{234}$ Dem entspricht die unterschiedliche Beurteilung des ,Wahrheitswertes', der sich zusammengenommen danach bemisst, ob Erlebtes zutreffend wiedergegeben wird, Kriegsereignisse faktisch richtig dargestellt werden und die Schilderung authentisch ist. In 37\% der Quellen (von insgesamt 337) herrschte die Ansicht vor, die Kriegsschilderung sei in diesem Sinne ,wahr،, 32\% waren der gegenteiligen Ansicht. ${ }^{235}$ Von November 1928 bis einschließlich Januar 1929 wurde fast einmütig angenommen, das im Roman Dargestellte sei ,wahr‘; von Februar bis März 1929 entwickelte sich in dieser Frage eine zunehmend kontroverse Sicht; von April bis Juli 1929 waren ,wahr` und ,unwahr' relativ gleichwertig verteilt; ab August 1929 kam es zu einer Polarisierung, bei zeitweiligem Überwiegen der Annahme, das Geschilderte sei ,unwahr'.236

Im Falle von Im Westen nichts Neues ist mit Blick auf die Erforschung möglicher zeitgenössischer Applikationen erneut ein Negativbefund festzuhalten. Obwohl die Rezeption von Remarques Roman eingehend untersucht wurde, hat die Forschung in der Regel keine Aussagen zu Applikationen gemacht, von Ausnahmen wie der oben ausführlicher zitierten einmal abgesehen. Die Ergebnisse der Forschung, insbesondere die der letztgenannten Arbeit, bieten aber eine gute Grundlage, um ausgewählte Quellen auf Applikationen hin zu untersuchen: Es war für die zeitgenössische Rezeption von zentraler Bedeutung, ob in der Welt der Akteur/-innen der Fall ist, was in der Welt des Textes der Fall ist, und es war gleichermaßen bedeutsam, ob die im Text auf das Geschehen entwickelte Perspektive eine ist, welche sich die Rezipient/-innen zu eigen machen wollten. In beiden Fällen liegt es nahe, dass Applikationen vorkommen und relevant sind. Da, wie gesehen, Autor und Verlag versuchten, die Rezeption des Romans zu steuern, erscheint es sinnvoll, in einem ersten Schritt nach möglichen intendierten Applikationen zu fragen (Kap. 4.3.2). Es ist damit zu rechnen, dass die Aussagen der Akteur/-innen nur bedingt zuverlässig sind. Sie interessieren daher weniger als richtige oder falsche Tatsachenbehauptungen, sondern als kommunikative Ereignisse, die potenziell sozial relevant sind und der Rezeptionssteuerung dienen sollen.

In Anbetracht des Umstandes, dass die vermeintliche ,Wahrheit“ des Romans eine besondere Rolle spielte, sollen in einem zweiten Schritt einschlägige

234 Vgl. Schneider: Erich Maria Remarques Roman Im Westen nichts Neues, S. 390.

235 Vgl. Schneider: Erich Maria Remarques Roman Im Westen nichts Neues, S. 391.

236 Vgl. Schneider: Erich Maria Remarques Roman Im Westen nichts Neues, S. 397 f. 
Quellen darauf hin untersucht werden, ob sich in diesem Zusammenhang kognitive Applikationen identifizieren lassen (Kap.4.3.3). Das erscheint auf den ersten Blick als durchaus aussichtsreich. Wie gesehen, interessierte an Remarques Roman insbesondere die Frage, welchen Realitätsgehalt das im Text Geschilderte hatte. Dabei ist weniger entscheidend, ob die Verfasser der Quellen zum Beispiel Kriegsveteranen waren oder selbst Verfasser einschlägiger Romane, auch wenn gerade Ersteres in der Wahrnehmung mancher Zeitgenossen sicherlich eine besondere Expertise und Autorität verbürgte. Wichtig ist, dass sie das Gelesene als wahre oder unwahre Schilderung auffassten, diesen Punkt als relevant erachteten und darüber schrieben. Da das im Roman Dargestellte zu einer Bewertung herausforderte, eine mögliche Tendenz des Romans diskutiert wurde und die Debatte stark politisiert war, soll in einem dritten Schritt geprüft werden, ob sich ethische Applikationen nachweisen lassen (Kap. 4.3.4). Es bietet sich insbesondere an, die Frage zu fokussieren, ob es sich um einen pazifistischen Roman handelt, weil diese Klassifikation geeignet ist, die Debatte zu bündeln, zumal mit Blick auf den übergeordneten Streitpunkt, ob der Roman eine kriegskritische Sicht vermittle und wie das zu bewerten sei. In Anbetracht der Fülle an potenziell zur Verfügung stehenden Rezeptionsdokumenten (weit über 400) kann die folgende Darstellung nur exemplarisch sein.

\subsubsection{Die intendierte, aber nicht gezeigte Applikation}

Remarque hat sich in Gesprächen mit Zeitungen und Zeitschriften verschiedentlich über seinen Roman, dessen Entstehung und seine Absichten geäußert. Zwar hat er mitunter den Eindruck erweckt, als erachte er es nicht für nötig, sich an den Diskussionen zu beteiligen, die sein Buch hervorrief, und das wie folgt begründet: „[W]enn eine Arbeit fertig ist, hat der Autor zu ihr nichts mehr zu bemerken, selbst auf die Gefahr hin, daß er mißverstanden wird. In diesem Falle wäre seine Arbeit eben nicht gelungen, und das Reden darüber hätte auch keinen Zweck. Ich bin aber der Meinung, daß ich nur dort mißverstanden worden bin, wo man mich von vornherein mißverstehen wollte. “237 Gleichwohl hat er verschiedentlich und durchaus konsequent zu seinem Roman Stellung genommen, und das auf eine Weise, die kaum anders aufgefasst werden kann denn als Versuch, vermeintlichem Missverstehen entgegenzuwirken.

237 Axel Eggebrecht: Gespräch mit Remarque. Zur Diskussion über Im Westen nichts Neues. Die Entstehungsgeschichte des Buches. Die inneren Motive. Faktoren des Erfolges. Weiteres Schaffen. In: Die literarische Welt. Jg. 5, Nr. 24, 14. Juni 1929, S. 1 f., hier S. 1. 
In demselben Gespräch, das Axel Eggebrecht mit ihm für Die literarische Welt führte, und das in gekürzter Fassung in Der Kampf um Remarque abgedruckt wurde, wandte er sich gegen politische Vereinnahmung, indem er seinen Roman als „unpolitisch“ und „untendenziös“ bezeichnete und geltend machte, dass ein Kriegsbuch nur dann $\mathrm{zu}$ Recht politisch verstanden werden dürfe, wenn der Autor „eine objektive Wertung und allgemeine Darstellung des Krieges“ beabsichtigt habe; etwas, das bei seinem Buch, das „unvollständig“ über den Krieg berichte und ,nur aus der Froschperspektive des einfachen Grabensoldaten“ geschrieben sei, offenkundig nicht der Fall sei. ${ }^{238}$ In dem, was sein Buch schildere, sei es jedoch „wahr und erlebt“, „weder nach der einen noch nach der anderen Seite hin übertrieben und überspitzt“, keine „Erfindung“ oder „Phantasie“. ${ }^{239}$ Er beharrte also darauf, eigenes Erleben zutreffend und authentisch wiederzugeben. In einem anderen Gespräch erklärte er: „Il en serait autrement si j'avais voulu écrire un ouvrage de stratégie, un livre objectif, un jugement d'état-major sur la guerre. Mais je m'en suis tenu à l'expérience, purement humaine“. Auf die Frage, ob seinem Buch „des aventures personnelles“ zugrunde lägen, antwortete er: „Oui, j’ai été sur le front, assez longtemps pour avoir vécu presque tout ce que j’ai décrit.“240

Daneben war es ihm ein Anliegen, von der Entstehung des Buches eine bestimmte Sicht zu vermitteln. In einem Gespräch mit Stefan Napierski für die polnische Wiadomosci Literackie soll er gesagt haben,

daß es innerhalb von sechs Wochen entstanden sei, ganz von allein, er wisse nicht wie; er kehrte nachmittags von seiner Arbeitsstelle zurück und arbeitete täglich, ohne es hinterher zu korrigieren. In seinem Manuskript, das er mir zeigt, gibt es so gut wie keine Streichungen und Änderungen; falls es welche gibt, sind sie ganz unbedeutend. Früher, als er versucht habe, etwas auszusprechen, - denn er hat bereits vorher Einiges drucken lassen, ohne sich jedoch für einen ,Literaten` zu halten - hätte er die Worte mit reiflicher Überlegung geordnet. Nun, nachdem er seinen Roman schon abgeschlossen habe, stehe er ihm mißtrauisch gegenüber, ein halbes Jahr habe er in der Schublade gelegen. ${ }^{241}$

Das entspricht nicht oder nur bedingt den Tatsachen. Die Forschung nimmt mittlerweile an, dass es drei vollständige handschriftliche Niederschriften

238 Eggebrecht: Gespräch mit Remarque, S. 1.

239 Eggebrecht: Gespräch mit Remarque, S. 1.

240 Wilhelm Scharp: Deux entretiens avec Erich Maria Remarque. In: Revue d'Allemagne et des pays de Iangue allemande. Jg. 3, Nr. 26, Dezember 1929, S. 1009-1022, hier S. 1011 und 1012. 241 Stefan Napierski: Ein Gespräch mit Remarque. In: Erich-Maria-Remarque-Jahrbuch 2 (1992), S. 12-14, hier S. 12 (zuerst auf Polnisch in Wiadomosci Literackie. Nr. 23, 9. Juni 1929). Vgl. dazu Eggebrecht: Gespräch mit Remarque, S. 1 f. 
gab. ${ }^{22}$ Außerdem konnte, wie erwähnt, gezeigt werden, dass der Roman in einem längeren und schließlich von intensiver Zusammenarbeit mit dem Verlag geprägten Prozess entstand. Besonderen Wert legte Remarque auf die Feststellung, aus innerem Antrieb gehandelt zu haben und mit dem Ziel, ein persönliches Problem zu bewältigen. An eine Veröffentlichung habe er zunächst gar nicht gedacht:

Recht lange hatte ich darüber nachgedacht, worin die Ursache dafür lag, daß ich nicht weiter kam und so viele Dinge im Leben meiner Generation soviel mehr Probleme bereiteten als für die Gleichaltrigen anderer Zeitalter. Bis mir plötzlich deutlich wurde, alle hatten wir ja den Krieg mitgemacht. Als eine Eingebung ist dann das Buch entstanden, ich schrieb es nicht, um es herauszugeben, sondern einfach um mich selbst zu entlasten. Mehr als ein halbes Jahr hat das Manuskript fertig in meinem Schreibtisch gelegen, ohne daß ich auch nur daran dachte, einen Verleger zu suchen. Freunde, die es zufällig fanden, haben mich dazu gebracht, seine Veröffentlichung zu versuchen, und so habe ich mich auf die Suche gemacht..$^{243}$

Die private Dimension und den psychohygienischen Impuls für das Schreiben hat er andernorts bekräftigt: „Si j’ai écrit un livre, c'est poussé par le seul souci de discuter sérieusement avec moi-même un problème qui me touche personnellement“; „Je ne m'inquiète pas de savoir si le livre que j'écris est intéressant ou non, je lui demande simplement de m'apporter une solution personnelle.“244 Besonderes Augenmerk verdient ferner das Bestreben, nicht als Autor hochliterarischer Texte wahrgenommen zu werden. Er wolle „kein hochstehender Künstler sein“, er habe „ein Buch geschrieben, das jedermann lesen kann“, sein „größtes Ideal“ sei es, „Kunst für alle schreiben zu können“. ${ }^{245}$ Vor dem Hintergrund des bereits Gesagten dürfte offenkundig sein, dass es Remarque um Selbstinszenierung $\mathrm{zu}$ tun war, die im Zusammenhang $\mathrm{zu}$ sehen ist mit dem Bestreben des Ullstein-Konzerns, den (zunächst im Untertitel nicht so bezeichneten) Roman als Kriegsliteratur erscheinen zu lassen, um ihm Resonanz zu verschaffen und ihn möglichst gewinnbringend absetzen zu können. Die Frage nach den Motiven der Akteur/-innen ist allerdings weniger entscheidend als die

242 Vgl. Schneider: Erich Maria Remarques Roman Im Westen nichts Neues, S. 211.

243 Erich Maria Remarque: Erich Maria Remarque über sein Werk. Wie Im Westen nichts Neues entstand. „Ich habe nicht geschrieben, um ein Kunstwerk zu schreiben, sondern um mir meiner eigenen Lage bewußt zu werden.“. In: Erich-Maria-Remarque-Jahrbuch 5 (1995), S. 109114, hier S. 110 (zuerst auf Niederländisch in: Algemeen Handelsblad. 8. März 1930, S. 5).

244 Frédéric Lefèvre: E. M. Remarque. In: F. L.: Une heure avec ... Bd. 6. Paris 1933, S. 141-151, hier S. 143; vgl. dazu S. 144 f. (zuerst in: Les nouvelles Littéraires. 25. Oktober 1930).

245 Remarque: Erich Maria Remarque über sein Werk, S. 111 und 112. 
Implikationen, welche diese öffentlichen Selbstdeutungen für den in Rede stehenden Sachverhalt haben.

Solche Verlautbarungen des Autors sind durchaus konsistent mit dem, was er nach eigener Aussage mit seinem Roman in darstellerischer Hinsicht beabsichtigte. Besonders deutlich wird das in einem Brief, den Remarque am 1. Juni 1929 an Sir Ian Hamilton schrieb und der bereits im November desselben Jahres zusammen mit zwei weiteren veröffentlicht wurde. Remarque äußerte sich ausführlich dazu, was sein Roman dem Publikum zeigen sollte, und gab an, das bisher nicht mit dieser Deutlichkeit gesagt zu haben: „I have as yet never spoken my mind so fully“. ${ }^{246}$ Sir Ian habe, so Remarque, die zentrale Darstellungsabsicht seines Romans (,the very heart of my book“) korrekt erfasst, sie bestehe darin, ,the fate of a generation of young men“ zu schildern, ,who at the crititcal age, when they were just beginning to feel the pulse of life, were set face to face with death“. ${ }^{247} \mathrm{Ihm}$ sei es lediglich darum gegangen, Verständnis für diese Generation zu wecken: „I merely wanted to awaken understanding for a generation that more than all others has found it difficult to make its way back from the four years of death, struggle and terror, to the peaceful fields of work and progress. “248 Zugleich sollte der Roman Ermunterung und Aufruf für diese Generation sein: „In reality, as it shows how much has been destroyed, it should serve as a call to them to rally for the peaceful battle of work and of life itself, the effort to achieve personality and culture.“249

Ähnlich äußerte er sich in Gesprächen. Dort nahm er Einschränkungen beziehungsweise Präzisierungen vor: „An Hundertausenden ist natürlich das Erlebnis Krieg abgelaufen wie eine Dusche. Andere sind wenigstens ohne Bruch durchgekommen. Manche haben sich ja auch so sehr daran gewöhnt, daß sie nachher ohne den Krieg gar nicht mehr auskamen. Aber wichtig sind ja alle die anderen, die zahllosen Zerrissenen, Getroffenen, Erlebnisfähigen, die dem Erlebnis Ausgelieferten. Die haben jetzt erst angefangen, sich wiederzufinden. “250 Er habe nicht den Anspruch, für alle zu sprechen: „Je n’ai jamais prétendu parler au nom de tous. Mon livre est subjectif. Beaucoup de vivants et de morts ont vécu une autre guerre que celle que j'ai décrite et l'ont ressentie d'une autre manière, par exemple portés par un enthousiasme religieux ou patriotique ......251

246 Erich Maria Remarque: Brief an Sir Ian Hamilton, 1. Juni 1929. In: Sir Ian Hamilton/E. R. M.: The End of War?, S. 404-408, hier S. 407.

247 Remarque: Brief an Sir Ian Hamilton, S. 405 und S. 405 f.

248 Remarque: Brief an Sir Ian Hamilton, S. 406.

249 Remarque: Brief an Sir Ian Hamilton, S. 407.

250 Eggebrecht: Gespräch mit Remarque, S. 1.

251 Scharp: Deux entretiens avec Erich Maria Remarque, S. 1015. 
Remarque beabsichtigte mithin, auf etwas aufmerksam zu machen, das in seiner Wahrnehmung einen Teil bestimmter Jahrgänge betraf, die als Soldaten am Krieg teilgenommen hatten. Für sie bedeutete der Krieg eine biographische Zäsur, die es ihnen schwer machte, danach ein normales, alltägliches Leben zu führen. Den Rezipienten sollte vermittelt werden, wie und warum das so ist. Denjenigen Lesern, die selbst davon betroffen sind, sollte die Darstellung dabei helfen, mit der Kriegserfahrung angemessen umzugehen. In beiden Fällen bedarf es der Applikation, um die Intention zu realisieren. Die Rezipient/-innen müssen zu der Überzeugung gelangen, dass es Menschen gibt, denen es tatsächlich so geht, und denen gegenüber eine entsprechende Haltung angemessen ist. Die Betroffenen müssen das Gelesene auf sich selbst beziehen, als zutreffende Schilderung eigenen Erlebens und der eigenen Situation erkennen und daraus die erforderlichen Konsequenzen ziehen. Remarque gab an, sich selbst in einer solchen Situation befunden zu haben. Das Schreiben des Romans habe ihm dabei geholfen, das Erlebte zu bewältigen: „Je me sentis libéré lorsque mon livre fut terminé. “252

Nach eigener Aussage wurde die Applikation von den Betroffenen, aber nicht nur von ihnen, realisiert. Jedenfalls berief er sich verschiedentlich auf angeblich zahllose, ja tausende von Briefen, die er erhalten habe, und in denen genau das mitgeteilt wurde:

Thousands upon thousands have even yet been unable to do it [sich erfolgreich in den Nachkriegsalltag zu integrieren]; countless letters from all countries have proved it to me. But all these letters say the same thing: ,We have been unable, because we did not know that our lethargy, our cynicism, our unrest, our hopelessness, our silence, our feeling of secession and exclusion arose from the fact that the regenerative power of our youth had been dissipated in the war. But now we will find the way, for you in your book have shown us the danger in which we stand, the danger of being destroyed by ourselves. But the recognition of a danger is the first step towards escape from it. We will now find our way back, for you have told us what it was that threatened us, and thereby it has become harmless. ${ }^{253}$

Viele Tausend Briefe von Soldaten, die den Krieg erlebt hatten, darunter vor allem viele Schwerverletzte, von Müttern, deren Söhne gefallen waren, kurz von Kriegsopfern erreichten mich, und das war für mich die Hauptsache, denn dadurch sah ich, daß das Buch nützlich war. Insbesondere viele Kriegsveteranen, die durch den Krieg aus ihrem moralischen Zusammenhang gerissen worden waren, schrieben, daß das Buch deshalb für sie so befreiend war, weil es ihnen ihre eigene Lage deutlich machte, und durch die Erkenntnis

252 Scharp: Deux entretiens avec Erich Maria Remarque, S.1014. Vgl. dazu Eggebrecht: Gespräch mit Remarque, S. 1; Remarque: Erich Maria Remarque über sein Werk, S. 100; Lefèvre: E. M. Remarque, S. 143.

253 Remarque: Brief an Sir Ian Hamilton, S. 406. 
dieser unterbewußten Schwierigkeiten waren sie imstande, wieder hochzukommen und $\mathrm{zu}$ versuchen, sich in der Gesellschaft wieder einen Platz zu erwerben, etwas, was ihnen bis jetzt unmöglich gewesen war. Sie konnten mit dem Leben nicht fertig werden und nahmen an, daß die Ursache, weshalb sie zu nichts imstande waren, bei ihnen selbst lag. Das Buch Im Westen nichts Neues gab ihnen den Anstoß einzusehen, daß allein der Eindruck der Situation, in der sie gelebt hatten, sie gelähmt hatte. Es gab ihnen neuen Mut, denn es stellte sich heraus, daß sie nicht wertlos waren, sondern gebückt gingen unter ihrem Schicksal. ${ }^{254}$

Die Selbsterkenntnis, welche Remarque zufolge von der Lektüre seines Romans ausging, hatte also in der Wahrnehmung der Akteure eminent wichtige lebenspraktische Konsequenzen. Sie konnten sich ihre eigene Situation erklären und die Voraussetzung für eine Entwicklung zum Besseren schaffen. Von der Lektüre sei eine „befreiende Wirkung“ ausgegangen. ${ }^{255}$ Ein solcher Umgang mit dem Roman setzt Applikation voraus, nämlich die Einsicht, dass das Geschilderte auf die eigene Person und Situation angewandt werden kann. In „many hundreds of letters“ hätten die Verfasser zum Ausdruck gebracht: „It is my own experience.“ - und dies unabhängig von Nationalität, sozialem Status oder der im Einzelnen unterschiedlichen ,äußeren` Erfahrung des Krieges. ${ }^{256}$

Manche Rezensionen legen eine solche Applikation nahe. Der Roman zeige, „ohne es mit einem Wort zu sagen, wie dieses Geschlecht lebt, lebt, mitsamt seinen Toten, wie es den Kopf erhebt, die zerschmetterten Glieder sammelt, langsam, tastend, wankend, stürzend, Schritt vor Schritt, unaufhaltsam, unbrechbar, zu marschieren beginnt““. ${ }^{257}$ Die Überlebenden seien von der Kriegserfahrung nachhaltig beeinträchtigt: „Das Erschütterndste an seinem Buch ist das Bekenntnis, daß der Krieg diese seine Generation zerstört hat, auch wenn er sie nicht tötete.“ “258 Derartige Kriegsbücher seien „der literarische Protest jener Generation, die in der Blüte ihrer Jugend vom Krieg erfaßt und aufs Grausamste

254 Remarque: Erich Maria Remarque über sein Werk, S. $110 \mathrm{f}$.

255 Remarque: Erich Maria Remarque über sein Werk, S. 111.

256 Remarque: Brief an Sir Ian Hamilton, S. 408.

257 Carl Zuckmayer: Erich Maria Remarque: „Im Westen nichts Neues“. In: Berliner Illustrirte Zeitung. Nr. 5, 31. Januar 1929, S. 174 f. Zitiert nach Schrader: Dokumentation, S. 22-25, hier S. 24. Vgl. dazu: „Das ist der Krieg, wie wir ihn an der Front gelebt haben, - grade wir, eine ganz bestimmte, mit wenigen Jahreszahlen abzugrenzende Generation, - die vor dem Krieg noch kein Leben hatte, keine Form und keinen Inhalt, die vom Krieg geboren und zerschmettert wurde, und die - mitsamt ihren Toten, - über den Krieg hinauslebt, als einziger neuer Anfang.“ (S. 22 f.)

258 Martha Steinitz: Noch einmal Remarque. In: Die Friedenswarte. Jg. 29, Nr. 8 (1929), S. 246. Zitiert nach Schrader: Dokumentation, S. 83 f., hier S. 83. 
dezimiert wurde““. ${ }^{259}$ Der Roman konnte also so wahrgenommen werden, dass er eine vom Krieg ,zerstörte‘, ,verlorene“ Generation darstelle - und dass dies ,eine ganz bestimmte, mit wenigen Jahreszahlen abzugrenzende Generation “ ist, ${ }^{260} \mathrm{zu}$ der man eine bestimmte Haltung einnehmen, das im Roman Gesagte mithin in kognitiver und emotionaler Sicht applizieren soll. Bereits der Artikel aus Anlass des Fortsetzungsabdruckes hatte in diese Richtung gewiesen. Mit ähnlichem Pathos wie bei manchem Rezensenten hieß es dort:

Von der Schulbank in den Feuerofen des Krieges geworfen, ist eine ganze Generation zerstört worden. Was nicht durch Eisen und Feuer ausgetilgt wurde, fand die Heimat nicht mehr. Herausgerissen aus allem Sein, losgelöst von Familie und Beruf, zweifelnd an allem Gewesenen und an allem Werdenden, verzweifelt über den gleichgültigen Gang des Alltags, von Wachträumen verfolgt, aus dem Schlaf durch jähes Erinnern aufgeschreckt, der Sorge um das tägliche Leben preisgegeben, im Kampf um die nackte Existenz mit zerrütteten Nerven, geschwächtem Körper. ${ }^{261}$

Betont wurde zugleich die von Remarque selbst vorgenommene Einschränkung. Die besagte Generation sei „keineswegs immer nur ,zerstört““ worden, in Remarques Roman sei „nur von denen die Rede, die das schreckliche Gesicht des Krieges nicht ertrugen“; in unzulässiger Weise werde „ihr Versagen [...] als Maß der Dinge genommen“. ${ }^{262}$ In einem internen Verlagsgutachten wurde eine solche Auffassung sogar recht weitreichend relativiert: „Die Schlussfolgerung, die der Autor zieht: ,Die junge Kriegsgeneration ist zerstört worden, auch soweit sie den Granaten entkam', ist glücklicherweise nicht allgemeingültig. Die übergrosse Mehrzahl hat sich doch in das Leben zurückgefunden, wenn auch oft nach Kämpfen und Irrwegen.“263

Es erweist sich als aufschlussreich, die intendierte (und konzernseitig unterstützte), zum Teil realisierte, zum Teil bestrittene Applikation zur Beschaffenheit des Textes in Beziehung zu setzen. Zu Erzähltechnik, Form und Stil des Romans liegen mehrere Arbeiten vor. ${ }^{264}$ Allgemein lässt sich sagen, dass die

259 F. C. Weiskopf: Bücher vom Krieg. In: Magazin für alle. Jg. 4, Nr. 4 (1929). Zitiert nach Schrader: Dokumentation, S. 70-72, hier S. 70.

260 Zuckmayer: Erich Maria Remarque: „Im Westen nichts Neues“, S. 23.

261 [Anon.]: Nichts Neues im Westen, S. [1].

262 Herbert Kranz: Menschen des großen Krieges. In: Die Tat. Monatsschrift zur Gestaltung neuer Wirklichkeiten. Jg. 21, Bd. 1 (1929/1930), S. 444-451, hier S. 449.

263 Carl Jödicke: [positives verlagsinternes Gutachten zur unkorrigierten Typoskriptfassung]. Zitiert nach Schneider: Erich Maria Remarques Roman Im Westen nichts Neues, S. 259-261, hier S. 260 .

264 Vgl. Peter Horn: Der „unbeschreibliche“ Krieg und sein fragmentierter Erzähler. Zu Remarques Kriegsroman Im Westen nichts Neues. In: Heinrich-Mann-Jahrbuch 4 (1986), S. 85- 
Geschichte aus der Perspektive des Protagonisten Paul Bäumer berichtet wird, der seine eigene Geschichte erzählt und häufig stellvertretend für eine Gruppe (seine Kameraden, die Kompanie, die Soldaten an der Westfront) spricht (vgl. die häufige Verwendung von ,wir`). Das erzählende Ich ist das erlebende; Ereignisse werden in der Regel zeitgleich (und im Präsens) geschildert oder mit nur geringem zeitlichem Abstand, von einigen Rückblicken auf Teile der Vorgeschichte abgesehen. Die Distanz zum Geschehen ist in der Regel sehr gering. Der Erzähler und andere Figuren kommentieren das Geschehen. Als Augenzeuge kann der Erzähler auf der einen Seite als zuverlässig gelten, auf der anderen gibt es nur seine ,Froschperspektive، (und die der anderen Figuren). Die Erzählsituation ist unterbestimmt und erweist sich als etwas künstlich. Über den Tod des Protagonisten, welcher dem Ende des Romans den Charakter eines Schlusses gibt, wird abschließend von einer anderen, nicht weiter spezifizierten Instanz berichtet. Es bleibt letztlich offen, welchen Stellenwert die Episoden haben, die Bäumer schildert. Die szenenartigen, manchmal summarischen Passagen, die parataktisch aneinandergereiht sind und zwischen denen bisweilen größere zeitliche Abstände liegen, könnten tagebuchähnliche oder berichtartige Aufzeichnungen des Protagonisten sein. Die am Ende auftretende Erzählinstanz wäre dann eine Art fiktiver Herausgeber. Es könnte sich alternativ um den eigentlichen Erzähler handeln, der die Figur des Protagonisten als erlebendes Ich auftreten lässt. In stilistischer Hinsicht fällt auf, dass sich der Text syntaktisch und semantisch auf einem mittleren Komplexitätsniveau bewegt und, wie von der Forschung gezeigt, an journalistischem Schreiben orientiert ist (Kriegsbericht, Kriegsreportage). Auffällig sind ferner Unsagbarkeits-Topoi, Andeutungen und Suggestion, die vielleicht sogar wirksamer als die ebenfalls vorhandenen expliziten Schilderungen einen Eindruck von der Brutalität des Kampfgeschehens vermitteln.

Als entscheidend für die intendierte Applikation erweist sich insbesondere ein weiterer Aspekt der formalen Beschaffenheit. Das Intendierte wird einleitend explizit benannt, wiederholt gesagt, nicht jedoch gezeigt. In einer Art Vorwort heißt es: „Dieses Buch soll weder eine Anklage noch ein Bekenntnis sein. Es soll nur den Versuch machen, über eine Generation $\mathrm{zu}$ berichten, die vom

108; Rüter: Erich Maria Remarque, S. 65-149; Günter Hartung: Zum Wahrheitsgehalt des Romans Im Westen nichts Neues. In: Erich-Maria-Remarque-Jahrbuch 1 (1991), S. 5-17; Brian Murdoch: Narrative Strategies in Remarque's Im Westen nichts Neues. In: New German Studies 17 (1992/1993), S. 175-201; Becker: Literarischer Protest und heimliche Affirmation, S. 34-88; Hans Wagener: Zwischen Realismus und Rhetorik. Zu Erich Maria Remarques Im Westen nichts Neues. In: Krieg und Literatur 6 (2000), S. 69-88. 
Kriege zerstört wurde - auch wenn sie seinen Granaten entkam.“265 Dass der Krieg Bäumer und seine Generation ,zerstört' habe, wird im Folgenden wiederholt gesagt, am Beginn und Ende des Romans sowie in kommentierenden und einordnenden Aussagen des Erzählers im Verlauf der Handlung. Die Jugend der jungen Männer, die sich von der Schulbank aus freiwillig zum Kriegseinsatz gemeldet hatten, sei „lange her“: „Wir sind alte Leute.“(S. 22) Von der Bindung an das soziale Umfeld sei „nichts geblieben“ (S. 23). Für nicht oder nur bedingt gefestigte Menschen wie sie habe der Krieg eine biographische Zäsur von erheblicher Tragweite bedeutet: „Wir waren noch nicht eingewurzelt. Der Krieg hat uns weggeschwemmt.“ (S. 24) In einem längeren Gespräch über die Frage, was man nach dem Krieg tun wolle, werden Desorientierung und Perspektivenlosigkeit deutlich, die als „das gemeinsame Schicksal unserer Generation“ bezeichnet werden (S. 80, vgl. S. 71-81). Eine Figur, welcher der Erzähler ausdrücklich beipflichtet, kommt zu dem Schluss: „Der Krieg hat uns für alles verdorben.“ (S. 80) Bäumer konstatiert an anderer Stelle: „Wir sind verlassen wie Kinder und erfahren wie alte Leute, wir sind roh und traurig und oberflächlich, - ich glaube, wir sind verloren.“ (S.111) Zum Ende hin fragt er: „Was soll danach noch geschehen? Und was soll aus uns werden?“ (S. 233) Und er gibt sich selbst die Antwort: „Wir werden uns nicht mehr zurechtfinden können.“ (S. 257) Außerdem prognostiziert er, dass seine Generation auf Unverständnis stoßen werde: „Man wird uns auch nicht verstehen“ (ebd.). Bereits zu einem früheren Zeitpunkt hatte er deutlich gemacht, dass das im Krieg Verdrängte sich nach dem Krieg Bahn brechen werde und eine „Auseinandersetzung auf Leben und Tod“ anstehe (S. 126). ${ }^{266}$

So oft der Erzähler dies beschwören mag, gezeigt wird es nicht. Die Handlung reicht nur bis Oktober 1918. Die Schilderung eines Heimaturlaubes (vgl. S. 136-166) kann zwar das Unverständnis der Daheimgebliebenen zeigen und die Schwierigkeiten Bäumers, sich in der zivilen Normalität zurechtzufinden, die Probleme im Nachkriegsalltag werden aber nicht deutlich. Gezeigt wird stattdessen der Alltag hinter und an der Westfront: Schwierigkeiten bei der

265 Erich Maria Remarque: Im Westen nichts Neues. Roman. Hg. von Thomas F. Schneider. Köln 2014, S. 5. Nachweise im Folgenden unmittelbar im Anschluss an das Zitat.

266 Vgl. dazu den Zusammenhang: „Und ich weiß: all das, was jetzt, solange wir im Kriege sind, versackt in uns wie ein Stein, wird nach dem Kriege wieder aufwachen, und dann beginnt erst die Auseinandersetzung auf Leben und Tod. Die Tage, die Wochen, die Jahre hier vor werden noch einmal zurückkommen, und unsere toten Kameraden werden dann aufstehen und mit uns marschieren, unsere Köpfe werden klar sein, wir werden ein Ziel haben, und so werden wir marschieren, unsere toten Kameraden neben uns, die Jahre der Front hinter uns: gegen wen, gegen wen?“(S. 126 f.) 
Befriedigung existentieller Bedürfnisse (Verpflegung, Schlaf, Kleidung), Drill und Schikane, Kameradschaft, Lazarett-Aufenthalte, Schanzarbeiten und das Kampfgeschehen an der Front. ${ }^{267}$

Denjenigen, die als Soldaten im Kriegseinsatz waren, und manchen anderen Zeitgenossen musste der Nachkriegsalltag wohl nicht gezeigt werden, um die in Rede stehende Applikation vornehmen zu können, da sie aus eigener Erfahrung oder Anschauung das Erforderliche ergänzen konnten. In Anbetracht dieses Umstandes überrascht es nicht, wenn ein Kriegsveteran wie Carl Zuckmayer, wie gesehen, zu der Einschätzung gelangte, dass der Roman auf die Schwierigkeiten der besagten Generation bei der Integration in den Nachkriegsalltag aufmerksam macht, „ohne es mit einem Wort zu sagen“. Dadurch, dass der Roman das Entscheidende nicht zeigt, eröffnet er jedoch die Möglichkeit anderer Lesarten. Es dürfte hinzukommen, dass die Andeutung und explizite Schilderung der Atrozitäten des Stellungskrieges geeignet ist, dieses Anliegen zu überlagern, da die Gewaltdarstellung in der Wahrnehmung einiger Rezipient/-innen prominenter sein dürfte als die auf den Nachkrieg bezogene Problematik. Ähnliches gilt für die Schilderung alltäglicher Begebenheiten, welche die Situation des Fronteinsatzes mit sich bringt, etwa der Kontakt zu einheimischen Frauen (Nahrungsmittel gegen Geschlechtsverkehr).

Gezeigt hat Remarque das, was er nach eigener Auskunft mit Im Westen nichts Neues beabsichtigte, in seinem nächsten Roman, Der Weg zurück (1931). Bereits 1927, also vor der Fertigstellung von Im Westen nichts Neues, hatte er den Plan zu diesem Roman, an dem er ab 1928 schrieb und in dem schließlich die Teile 2 und 3 der ursprünglich geplanten Trilogie aufgingen. ${ }^{268}$ Die Handlung von Der Weg zurück setzt im November 1918 ein und schildert die Rückkehr einer Soldatengruppe von der Westfront in eine deutsche Provinzstadt. Die scheiternde Integration der Kriegsheimkehrer wird an verschiedenen Figuren

267 Der Roman bietet damit eher eine Alltagsgeschichte denn z. B. eine Militärgeschichte des Stellungskrieges, vgl. dazu an historiographischen Arbeiten z. B. Neil M. Heyman: Daily life during World War I. Westport, CT 2002; Christoph Nübel: Durchhalten und Überleben an der Westfront. Raum und Körper im Ersten Weltkrieg. Paderborn 2014. Vgl. für einschlägige Quellen Bernd Ulrich/Benjamin Ziemann (Hg.): Frontalltag im Ersten Weltkrieg. Ein historisches Lesebuch. Essen 2008; Jens Flemming/Klaus Saul/Peter-Christian Witt (Hg.): Lebenswelten im Ausnahmezustand. Die Deutschen, der Alltag und der Krieg 1914-1918. Frankfurt a. M. u. a. 2011; vgl. die Dokumentation von Erinnerungen in: Wolf-Rüdiger Osburg: Hineingeworfen. Der Erste Weltkrieg in den Erinnerungen seiner Teilnehmer. Berlin ${ }^{2} 2013$.

268 Vgl. dazu Thomas F. Schneider: Die Revolution in der Provinz. Erich Maria Remarque: Der Weg zurück (1930/31). In: Ulrich Kittstein (Hg.): „Friede, Freiheit, Brot!“ Romane zur deutschen Novemberrevolution. Amsterdam/New York 2009, S. 255-267, hier S. 256. 
und in verschiedenen Situationen deutlich gezeigt. Heinrich Mann schrieb in einer Besprechung für die Vossische Zeitung: „Das nachträgliche Leben ist der zweite Krieg des Geschlechtes, und wieder ein verlorener. Es hat aussichtslos gekämpft gegen die Verständnislosigkeit der Heimat, gegen die allgemeine Verschwörung, es zu verraten und aufzuopfern.“269

\subsubsection{Wahrheit und Wahrhaftigkeit}

In zahlreichen Rezensionen wurde, wie erwähnt, Wert gelegt auf die Feststellung, dass das im Roman Dargestellte eine zutreffende Schilderung des Krieges sei. Die Rede ist dann vor allem davon, dass es ,wahr‘ oder ,wahrhaftig“ sei. Ernst Toller nannte den Roman „das stärkste Dokument der ,großen Zeit““, es sei „ganz wahrhaftig“ und biete „Wirklichkeit“: „So haben die deutschen Muschkoten im Schützengraben gelebt, so die französischen, so die englischen.“270 Bruno Frank stellte fest: „Es deklamiert nicht, es klagt nicht einmal an, es stellt nur dar, und jedes Wort blutet vor Wahrheit.“271 Eggebrecht erklärte: „[Z]um Teufel, ja, so war es, genau so, sonst wäre ja alles gar nicht möglich gewesen“. ${ }^{272}$ Diese drei Beispiele mögen genügen, um zu illustrieren, wie euphorisch, pathetisch und emotional die Wahrheit des Dargestellten betont wurde.

Im Ton bisweilen etwas dezenter, in der Sache aber ähnlich dezidiert sind Texte, mit denen die Vossische Zeitung die Publikation des Romans flankierte. In der Anzeige anlässlich des Erscheinens der Buchausgabe hieß es, der Roman habe das „Grauen“ des Krieges „in der letzten Wahrheit der Natur heraufbeschwor[en]“, eine Einschätzung, die durch ein Autoritätsargument - die Einschätzung der „wahren Sachkenner“, nämlich der Kriegsveteranen - beglaubigt werde. ${ }^{273}$ In einer umfangreichen Rezension wurde dem Roman bescheinigt,

269 Heinrich Mann: Remarque, sein zweiter Roman. In: Vossische Zeitung. Nr. 100, 30. April 1931, Unterhaltungsblatt, S. [9].

270 Ernst Toller: Buchchronik der Woche: „Im Westen nichts Neues“. In: Die Literarische Welt. Jg. 5, Nr. 8, 22. Februar 1929, S. 5.

271 Bruno Frank: Erster Hinweis. In: Das Tagebuch. Jg. 10, 19. Januar 1929, S. 107 f. Zitiert nach Tilman Westphalen: Materialien. In: Erich Maria Remarque: Im Westen nichts Neues. Roman. Hg. von T. W. Köln 1998, S. 201-261, hier S. 207.

272 Axel Eggebrecht: Paul Bäumer, der deutsche Unbekannte Soldat. In: Die Weltbühne. Jg. 25, H. 6, 5. Februar 1929, S. 211-213, hier S. 213.

273 [Anon.]: „Im Westen nichts Neues“. Remarques Buch erscheint, S. [9]. 
„keine Lüge“ zu enthalten und „tendenzlos“ zu sein. ${ }^{274}$ In ausgewählten Leserbriefen wurden der dokumentarische Charakter und die Wahrheit in der Darstellung herausgestellt. Der Roman sei „[n]aturgetreu wie ein photographisches Dokument, von einem Dichter erfühlt und gestaltet“; ein anderer Leser meinte: „Ich kenne kein Buch, das so wahr und so vollständig zugleich die damalige Kriegsarbeit des einzelnen Soldaten schildert. So war es.“275 Weitere Belege ließen sich anführen. Es ist von der „entsetzlichen Wahrheit“ des Romans die Rede; davon, dass das in ihm Geschilderte „Wahrheit, reine gültige Wahrheit“ sei, oder davon, dass der Roman „ein durchaus wahrhaftiges Bild des Krieges“ biete. ${ }^{276}$ Die Rezensent/-innen und Leserbriefschreiber/-innen verglichen also das im Roman Dargestellte mit ihrer Lebenswirklichkeit, zumal dem eigenen Erleben, und kamen zu dem Schluss, dass es wahr und wahrhaftig ist.

Solche Aussagen in den Quellen sind Ergebnisse von Applikationen des Gelesenen. Bedeutsam sind Art und Umfang der Applikation. Für die Akteure war die Applizierbarkeit des Geschilderten das eigentlich Relevante an Remarques Roman. Die Annahme, dass hier von Applikationen gesprochen werden kann, ist kurz zu begründen. Die Mehrzahl der Zeitgenossen hat den Text, wie gesehen, als literarischen aufgefasst. Die generischen Anforderungen an Kriegsliteratur erfüllte er in ihrer Wahrnehmung in mustergültiger Weise. Den Roman so $\mathrm{zu}$ lesen, dass und wie er den Stellungskrieg an der Westfront zeigt, scheint auf den ersten Blick eine Sache des reinen Textverstehens zu sein. Anzunehmen, dass es sich in der Realität genau so verhalten hat, wie im Roman dargestellt, steht aber mit einem Akt der Applikation des Gelesenen in Verbindung. Der Grund ist einfach und ergibt sich aus den situativen Gegebenheiten: Was dieser Krieg gewesen sei und was ihn ausmachte, war zeitgenössisch höchst umstritten. Wer der Auffassung war, dass der Roman eine wahre und wahrhaftige Darstellung des Krieges biete, inferierte nicht einfach ein unstrittiges Weltwissen, ob es nun aus eigener Erfahrung stammte oder aus anderen Quellen, um den Text zu verstehen und mit Blick auf bestimmte Lektüreziele oder Wirkungen zu rezipieren. Er nahm Stellung zu der höchst umstrittenen Frage, wie der Krieg

274 Fritz von Unruh: „Im Westen nichts Neues“. Erich Maria Remarques Roman. In: Vossische Zeitung, 5. Februar 1929, Nr. 30, Das Unterhaltungsblatt, S. [9 f.], hier S. [9].

275 Das Fronterlebnis in der Dichtung. „Im Westen nichts Neues“. [Leserbriefe]. In: Vossische Zeitung. 16. Dezember 1928, Nr. 594, S. [26 f.], hier S. 26.

276 Bernhard Kellermann: „Im Westen nichts Neues“. In: Berliner Morgenpost. Nr. 27, 31. Januar 1929. Zitiert nach Schrader: Dokumentation, S. 19-22, hier S. 20; Zuckmayer: Erich Maria Remarque: „Im Westen nichts Neues“, S. 24; Anna Siemsen: Kriegsbücher. In: Der Klassenkampf. Jg. 3, Nr. 23 (1929), S. 725-728. Zitiert nach Schrader: Dokumentation, S. 63-69, hier S. 64 . 
tatsächlich gewesen sei und wies dem Roman die Eigenschaft zu, in bedeutsamer Weise auf die Lebenswelt beziehbar zu sein, zu neuen Einsichten zu führen oder bestehende Überzeugungen zu verstärken sowie etwaige anderslautende Überzeugungen zu korrigieren.

In ebenso zahlreichen Rezensionen wurden die Wahrheit des Dargestellten und dessen Applizierbarkeit auf unterschiedliche Weise bestritten oder eingeschränkt. Es liegen damit Fälle negativer kognitiver Applikation vor. Häufig wurde zugestanden, dass der Roman Manches zutreffend schildere, er sei in seiner Darstellung jedoch einseitig und tendenziös, folglich bestenfalls in Teilen wahr, nicht jedoch im Ganzen und mit Blick auf Wesentliches. Es gab Einschätzungen wie diejenige, dass der Roman „nicht objektiv, sondern tendenziös“ sei. ${ }^{277}$ Dasjenige, „was den Krieg eigentlich ausmachte“, habe Remarque „nicht gesehen, nicht erlebt“. ${ }^{278}$ In aus heutiger Sicht vielleicht nicht ohne Weiteres nachvollziehbarer Weise wurde im Deutschen Adelsblatt bemängelt: „Schöne und erhebende Erlebnisse fehlen gänzlich."279 Ähnlich äußerte sich der Rezensent in Deutsche Wehr, wenn er beklagte, dass in dem Roman „einfach ein minderwertiger Teil [des Heeres] als gleichbedeutend mit dem Ganzen hingestellt“ werde und ,alle erhebenden Momente des Kriegslebens [...] einfach fortgelassen werden“. ${ }^{280}$ Verbunden mit antiliberalen und antisemitischen Insinuierungen kritisierte der Völkische Beobachter, Romane wie derjenige Remarques schilderten „den Krieg in Feld und Heimat, so wie er auch war, mit seiner Not, seiner Häßlichkeit und seinem Kleinkram, doch seine Höhepunkte, die jeder wahre

277 [Vorname nicht ermittelt] Pflug: Erziehung zur Knochenerweichung. In: Berliner BörsenZeitung. Jg. 74, Nr. 223, 16. Mai 1929, S. 2. Zitiert nach Schrader: Dokumentation, S. 93-96, hier S. 94.

278 Rudolf G. Binding: Krieg für genügsame Leute. In: Die Literatur. Jg. 31, H. 9, Juni 1929, S. 505 f., hier S. 505. Vgl. dazu z. B. eine Einschätzung wie diese: „Wir sind gewiß, daß es [das Buch] alles andere als die Schilderung des inneren Erlebens des Frontsoldaten ist. Manche Gefühle, die den Soldaten durchtoben, sind zweifellos richtig erfaßt. Die schwachen Stunden sind gut wiedergegeben, aber das Heldische, das den Mitläufer auf Befehl überragte, das das Kleine im Menschen besiegte, das fehlt.“ - [Anon.]: Im Westen nichts Neues. Der Dichter ... ... und wir Jungen, S. 88.

279 Graf von Schlieffen: Im Westen nichts Neues. In: Deutsches Adelsblatt. Nr. 12, 16. März 1929, S. 168. Vgl. dazu die anschließende rhetorische Frage: „Sollte es wirklich viele Frontsoldaten geben, in deren Gedächtnis nur das Grausige und Schreckliche des Krieges und nicht mindestens ebensoviele Erinnerungen an Heldentaten und schönes Erleben zurückgeblieben sind?“

280 Freiherr von der Goltz: [Rezension von Remarque: Im Westen nichts Neues]. In: Deutsche Wehr. Zeitschrift für Heer und Flotte. Jg. 2, Nr. 14, 10. April 1929. Zitiert nach Schrader: Dokumentation, S. 84 f., hier S. 85. 
Frontsoldat erlebt, werden geschickt verschwiegen, und vergebens sucht man nach einem Hinweis, daß der Krieg nicht nur vernichtete, sondern daß in ihm auch Unvergängliches entstanden ist - daß er für alle die, die ihn zu tiefst erlebt, ein unversiegbarer Kraftquell wurde“. ${ }^{281}$ Aber nicht allein aus Sicht eines preußischen und völkischen, nationalsozialistischen Militarismus wurde die im Roman enthaltene Schilderung als in wesentlichen Hinsichten unzutreffend angesehen. Es wurde zum Beispiel kritisiert, dass der Roman „kein wahres Gesamtbild“ biete, „denn in diesem Bilde gibt es nur den passiven, alles ruhig hinnehmenden, in sein Schicksal ergebenen Soldaten, gibt es kein Anzeichen von Auflehnung und Widerstand gegen den Krieg“. ${ }^{282}$ Sogar ein im Grundsatz sehr positives konzerninternes Gutachten hatte im Detail Vorbehalte. Remarque zeige „die Menschen als willenlose Objekte der Kriegsfurie, was nicht uneingeschränkt zutrifft“; mitunter seien seine Schilderungen „einseitig und verallgemeinernd“ oder „reichlich tendenziös““.283

Stellungnahmen wie diese waren zum Teil sicherlich als Reaktion auf die positiven Applikationen verfasst worden. Außerdem dürften sie sich zum Teil aus einer bestimmten Rezeptionserwartung ergeben. Wer zu dem Ergebnis kam, dass das im Roman Dargestellte nicht oder nur bedingt wahr sei, hatte den Roman womöglich in der durch die Lektüre enttäuschten Erwartung gelesen, dass er etwas Wahres mitteile, also appliziert werden kann, und vorausgesetzt, dass die Vermittlung einer wahren Sicht auf den Weltkrieg lebensweltlich bedeutsam ist. Jedenfalls sind solche Stellungnahmen Indizien für die Relevanz, welche die kognitive Applikation des Romans zeitgenössisch besaß.

Die positive kognitive Applikation wiederum nahm verschiedene Formen an. Besonders häufig wurde dem Roman die Funktion zugeschrieben, der Erinnerung $\mathrm{zu}$ dienen. ${ }^{284}$ Stellvertretend sei die folgende Einschätzung zitiert: Der Roman

281 Erich Limpach: Neudeutsche Kriegsliteratur. „Jahrgang 1902“ - „Soldat Suhren“ - „Im Westen nichts Neues“ - „Krieg“ - Kriegsbücher, aber keine Soldatenbücher. In: Völkischer Beobachter. Reichsausgabe. Jg. 4, Nr.1, 16. Februar 1929, Beilage: Der Deutsche Frontsoldat. Zitiert nach Schrader: Dokumentation, S. 36-38, hier S. 36.

282 Weiskopf: Bücher vom Krieg, S. 71.

283 Jödicke: [positives konzerninternes Gutachten zur unkorrigierten Typoskriptfassung], S. 259, 260 und 261. Unter anderem heißt es dort: „Die Schilderung ist kein Pandämonium des Krieges. Sie zeigt nur, wie seine Schrecken auf eine beschränkte Zahl von Menschen wirken. Viele seelische Typen fehlen“" (S. 314).

284 Vgl. dazu Astrid Erll: Gedächtnisromane. Literatur über den Ersten Weltkrieg als Medium englischer und deutscher Erinnerungskulturen in den 1920er Jahren. Trier 2003, zu Remarques Roman im Vergleich mit einem englischen S. 254-277. 
gibt uns die Gewißheit, das Erlebnis der Millionen zwischen Argonnen und Flandern kann nie vergessen werden. Immer wieder wird es in neuen Formen an das Gewissen der Völker klopfen. Es ist kein Zufall, daß in diesen letzten Monaten die Kriegsliteratur wieder hervor darf [...]. Unmittelbar nach dem Zusammenbruch waren die Nerven der Menschen zermürbt, in den zehn Jahren danach haben sie sich wieder erholt und können heute die allgemeine furchtbare Kriegserschütterung objektiv nachprüfen. ${ }^{285}$

Daneben wurde die stellvertretende, exemplarische Gestaltung hervorgehoben, die Identifikation ermögliche. Der Roman schildere „typische Fälle eines Millionenerlebnisses“. ${ }^{286}$ In werbewirksamer und etwas suggestiver Weise hieß es in der Rezension in der Vossischen Zeitung:

\begin{abstract}
,Als wäre mein eigenes Erleben geschildert worden - so tief hat mich dieses Bekenntnis erschüttert ...', sagte mir gestern ein junger Architekt, während er das Remarquesche Buch aus der Tasche zog. Tausende waren schon beim Vorabdruck in der ,Voß' ebenso aufgewühlt - Hunderttausende werden es morgen und übermorgen sein, wenn sie klopfenden Herzens auf dem Hin und Her ihrer Arbeitswege darin lesen. Und wohl jeder wird am Ende der dreihundert Seiten mit neuen Augen um sich sehen ...287
\end{abstract}

Außerdem wurde der Roman so gelesen, dass er allgemeine anthropologische Einsichten in menschliches Erleben in der Extremsituation des Krieges biete. Der Roman sei

[k]ein Buch vom Krieg, ein Buch vom Menschen im Kriege, darin die Pulse der letzten Zuckungen zerschmetterter Seelen schlagen. Kein Buch nur einer Generation, sondern gültig für die ganze Vielheit älterer und jüngerer Menschen, über die dieser Krieg als ein Riesentank hinweggegangen. Kein Buch nur eines Kriegsschauplatzes, vielmehr das Schicksal

285 Unruh: „Im Westen nichts Neues“, S. [9]. Vgl. dazu z. B. Kellermann: „Im Westen nichts Neues“, S. 19; Ernst Lemmer: Schluß mit den Kriegsbüchern! In: Berliner Tageblatt. 27. Juni 1930. Zitiert nach Schrader: Dokumentation, S. 72-75, hier S. 72; Frank: Erster Hinweis, S. 207; Toller: Buchchronik der Woche, S. 5. Vgl. die Rede vom Roman als „Monument“ - [Anon.]: „Im Westen nichts Neues“. Ueber ein neues Kriegsbuch. In: Das Reichsbanner Schwarz - Rot Gold. Jg. 6, Nr. 5, 2. Februar 1929, S. 34 f. Zitiert nach Schrader: Dokumentation, S. 86-88, hier S. 88. In Leserbriefen ist davon die Rede, der Roman mache die Erinnerung an das Geschehene „untilgbar“, er sei ein „Erinnerungsbuch[]“ und könne der Gefahr entgegenwirken, dass die Zeitgenossen die „Sinnlosigkeit des Krieges“ wieder „vergessen“ - Das Fronterlebnis in der Dichtung, S. [26] und [27].

286 Eggebrecht: Paul Bäumer, der deutsche Unbekannte Soldat, S. 213. Vgl. dazu: „Einer hat für uns Alle gesprochen, für uns Muschkoten“ - Toller: Buchchronik der Woche, S. 5. Ähnlich die folgende Aussage: „Der durch den Krieg verpfuschte Mensch des Alltags, das entwurzelte Volk erkennt sich in Remarques Buch.“ - Ibel: Remarque oder Der Bankrott des demokratisierten Militarismus, S. 99.

287 Unruh: „Im Westen nichts Neues“, S. [9]. 
aller, wo immer sie hingestellt und hingestoßen waren, die durch diese Hölle gegangen sind. Ein Werk, das all das festhält, was den Berichterstattern aller Art und jeden Formates als unwesentlich erschien - das Menschliche. ${ }^{288}$

In fast schon topischer Manier wurde die Darstellungsleistung und damit verbundene Resonanz des literarischen Textes hervorgehoben, die anderen Textsorten, hier historiographischen Darstellungen und statistischen Materialien, überlegen sei: „Dieses Buch sollte in Millionen Exemplaren verbreitet, übersetzt, in den Schulen gelesen, von allen den Krieg bekämpfenden Gruppen gekauft und verschenkt werden. Es sagt mehr über das Volk und seinen Anteil am Krieg aus als dickleibige historische Wälzer und Statistiken." ${ }^{289}$

Der Umstand, dass es zeitgenössisch als so wesentlich angesehen wurde, die Frage nach der Wahrheit des Dargestellten (und der korrekten Erinnerung) zu erörtern und (Negativ-)Applikationen vorzunehmen, hat sicherlich mit den generischen Erwartungen der Rezipient/-innen zu tun sowie mit der Strategie des Ullstein-Konzerns und der (Selbst-)Inszenierung des Autors. $\mathrm{Zu}$ beachten ist ferner, wie angedeutet, das historische Ereignis selbst, dessen Wahrnehmung durch die Zeitgenossen und die Gegebenheiten der Weimarer Republik. Der Erste Weltkrieg hatte bekanntlich individuelle, gemeinschaftliche und gesellschaftliche Folgen von bisher nicht gekannter Tragweite, wie zumindest kurz anzudeuten ist. ${ }^{290}$ Erhebliche Teile der männlichen Bevölkerung wurden zum Kriegsdienst eingezogen, Millionen von ihnen wurden getötet oder schwer verletzt, gerieten in Kriegsgefangenschaft oder blieben verschollen. In die Milliarden gehende Summen mussten für die Kriegsführung aufgebracht werden. Der Krieg war insofern ,total', als die gesamte Gesellschaft darauf ausgerichtet wurde und als ,Heimatfront' daran mitwirken musste. Mit zunehmendem Verlauf des Krieges verschlechterte sich die Versorgungslage der Zivilbevölkerung dramatisch. Die Kampfhandlungen hatten eine nach Art und Ausmaß bisher unbekannte Dimension. $\mathrm{Zu}$ nennen ist der Abnutzungs- und Stellungskrieg an der Westfront, der Einsatz von Giftgas, ersten Panzern und Kampfflugzeugen, mithin der industrielle Charakter des Krieges. Im Zuge der Novemberrevolution wurde die Monarchie durch eine parlamentarische Republik ersetzt. Für die Weimarer Republik bedeutete der Krieg mit seinen politischen, sozialen, wirt-

288 [Anon.]: [Rezension von Remarque: Im Westen nichts Neues]. In: Wiener Zeitung. 25. April 1929, S. 7.

289 Toller: Buchchronik der Woche, S. 5.

290 Vgl. zum Folgenden eine allgemeine Darstellung wie Gerhard Henke-Bockschatz: Der Erste Weltkrieg. Eine kurze Geschichte. Stuttgart 2014. 
schaftlichen und diplomatischen Folgelasten eine schwere Hypothek. ${ }^{291}$ Hinzu kamen eine revanchistische Grundstimmung in Teilen der Bevölkerung und die Ablehnung der demokratisch verfassten Republik von beträchtlichen und im Laufe der Jahre stärker werden rechts- und linksradikalen Kräften sowie bei den alten Eliten des Kaiserreiches. Für die Zeitgenossen war der Krieg Teil der eigenen Biographie, seine weitreichenden Folgen für das eigene Leben waren 1928/1929 noch unmittelbar präsent. Der Krieg, seine Ursachen und Folgen waren ein konfliktträchtiges Politikum, die Wahrnehmung und Deutung des Krieges umstritten. Das dürfte viele Zeitgenossen dazu disponiert haben, dass Geschilderte an eigenen Erfahrungen oder an anderweitig erworbenen Überzeugungen zu messen und als lebensweltlich bedeutsam einzustufen.

Verstärkt wird dergleichen durch formale und stilistische Aspekte. Neben dem bisweilen journalistischen und berichthaften Stil ist wohl die Erzählsituation bedeutsam und die Rolle, welche der Erzähler einnimmt. Er schildert, was er erlebt, tritt als Augenzeuge auf und als jemand, der über die relevanten Dinge Bescheid weiß und daher den vorausgesetzten Adressaten in erläuternden Passagen darüber informieren kann, wie der Alltag an und hinter der Front abläuft. Es kommt hinzu, dass der Schauplatz weitgehend unbestimmt bleibt und als exemplarisch und typisch wahrgenommen werden kann. Im Westen nichts Neues erweist sich als ein literarischer Text, bei dem die kognitive Applikation des Dargestellten - im Zusammenspiel mit der formalen Beschaffenheit und den historischen Gegebenheiten - von herausragender Bedeutung ist.

\subsubsection{Politische Applikation: Ein pazifistischer Roman?}

Neben der Frage nach Wahrheit und Wahrhaftigkeit des Romans war es die Frage nach der ethischen Beurteilung des dargestellten Kriegsgeschehens, welche die zeitgenössische Rezeption bestimmte. Besonders gut und exemplarisch lässt sich das an der kontroversen Einschätzung zeigen, ob von dem Roman eine pazifistische Wirkung ausgehen könne; eine Einschätzung, die häufig eng verknüpft war mit politischen und weltanschaulichen Standpunkten. ${ }^{292}$ Es verwundert nicht, dass aus bellizistischer Sicht angenommen wurde, dass der Roman pazifistische Haltungen hervorbringen und verstärken könne, und dass

291 Vgl. z. B. Detlef Lehnert: Die Weimarer Republik. Parteienstaat und Massengesellschaft. Stuttgart 1999; Ulrich Kluge: Die Weimarer Republik. Paderborn u. a. 2006.

292 Vgl. zum Pazifismus Karl Holl/Wolfram Wette (Hg.): Pazifismus in der Weimarer Republik. Beiträge zur historischen Friedensforschung. Paderborn 1981. 
er deswegen negativ bewertet wurde. So finden sich Aussagen wie diese: „In geschicktester und für den harmlosen Leser unauffälliger Weise ist nur das zusammengestellt, was abschreckend wirkt und geeignet ist, den Gedanken ,Nie wieder Krieg‘ zu wecken und zu verstärken.“293 Der Roman sei „eine raffinierte pazifistische Propaganda“, deren „Zweck“ darin bestehe, „der heranwachsenden Jugend eine unüberwindliche Abscheu vor dem Kriege, überhaupt vor allem Militärischen, ins Herz zu senken“. 294 Romane wie derjenige Remarques seien „allein dazu angetan, pazifistische Gedanken zu erwecken“.295 Aus diesem Grunde wurde das Buch aus marxistischer Sicht abgelehnt, wenn auch naturgemäß mit anderer Begründung: „Pazifismus ist die furchtbarste Kriegsschuldlüge, weil er die wahren Ursachen des Krieges, die in den politischökonomischen Voraussetzungen der bürgerlichen und kapitalistischen Gesellschaftsordnung liegen, leugnet und sich weigert, ihre einzig mögliche Beseitigung durch den gewaltsamen Sturz dieser Gesellschaftsordnung zu fordern. “296

Leserbriefe in der Vossischen Zeitung hingegen lobten einhellig den Pazifismus, welcher von Remarques Roman ausgehen könne, und wurden vermutlich unter anderem deswegen abgedruckt. Er sei „die wunderbarste Antikriegspropaganda, die es geben kann“. ${ }^{297}$ Der Pazifismus, wie ihn dieses Buch vermittle, sei die einzig angemessene Lehre aus der Erfahrung des Krieges: „Wenn nur ein Sinn in dem unsinnigsten aller Leben, das wir 1914-1918 führten, sein kann, so muß es der Gedanke des Pazifismus sein, der danach seinen Siegeszug antreten sollte.“298 Darin sei der Roman besonders effektiv: „Ein solches Buch, ohne gesellschaftliche und politische Verblendung geschrieben und ebenso gelesen, kann mehr erreichen als so und so viele pazifistische Veranstaltungen.“299 In aufschlussreicher Weise wurde in einer Quelle das Verhältnis von Absicht, Text und Wirkung reflektiert. Remarque habe nicht beabsichtigt, einen

293 Schlieffen: Im Westen nichts Neues, S. 34.

294 Von der Goltz: Erich Maria Remarque: „Im Westen nichts Neues“, S. 84.

295 Limpach: Neudeutsche Kriegsliteratur, S. 36.

296 [Anon.]: [Rezension von Remarque: Im Westen nichts Neues]. In: Die rote Fahne. 4. März 1929. Zitiert nach Westphalen: Materialien, S. 218 f., hier S. 218. Vgl. dazu Karl Schröder: Erzählende Literatur. Erich Maria Remarque: Im Westen nichts Neues. In: Sozialistische Bildung. Nr. 2 (1929), Beilage: Die Bücherwarte, S. 19 f. Zitiert nach Schrader: Dokumentation, S. 76 f.; Siemsen: Kriegsbücher, S. 65. Der Roman wurde aus Sicht der radikalen Linken gar als „Aufrüstungsliteratur“ bezeichnet - Karl August Wittfogel: Romane über den imperialistischen Krieg. Der Fall Remarque. In: Die Rote Fahne. 26. Juli 1930. Zitiert nach Schrader: Dokumentation, S. 78 f., hier S. 78.

297 Das Fronterlebnis in der Dichtung, S. [26].

298 Das Fronterlebnis in der Dichtung, S. [26].

299 Das Fronterlebnis in der Dichtung, S. [27]. 
pazifistischen Roman zu schreiben, und der Text sei keiner, allerdings könne er so rezipiert werden und gerade dadurch pazifistisch wirken: „Remarques Roman ist kein pazifistisches Buch. Aber das haben die Nationalisten, die in diesem Punkt eine feine Nase haben, genau gerochen: es wird in seiner Wirkung viel stärker für den Friedensgedanken werben, als es hundert Romane tun könnten, die nur um dieser Absicht willen geschrieben sind.“300

Wenn angenommen wird, dass die Lektüre des Romans ethische Überzeugungen, nämlich eine grundsätzliche Ablehnung des Krieges, hervorbringen oder verstärken könne, dann handelt es sich um den Fall einer (befürchteten) Applikation. Es ist das eine, zu sagen, dass der Roman ein „pazifistisches Buch“ sei, also pazifistisches Gedankengut beinhaltet. Es ist etwas anderes, anzunehmen, dass er geeignet ist, pazifistisch zu wirken. Damit Letzteres geschehen kann, müssen die Rezipient/-innen das Gelesene auf sich und ihre Lebenswelt anwenden und zu dem Ergebnis kommen, dass das im Roman Dargestellte geeignet ist, ihre Überzeugungen zu modifizieren.

Skepsis mit Blick auf die pazifistische Wirkung des Romans äußerten häufig gerade diejenigen, die eine solche Haltung vertraten oder ihr aufgrund ihres politischen Standpunktes (z. B. demokratisch, liberal) nahestanden. In der Friedenswarte hieß es, die Wirkung des Romans sei „sicherlich nicht notwendigerweise pazifistisch, und vor allem nicht absichtlich so“. ${ }^{301}$ In der Vossischen Zeitung wurde zwar die Hoffnung auf „eine allgemeine Atmosphäre des Friedens“ zum Ausdruck gebracht, ob Remarques Roman dazu beitragen könne, sei jedoch ungewiss: „Wieviele Soldaten werden auch dieses Buch wieder lesen und ihre Gewehre doch nicht zur Seite stellen. Wieviele Generäle und noch höhere Chargen im Volk werden trotzdem ihre Kriegsorden und ,Ehren'zeichen unbeschämt weiter zur Schau tragen.“302

Als besonders aussagekräftig erweisen sich Stellungnahmen in der Weltbühne. Karl Hugo Sclutius erklärte dort, der Roman sei „kein Anti-Kriegsbuch, wie es aus den tausend Schlünden pazifistischer Reklame herausbrüllt“, statt „Pazifismus“ biete er nämlich „Kriegspropaganda“. ${ }^{303}$ Er begründete seine Auffassung damit, dass von einer Darstellung des Krieges, wie sie Remarque biete, keine abschreckende Wirkung ausgehe; sie fasziniere vielmehr, indem sie zur

300 [Vorname nicht ermittelt] Frosch: Die Einkreisung Remarques. In: Die Welt am Montag. 27. Mai 1929. Zitiert nach Schrader: Dokumente, S. 79-82, hier S. 82.

301 Steinitz: Noch einmal Remarque, S. 83.

302 Unruh: „Im Westen nichts Neues“, S. [9].

303 Karl Hugo Sclutius: Pazifistische Kriegspropaganda. In: Die Weltbühne. Jg. 25, H. 14, 2. April 1929, S. 517-522, hier S. 517. Vgl. dazu Karl Hugo Sclutius: Nochmals: Pazifistische Kriegspropaganda. In: Die Weltbühne. Jg. 25, H. 22, 28. Mai 1929, S. 826 f. 
Identifikation mit den Figuren einlade, unerfüllte Wunschträume anspreche und ein Bedürfnis nach Abenteuer und Ausbruch aus dem Alltag erwecke. ${ }^{304} \mathrm{Er}$ stellte die rhetorische Frage: „Wollt Ihr wieder eineinhalb Millionen Kriegsfreiwillige? Reiht den Remarque den Schulbibliotheken ein, und Ihr werdet sie haben. “305 Ein wohl hinter einem Pseudonym verborgener Leserbriefschreiber pflichtete ihm bei und ergänzte, dass der Roman an biologisch beschreibbare niedere Instinkte appelliere. ${ }^{306}$ Zustimmend äußerte sich Arnold Zweig, indem er „die alte Freude am Krieg als unbürgerlicher Lebensform, als Gelegenheit zum großen Abenteuer“ kritisierte. ${ }^{307}$ Remarque wurde vorgeworfen, sich zu passiv zu verhalten. Sein Roman hätte eine „gewaltige Waffe“ sein können „mit einem Mann dahinter“: „Aber dieser Mann war nicht da sondern nur ein Glückskind, das einen Zufallstreffer gemacht und sich daraufhin sofort ins Privatleben zurückgezogen hat. “308 Rezeptionsdokumente dieser Art sind in zweierlei Hinsicht aufschlussreich. Zum einen verweisen sie auf Applikationen, die, so die Annahme, gerade nicht vorgenommen werden: Das Publikum lese den Roman und komme gerade nicht $\mathrm{zu}$ dem Schluss, dass eine pazifistische Haltung angemessen sei. Zum anderen wird eine entgegengesetzte Applikation befürchtet: Das Gelesene sei aufgrund seiner Darbietung geeignet, ein reizvolles Bild des Krieges zu vermitteln und Kriegsbegeisterung hervorzurufen.

Der Roman wurde nicht allein mit Blick auf seinen vermeintlichen Pazifismus wahrgenommen, er konnte mit verschiedenen weltanschaulichen und politischen Auffassungen verbunden werden und $\mathrm{zu}$ Bewertungen Anlass geben. Das wurde bereits von den Zeitgenossen reflektiert. Um den Krieg zu überwinden, so die Meinung in einer Quelle, müsse man „die Sphinxfrage nach seinem Sinn“ beantworten. Das sei bisher nicht geschehen; ein Umstand, der sich auf den Umgang mit Kriegsliteratur auswirke: „In das leere Gelände der halben Antworten, der Halbwahrheiten, der parteimäßigen Schlagworte, der vertauschten Akzente rutschen meistens die Beurteilungen der vielen erzählenden Kriegsbücher, die jetzt erschienen sind.“ ${ }^{309}$ Remarques Roman sei geeignet,

304 Vgl. dazu Sclutius: Pazifistische Kriegspropaganda, S. 520-522.

305 Sclutius: Pazifistische Kriegspropaganda, S. 521.

306 Vgl. Charles Movie: Der Dichter und der Führer. In: Die Weltbühne. Jg. 25, H. 15, 9. April 1929, S. 576.

307 Arnold Zweig: Kriegsromane. In: Die Weltbühne. Jg. 25, H. 16, 16. April 1929, S. 597-599, hier S. 597.

308 Carl von Ossietzky: Der Fall Remarque. In: Die Weltbühne. Jg. 28, H. 15, 12. April 1932, S. 548-550, hier S. 550.

309 Kranz: Menschen des großen Krieges, S. 444. Vgl. dazu den Befund in einem Forschungsbeitrag: „An Im Westen nichts Neues wurden ,Sinn“ oder ,Unsinn“ dieses verlorenen Krieges 
der (heuchlerischen) Kriegsverherrlichung entgegenzuwirken, wie sie in Schule und Politik praktiziert werde, und könne eine aufklärerische Wirkung haben:

Dieses Buch sei all denen in die Hand gedrückt, die Aufklärung wünschen über das ,Stahlbad“ des Krieges. Besonders auch - in Leder gebunden - den Gewaltigen, die heute wieder hinter gepolsterten Türen die Völker regieren, diesen zu allen Zeiten ,Unabkömmlichen', die so herrlich über Heldentum reden können. Man müßte einzelne Kapitel in der Schule vorlesen, wenn sich falsche Heldengefühle in den jungen Herzen regen. ${ }^{310}$

Gegen falschen Heroismus zeige der Roman, wie Menschen im Krieg agierten, und mache deutlich, dass das Soldatenleben „kein Marsch zum Helden“ sei, sondern „ein Rückmarsch zum Tier“. ${ }^{311}$ Abwägend mit Blick auf die gewünschte Wirkung und mit der konkreten Hoffnung, dass die Lektüre des Romans dazu führen könne, bei „jungen, vom Nationalismus angesteckten Leuten“ ein Umdenken zu bewirken, das sich im Handeln niederschlage, hieß es in einer anderen Quelle, für einige „würde der Krieg trotzdem das heroisch-begeisternde Gesicht behalten“: „Aber jene, die Gefühl und Geist und Phantasie genug besitzen, das Buch nachzuempfinden, die würden wohl an diesen 298 Seiten klarer sehen und reifer handeln lernen." ${ }^{312}$ In allen drei Fällen deuten die Aussagen in den Rezeptionsdokumenten auf mögliche Applikationen hin: Der Roman ist in dieser Wahrnehmung geeignet, ein angemessenes, kritisches Bild des Krieges $\mathrm{zu}$ vermitteln und unangemessenen (heroischen, nationalistischen) Auffassungen entgegenzuwirken.

Zum gegenteiligen Ergebnis kamen, wenig überraschend, völkische und nationalsozialistische Rezensenten, die eine negative Applikation vornahmen. Eine Sammelbesprechung von Kriegsliteratur im Völkischen Beobachter endete mit dem folgenden Appell:

Augen auf, deutsche Frontsoldaten und Nationalisten, man sucht an euer Heiligstes zu tasten. Gebt den Feinden unseres Volkes, den Verächtern alles Heldischen die rechte Antwort: Kauft die Kriegsbücher deutscher Nationalisten! Denn euer Vater war der Krieg.

erörtert, somit nicht nur das Selbstverständnis der Gesellschaft, sondern auch das des einzelnen Mitglieds der Gesellschaft, ob es nun selbst Kriegsteilnehmer gewesen war oder nicht.“ Schneider: „Die Meute hinter Remarque“, S. 143.

310 Kellermann: „Im Westen nichts Neues“, S. 22. Unmittelbar im Anschluss äußert sich der Rezensent allerdings pessimistisch über die Möglichkeit einer solchen Wirkung: „Aber, ich fürchte, es gibt noch immer genug Kantoreks, die die Lektüre dieses Buches nie gestatten werden."

311 Unruh: „Im Westen nichts Neues“, S. [9].

312 [Anon.]: „Im Westen nichts Neues“. Ueber ein neues Kriegsbuch, S. 86. 
Die Augen von Millionen toter Brüder sind auf euch gerichtet. In euren Händen liegt die Zukunft unseres Volkes. Kampf ist eure Sendung - euer Schicksal. ${ }^{313}$

Einige Monate später wurde dort Remarques Roman erneut thematisiert. Er sei „eine jauchzende Entschuldigung der Deserteure, Überläufer, Meuterer und Drückeberger und somit ein zweiter Dolchstoß an der Front, an den Gefallenen aber eine Leichenschändung“. ${ }^{314}$ Eine solche Aussage zeigt, wie Remarques Roman vor dem Hintergrund der revanchistischen nationalistischen Erinnerungskultur wahrgenommen wurde, hier also der Vorstellung, dass für die militärische Niederlage nicht das auf dem Schlachtfeld ungeschlagene deutsche Heer verantwortlich sei, sondern die Akteure der Novemberrevolution. ${ }^{315}$

Entgegen der erklärten Absicht des Autors und der Strategie des UllsteinKonzerns wurde der Roman also durchaus ,politisch“ gelesen, etwa als kriegskritischer und pazifistischer Roman, und auf dieser Grundlage unterschiedlich beurteilt. Das dürfte mit den historischen Umständen zu tun haben, vor allem der allgemeinen Radikalisierung der politischen Positionen. ${ }^{316}$ Die Deutung und Bewertung des Weltkrieges waren in der Weimarer Republik, wie bereits erwähnt, heftig umstritten. ${ }^{317}$ Remarque habe, so Carl von Ossietzky, ,an das erre-

313 Limpach: Neudeutsche Kriegsliteratur, S. 38. Diese Quelle deutet an, welche Rolle der Kriegserfahrung in paramilitärischen Gruppierungen der Weimarer Republik (Freikorps, Stahlhelm, SA) zugeschrieben wurde; vgl. dazu Volker Rolf Berghahn: Der Stahlhelm. Bund der Frontsoldaten 1918-1935. Düsseldorf 1966; Peter H. Merkl: The Making of a Stormtrooper. Princeton, NJ 1980; Peter Longerich: Die braunen Bataillone. Geschichte der SA. München 1989.

314 Hans Zöberlein: Im Westen nichts Neues. In: Völkischer Beobachter. Jg. 4, Nr. 7, 14. Juni 1929. Beilage: Der deutsche Frontsoldat. Zitiert nach Westphalen: Materialien, S. 237 f., hier S. 238. Vgl. zur nationalsozialistischen Diffamierung Remarques Paul Oskar Heyse: Die Cocktails des Herrn E.M. Remarque. In: Der Nationalsozialist. Nr. 19, 11. Mai 1929. Zitiert nach Thomas F. Schneider: [Materialanhang]. In: Erich Maria Remarque: Im Westen nichts Neues. Roman. Hg. von Th. F. Sch. Köln 2014, S. 348-351.

315 Vgl. dazu Boris Barth: Dolchstoßlegenden und politische Desintegration. Das Trauma der deutschen Niederlage im Ersten Weltkrieg 1914-1933. Düsseldorf 2003.

316 Vgl. dazu Gollbach: Die Wiederkehr des Weltkrieges in der Literatur, S. 6-39. In einer historiographischen Arbeit wurde die These vertreten, dass der Roman weniger etwas aussage über den Krieg als vielmehr über die Mentalität der Nachkriegsjahre, vgl. Modris Eksteins: All Quiet on the Western Front and the Fate of a War. In: Journal of Contemporary History 15 (1980), S. 345-365, hier S. 351. Zu den politischen Implikationen, welche der Roman haben konnte, selbst wenn solche nicht intendiert gewesen seien und im Roman nicht im Vordergrund stünden, vgl. Rüter: Erich Maria Remarque, S. 144-149.

317 Vgl. z. B. die Beiträge in Jost Dülffer/Gerd Krumeich (Hg.): Der verlorene Frieden. Politik und Kriegskultur nach 1918. Essen 2002; eine Zusammenstellung von Quellen bietet Bernd 
gendste Thema unsrer Tage gerührt“, welches „Deutschland bis heute in zwei Teile spaltet: - an den Krieg““.318 Eine wichtige Rolle dürfte die Beschaffenheit des Textes spielen. Zeitgenössisch wurde der Roman von manchen so gelesen, dass er eine neutrale Darstellung des Krieges biete, die frei von Kommentaren und anderen Versuchen der auktorialen Rezeptionssteuerung sei, und deswegen hinsichtlich einer Deutung offen. Der Roman konnte so wahrgenommen werden, „daß Remarque nicht dem Leser eine fertige Gesinnung Seite für Seite einlöffelt, sondern es ihm überläßt, selbst aus dem Buch Schlüsse zu ziehen“. Er habe „niemand zu irgend etwas mit Gewalt bekehren wollen“; außerdem sei festzustellen, „daß er einem nicht andauernd den Kopf mit privaten Meinungen verkeilt, sondern die Tatsachen durch sich wirken läßt““. ${ }^{319}$ In diesem Sinne wurde in einem Gespräch die folgende Einschätzung mitgeteilt, der Remarque nicht widersprach: „Man könnte also vielleicht sagen, daß die politische Auffassung oder Auswertung des Buches die Sache jedes einzelnen ist. Es selbst ist neutral wie ein Spiegel. Jeder wird seine eigene politische Absicht daraus entwickeln können.“320

Betrachtet man den Roman vor diesem Hintergrund, so fällt auf, dass der Erzähler das Geschehen in einer Art und Weise berichtet und kommentiert, die geeignet ist, eine bestimmte (wertende) Perspektive darauf nahezulegen. So wird etwa die Frage nach dem Sinn des Sterbens der jungen Männer aufgeworfen. Über einen schwer verwundeten und moribunden Klassenkameraden sagt der Erzähler nach einem Besuch im Lazarett: „Da liegt er nun, weshalb nur? Man sollte die ganze Welt an diesem Bette vorbeiführen und sagen: Das ist Franz Kemmerich, neunzehneinhalb Jahre alt, er will nicht sterben. Laßt ihn nicht sterben!“ (S. 32) Potenziell fragwürdig erscheint der Krieg aufgrund der

Ulrich (Hg.): Krieg im Frieden. Die umkämpfte Erinnerung an den Ersten Weltkrieg. Quellen und Dokumente. Frankfurt a. M. 1997.

318 Ossietzky: Der Fall Remarque, S. 550.

319 [Vorname nicht ermittelt] Frosch: Die Einkreisung Remarques, S. 82. Dort wird in diesem Umstand eine Erklärung für den Erfolg des Romans gesehen.

320 Eggebrecht: Gespräch mit Remarque, S. 2. Die Offenheit und Anschlussfähigkeit des Romans wurde in der Forschung betont, vgl. Müller: Der Krieg und die Schriftsteller, S. 63-65. In einem anderen Forschungsbeitrag wird festgestellt: „Das Bild des ,modernen“ Krieges, das Im Westen nichts Neues zeichnet, ist dabei ein spezielles und unabhängig von politischen Positionen zwar desillusionierendes, aber dennoch mehrheitsfähiges und vielfach instrumentalisierbares.“ - Schneider: Das virtuelle Denkmal des unbekannten Soldaten, S. 90. So auch Thomas F. Schneider: „Endlich die Wahrheit über den Krieg!“ Erich Maria Remarques Im Westen nichts Neues als Kulminationspunkt in der Diskussion um den Ersten Weltkrieg in der Weimarer Republik. In: Mitteilungen des Deutschen Germanistenverbandes 62 (2015), S. 87-102, hier S. 89. 
vielen Menschenleben, die er fordert, zumal aus der Perspektive einer Figur, die der Erzähler als besonders zuverlässig charakterisiert. Nachdem die Kompanie bei Schanzarbeiten an der Front attackiert und zahlreiche unerfahrene junge Rekruten getötet oder schwer verletzt wurden, heißt es über einen erfahrenen und älteren Soldaten: „Kat schüttelt den Kopf. ,So junge Kerle‘ - Er wiederholt es: ,So junge, unschuldige Kerle -““ (S. 68) Kurz vor Ende der Handlung, im Sommer 1918, schildert der Erzähler die hohen Verluste, welche die unzureichend ausgerüsteten und unerfahrenen, schlecht ausgebildeten Truppen erleiden, und gibt dazu einen Kommentar dieser Figur wieder: „Ein einziger Flieger knallte aus Spaß zwei Kompanien von ihnen [den neuen Truppen] weg, ehe sie etwas von Deckung wußten, als sie frisch aus dem Zuge kamen. ,Deutschland muß bald leer sein', sagt Kat.“ (S. 247)

Beobachtungen dieser Art ließen sich leicht vermehren. Am Ende einer ausführlichen Schilderung eines Fronteinsatzes stellt der Erzähler das Resultat der Kampfhandlung den massiven Verlusten gegenüber. Aus seiner Kompanie haben von 150 Soldaten nur 32 überlebt. Seine Schilderung des Stellungskrieges beendet er mit den Worten: „Doch das Stückchen zerwühlter Erde, in dem wir liegen, ist gehalten gegen die Übermacht, nur wenige hundert Meter sind preisgegeben worden. Aber auf jeden Meter kommt ein Toter.“ (S. 122) Sinn und Berechtigung des Krieges werden ihm anlässlich einer Begegnung mit russischen Kriegsgefangenen bei einem Heimataufenthalt unklar. Der Anblick der unterernährten und kranken ,Feinde‘, in denen er gewöhnliche Menschen erkennt, erschüttert ihn. ${ }^{321}$ Er bemerkt dazu: „Ein Befehl hat diese stillen Gestalten zu unsern Feinden gemacht; ein Befehl könnte sie in unsere Freunde verwandeln. An irgendeinem Tisch wird ein Schriftstück von einigen Leuten unterzeichnet, die keiner von uns kennt, und jahrelang ist unser höchstes Ziel das, worauf sonst die Verachtung der Welt und ihre höchste Strafe ruht.“ (S. 172)

Die Kriegserfahrung stellt in der Wahrnehmung des Erzählers letztlich alles in Frage. In der vielleicht zentralen Reflexion des Romans bemerkt er anlässlich eines Lazarettaufenthaltes:

Man kann nicht begreifen, daß über so zerrissenen Leibern noch Menschengesichter sind, in denen das Leben seinen alltäglichen Fortgang nimmt. Und dabei ist dies nur ein einziges Lazarett, nur eine einzige Station - es gibt Hunderttausende in Deutschland, Hundert-

321 Vgl. etwa die folgende Aussage: „Es ist sonderbar, diese unsere Feinde so nahe zu sehen. Sie haben Gesichter, die nachdenklich machen, gute Bauerngesichter, breite Stirnen, breite Nasen, breite Lippen, breite Hände, wolliges Haar. Man müßte sie zum Pflügen und Mähen und Apfelpflücken verwenden. Sie sehen noch gutmütiger aus als unsere Bauern in Friesland.“ (S. 169) 
tausende in Frankreich, Hunderttausende in Rußland. Wie sinnlos ist alles, was je geschrieben, getan, gedacht wurde, wenn so etwas möglich ist! Es muß alles gelogen und belanglos sein, wenn die Kultur von Jahrtausenden nicht einmal verhindern konnte, daß diese Ströme von Blut vergossen wurden, daß diese Kerker der Qualen zu Hunderttausenden existieren. Erst das Lazarett zeigt, was Krieg ist. (S. 232 f.)

Diese Überlegungen, so weitreichend sie sind, bleiben allerdings auf (allgemein-)menschliches Erleben und auf die „Kultur“ beschränkt. Politische Aussagen oder solche, die dahingehend verstanden werden können, kommen nicht vor. Bisweilen wird auf die politische Dimension des Krieges lediglich eine pikareske Sicht vermittelt. ${ }^{322}$ Explizite Figurenrede oder Erzählerreflexionen und die dadurch nahegelegte Perspektivierung des Geschehens sind nur ein in diesem Zusammenhang einschlägiges Mittel der Darstellung, allerdings ein besonders deutliches und vermutlich effektives. Andere ließen sich ergänzen, etwa erneut die Erzählsituation oder die Auswahl und Gewichtung dessen, was dargestellt wird.

Es dürfte deutlich geworden sein, dass das Geschehen an der Front und im besetzten Gebiet sowie in der Heimat so in einer Art und Weise gerahmt wird, die zu einer Bewertung herausfordert. Allerdings bleibt offen, welche genau das sein soll und welche Schlüsse im Einzelnen daraus zu ziehen sind. Das wird vielleicht an einer Episode besonders ersichtlich. Der Erzähler muss bei einer nächtlichen Patrouille an der Front in einem Granattrichter Zuflucht suchen und begegnet dort einem französischen Soldaten, den er mit einem Messer schwer verwundet. Er ist gezwungen, einige Stunden mit dem sterbenden Soldaten in der Deckung auszuharren. Den Toten redet er folgendermaßen an:

Jetzt sehe ich erst, daß du ein Mensch bist wie ich. Ich habe gedacht an deine Handgranaten, an dein Bajonett und deine Waffen; - jetzt sehe ich deine Frau und dein Gesicht und das Gemeinsame. Vergib mir, Kamerad! Wir sehen es immer zu spät. Warum sagt man uns nicht immer wieder, daß ihr ebenso arme Hunde seid wie wir, daß eure Mütter sich ebenso ängstigen wie unsere und daß wir die gleiche Furcht vor dem Tode haben und das gleiche Sterben und den gleichen Schmerz -. Vergib mir, Kamerad, wie konntest du mein Feind sein. (S. 198).

322 In einem Gespräch über den Krieg gibt der Erzähler wieder, was ein Kamerad gesagt hat: „Kropp dagegen ist der Denker. Er schlägt vor, eine Kriegserklärung solle eine Art Volksfest werden mit Eintrittskarten und Musik wie bei Stiergefechten. Dann müßten in der Arena die Minister und Generäle der beiden Länder in Badehosen, mit Knüppeln bewaffnet, aufeinander losgehen. Wer übrigbliebe, dessen Land hätte gesiegt. Das wäre einfacher und besser als hier, wo die falschen Leute sich bekämpfen.“ (S. 41) 
Beim Verlassen des Granattrichters gelobt er, er wolle „kämpfen gegen dieses, das uns beide zerschlug: dir das Leben - und mir -? Auch das Leben.“ (S. 201) Außerdem beteuert er: „Es darf nie wieder geschehen.“ (ebd.) Unmittelbar im Anschluss heißt es jedoch: „,Ich werde alles halten, alles halten, was ich dir versprochen habe -‘, aber ich weiß schon jetzt, daß ich es nicht tun werde.“ (S. 201) Und nur wenig später: „Den Toten habe ich vergessen.“ (S. 202) Nach der Rückkehr zu seinem Kameraden erzählt er ihnen, was geschehen ist; sie sind der Meinung, dass er sich deswegen keinerlei Gedanken machen müsse. Davon überzeugt sich schließlich der Erzähler selbst: „Krieg ist schließlich Krieg.“ (S. 204, dazu S. 203 f.)

Die hier hervortretende Inkonsistenz des Erzählers, die geeignet ist, seine axiologische Zuverlässigkeit in Zweifel zu ziehen, mag figurenpsychologisch mit der Situation erklärbar sein; sie zeigt allerdings, dass das Dargestellte nicht nur für sich genommen, sondern auch aufgrund seiner Darbietung zu einer Bewertung herausfordert, allerdings keine explizit vornimmt oder anbietet. Das hat nicht zuletzt wiederum mit der Konzeption der Erzählinstanz zu tun. Als Teilnehmer des Geschehens ist sie, wie gesagt, in gewisser Hinsicht epistemisch privilegiert. Sie kann eigenes Erleben authentisch und eindrücklich schildern. Zugleich ist ihre Perspektive aber eingeschränkt. Eine übergeordnete, souveräne Sicht auf das Geschilderte gibt es in diesem Roman nicht. In dieser Hinsicht ist der Text tatsächlich in einem relevanten Sinne ,offen'. Außerdem werden neben den Kampfeinsätzen solche Dinge aus dem Alltag hinter der Front, aus der Vorgeschichte und von einem Heimaturlaub berichtet, die wenig dazu angetan sind, ein heroisches Bild des Soldatenlebens zu zeichnen (z. B. Diebstahl von Gänsen, gemeinsamer Stuhlgang). Bisweilen wird das Soldatenleben sarkastisch kommentiert, etwa Drill und Schikanen. Aber auch in solchen Fällen bleibt unklar, welche Konsequenzen daraus gezogen werden sollen.

In einem Forschungsbeitrag wurde festgestellt: „Like all major writers, he [Remarque] shows us what is wrong with our world, not how to put it right." 323 Man könnte noch weiter gehen und sagen, dass der Roman die Einschätzung nahelegt, dass etwas falsch ist, aber bereits offen lässt, was genau und warum. Der Text lässt sowohl die ethisch-moralische Bewertung des Geschilderten offen als auch seine politische Einordnung. Gerade deswegen forderte er aber zu einer moralischen Bewertung und ethischen Applikation auf, gerade darin lag das

323 Brian A. Rowley: Journalism into Fiction: Im Westen nichts Neues. In: Holger Klein (Hg.): The First World War in Fiction. A Collection of Critical Essays. London 1976, S. 101-111 und 222-224, hier S. 111. 
textseitige Potenzial für politische und sonstige weltanschauliche Vereinnahmung oder Ablehnung.

Zusammenfassend lässt sich festhalten: Remarque wollte, zumindest nach eigener Aussage, mit Im Westen nichts Neues denjenigen Weltkriegsteilnehmern seiner Generation, die, ähnlich wie er, unter den Folgen des Kriegseinsatzes litten, lebenspraktische Hilfe geben. Bei anderen sollte der Roman Verständnis für die Angehörigen dieser Generation hervorrufen. In beiden Fällen bedarf es der Applikation des Geschilderten. In den überlieferten Rezeptionsdokumenten dominierten zwei andere Arten des Umgangs mit dem Roman, die Frage nach der Wahrheit dessen, was Remarque über den Krieg schreibt, und die Frage nach der Beurteilung des Krieges und der darauf im Roman vermeintlich vermittelten Perspektive. Diese beiden Formen des Umgangs mit dem Roman werden nur verständlich, wenn man sie als (Negativ-)Applikationen auffasst. Es hat sich gezeigt, dass solche Applikationen wesentlich umstritten waren. Aufschlussreich ist in diesem Zusammenhang ein Detail der zeitgenössischen Rezeption von Kriegsliteratur. Über die Bücher Ernst Jüngers sagte Remarque in einem Gespräch: „Je trouve d'ailleurs que ces livres exercent une influence encore plus pacifiste que tous les autres. On voit chez lui la guerre toute nue, le plaisir cruel de la tuerie ...“.324 Das Wäldchen 125 und In Stahlgewittern rezensierte er wohlwollend. ${ }^{325}$ Umgekehrt wurde, wie gesehen, Remarques Roman vorgeworfen, eigentlich „Kriegspropaganda“ zu sein. Jüngers Texte konnten also als pazifistisch angesehen werden, Im Westen nichts Neues hingegen als nichtpazifistisch. Das eine wie das andere dürfte aus heutiger Sicht überraschen. Daran zeigt sich, dass es Fälle gibt, in welchen ein literarischer Text aufgrund seiner Beschaffenheit und in Verbindung mit den historischen Umständen verschiedene Applikationen ermöglicht und es strittig ist, ob eine gegebene Applikation zulässig und erstrebenswert ist.

An allen drei Romanen, die in diesem Kapitel behandelt wurden, wird insbesondere deutlich, dass und wie für die Rezeption und die Applikation der Bezug des Textes auf situative oder allgemeine lebensweltliche Gegebenheiten von herausragender Bedeutsamkeit sein kann. Reuters Aus guter Familie konnte von der Mehrheit kaum anders gelesen und appliziert werden denn mit Blick auf die ,Mädchenfrage“ und ihre geschlechtergeschichtlichen Implikationen.

324 Scharp: Deux entretiens avec Erich Maria Remarque, S. 1020.

325 Vgl. Erich Maria Remarque: Soldat Suhren, Roman von Georg von der Vring - Ringen an der Somme, von Otto Riebicke - Das Wäldchen 125, von Ernst Jünger - In Stahlgewittern, von Ernst Jünger - Das Frontbuch, von Franz Schauwecker. In: Sport im Bild. Nr. 12, 8. Juni 1928, S. $895 \mathrm{f}$. 
Manns Buddenbrooks legten es nahe, dass Gelesene vor dem Hintergrund einer zeitgenössischen mentalitätsgeschichtlichen Disposition zu rezipieren, welche beeinflusste, was als Thema des Romans angesehen und wie die darauf eingenommene Perspektive wahrgenommen wurde. Die Rezeption von Remarques Im Westen nichts Neues und die Applikationen bleiben unverständlich, wenn man nicht erkennt, dass und wie im Einzelnen die Erfahrung des Krieges und seine Wahrnehmung in der Weimarer Republik eine Rolle spielten. Es handelt sich, wie festgehalten werden kann, um solche Gegebenheiten, die weniger mit den globalen gesellschaftlichen Strukturen, den geistesgeschichtlichen Strömungen oder der Politik der Herrschenden zu tun haben, sondern vor allem mit der ,Mikroebene‘, den Mentalitäten und alltäglichen Erfahrungen. 